ROBERT J. BARRO

Harvard University

XAVIER SALA-I-MARTIN

Yale University

\title{
Convergence across States and Regions
}

AN IMPORTANT economic question is whether poor countries or regions tend to converge toward rich ones. We want to know, for example, whether the poor countries of Africa, South Asia, and Latin America will grow faster than the developed countries, whether the south of Italy will become like its north, whether and how fast the eastern regions of Germany will attain the prosperity of the western regions, and-in a historical context-how the American South became nearly as well off as the North.

Although some economic theories predict convergence, the empirical evidence has been a subject of debate. In this study we add to the evidence by extending our previous analysis of economic growth across the U.S. states. ${ }^{1}$ We examine the growth and dispersion of personal income since 1880 and relate the patterns for individual states to the behavior of regions. We then analyze the interplay between net migration and economic growth. We also study the evolution of gross state product since 1963 and relate the behavior of aggregate product to productivity in eight major sectors. The overall evidence weighs heavily in favor of convergence: both for sectors and for state aggregates, per capita income

Our research has benefited from support by the National Science Foundation and the Bradley Foundation. We appreciate comments on this and related research from members of the Brookings Panel and from Gary Becker, Olivier Blanchard, Paul David, Steve Durlauf, Susan Guthrie, Carol Heim, Anne Krueger, Edward Lazear, Bob Lucas, Greg Mankiw, Kevin M. Murphy, Danny Quah, Sergio Rebelo, and Gavin Wright. We also appreciate research assistance from Michael Kremer and Casey Mulligan.

1. Barro and Sala-i-Martin (1990). 
and product in poor states tend to grow faster than in rich states. The rate of convergence is, however, not rapid: the gap between the typical poor and rich state diminishes at roughly 2 percent a year.

We apply the same framework to patterns of convergence across 73 regions of Western Europe since 1950. The process of convergence within the European countries is in many respects similar to that for the United States. In particular, the rate of convergence is again about 2 percent a year.

We conclude by using the findings to forecast the convergence process for the eastern regions of unified Germany. The results are not very encouraging. If the histories of the U.S. states and European regions are useful guides, the convergence process will occur, but only at a slow pace.

\section{Framework of the Analysis}

Our previous study, which we refer to as our 1990 study throughout the rest of this paper, examined convergence patterns for economic growth across the U.S. states. ${ }^{2}$ We based our main analysis on a growth equation that derives, as a log-linear approximation, from the transition path of the neoclassical growth model for closed economies. ${ }^{3} \mathrm{We}$ follow the same research strategy in this paper; that is, we begin with the closedeconomy framework and then consider how the model would be affected by open-economy elements that are important to U.S. states and European regions.

We showed in our 1990 study that the transitional growth process in the neoclassical model can be approximated as

$$
(1 / T) \cdot \log \left(y_{i t} / y_{i, t-T}\right)=x_{i}^{*}+\log \left(\hat{y}_{i}^{*} / \hat{y}_{i, t-T}\right) \cdot\left(1-e^{-\beta T}\right) / T+u_{i t},
$$

where $i$ indexes the economy, $t$ indexes time, $y_{i t}$ is per capita output (equal to income per person as well as income per worker in the standard model), $x_{i}^{*}$ is the steady-state per capita growth rate (corresponding to exogenous, labor-augmenting technological progress in the standard model), $\hat{y}_{i t}$ is output per effective worker (that is, the number of workers adjusted for the effect of technological progress), $\hat{y}_{i}^{*}$ is the steady-state

2. Barro and Sala-i-Martin (1990).

3. Solow (1956); Cass (1965); Koopmans (1965). 
level of output per effective worker, $T$ is the length of the observation interval, the coefficient $\beta$ is the rate of convergence, and $u_{i t}$ is an error term. (The error term is a distributed lag of disturbances between dates $t-T$ and $t$.) Thus the convergence coefficient, $\beta$, indicates the rate at which $\hat{y}_{i t}$ approaches $\hat{y}_{i}^{*}$.

On the production side, the neoclassical model assumes diminishing returns to capital, exogenous technological progress, full employment, a fixed relation between the labor force and population, and exogenous growth of population. With respect to preferences, the model assumes that the saving rate derives from the choices made by utility-maximizing households over an infinite horizon. (The infinite horizon can represent individuals who are connected to their descendants through a chain of intergenerational transfers.) The steady-state value of output per effective worker, $\hat{y}_{i}^{*}$, depends on the parameters of technology and preferences. We can extend the notion of technology to include natural resources, such as geography, fertile land, and the availability of minerals, as well as governmental policies (considered exogenous) that affect property rights, the provision of infrastructure services, tax rates, and so on.

\section{The Rate of Convergence}

The convergence coefficient, $\beta$, depends on the productivity of capital and the willingness to save. In particular, the source of convergence in the neoclassical growth model is the assumed diminishing returns to capital. If the ratio of capital (and hence output) to effective labor declines relative to the steady-state ratio, then the marginal product of capital rises. Therefore, for a given saving behavior, an economy grows faster the further it is below the steady state, that is, the higher $\hat{y}_{i}^{*} / \hat{y}_{i, t-T}$ in equation 1. If we compare different production functions, then $\beta$ is higher if diminishing returns to capital set in faster. For example, for a Cobb-Douglas production function with capital share $\alpha$, a smaller $\alpha$ corresponds to a larger $\beta$. As the capital share tends to one, so that diminishing returns to capital no longer apply, the rate of convergence tends to zero. This case corresponds to endogenous growth models with constant returns to a broad concept of capital. ${ }^{4}$

4. See discussion in Rebelo (1990). 
The rate of convergence also depends on saving behavior, although more on the variation in the saving rate over the transition to the steady state than on the level of the saving rate. We have explored these effects in a related paper, one result of which is that a greater willingness to substitute intertemporally tends to raise $\beta .^{5}$

Although the coefficient $\beta$ can differ across economies, we neglect these differences in the subsequent discussion. This assumption is probably satisfactory for the U.S. states, which are likely to be similar in terms of the underlying parameters of technology and preferences. The theory also implies that pure differences in the levels of technologyand hence in levels of per capita income that derive from these technological differences-do not affect $\beta$. Thus, the convergence coefficients, $\beta$, can be similar across economies that appear in other respects to be very different.

We noted in our 1990 study that our empirical estimates of $\beta$ for the U.S. states-somewhat greater than 2 percent a year-accord with the neoclassical growth model only if diminishing returns to capital set in very slowly. For example, with a Cobb-Douglas production function, the capital-share coefficient, $\alpha$, has to be in the neighborhood of 0.8 . We also argued that this high value for $\alpha$ is reasonable if we take the appropriately broad view of capital to include nonhuman and human components. That is, education and other expenditures on people are important parts of the investment process.

\section{Capital and Labor Mobility}

The closed-economy model cannot be applied literally to the U.S. states or the regions of other countries. If technologies are the same, then convergence in per capita outputs and capital stocks occurs more rapidly in open economies than in closed economies, whereas convergence in per capita incomes and assets occurs less rapidly. ${ }^{6}$ Models that assume perfect capital mobility tend to have unrealistic implications, such as the prediction that the most patient economy, the one with the lowest rate of time preference, owns everything asymptotically and that

5. Barro and Sala-i-Martin (1991, chap. 1).

6. Barro and Sala-i-Martin (1990) discusses some implications of capital mobility. 
less patient economies eventually have negative assets and negligible consumption per effective worker. ${ }^{7}$ Also, our empirical findings do not exhibit the distinctions in the behavior of output and income that are predicted by models with perfect capital markets. We have considered models in which "imperfections" in capital markets imply that only a fraction of physical capital serves as collateral on loans. ${ }^{8}$ In the context of the U.S. states, such models apply if the residents or the government of a state cannot borrow nationally to finance all their expenditures on education and other forms of investment in human capital. This type of model predicts that product and income eventually behave in a similar manner and that each exhibits the kind of convergence property implied by the closed-economy specification of equation 1 .

In a model that allows for labor mobility, raw labor tends to migrate toward richer economies, which have higher wage rates. This movement of persons lowers the capital-labor ratio in places with initially high ratios; hence, diminishing returns to capital set in more rapidly and the convergence coefficient, $\beta$, is higher for any given parameters of preferences and technology. ${ }^{9}$ In other words, if the other parameters are given, the capital-share coefficient for a Cobb-Douglas production function would have to be even higher than 0.8 to be consistent with empirical estimates of $\beta$.

The rate of convergence also tends to be higher if we allow for the flow of technological advances from rich to poor economies. ${ }^{10}$ However, differences in levels of technology can alter the implications of capital mobility. Human and physical capital may move from poor to rich economies and thereby create a force toward divergence.

7. Some of the counterfactual results of open-economy models with perfect capital markets disappear if we assume that people become less patient as they raise assets and consumption; see Uzawa (1968). This form of preferences is introspectively unappealing, but Blanchard (1985) shows that the aggregation across individuals makes overall economies act this way. In particular, the initially most patient economy stops short of owning everything in the long run, and the less patient economies do not tend toward zero consumption per effective worker. Assets are, however, still likely to become negative for less patient economies.

8. Cohen and Sachs (1986); Barro and Sala-i-Martin (1991, chap. 2).

9. Convergence can be less rapid if immigrants to rich economies are substantially above average in human capital. See Borjas (1990) for a discussion of the characteristics of immigrants.

10. See Nelson and Phelps (1966) for an early model of technological diffusion. 


\section{Two Concepts of Convergence}

We discussed in our 1990 study two concepts of convergence related to equation 1 . The first, called $\beta$ convergence, relates to poor economies growing faster than rich ones, and the second, called $\sigma$ convergence, involves a decline over time in the cross-sectional dispersion of per capita income or product. The model in this paper implies a form of conditional $\beta$ convergence in that, for given steady-state values $x_{i}^{*}$ and $\hat{y}_{i}^{*}$, an economy's per capita growth rate is higher the lower the starting level of per capita output, $y_{i, t-T}$. The convergence is conditional in that $\hat{y}_{i, t-T}$ enters in relation to $\hat{y}_{i}^{*}$, which may differ across economies. The coefficient $\beta$ measures the speed of this conditional convergence. To isolate $\beta$ empirically we have to hold constant the differences in the steady-state values $x_{i}^{*}$ and $\hat{y}_{i}^{*}$. Although we included some additional variables as proxies for these differences, we found that the variations in the steady-state values seemed to be minor across the U.S. states. These variations appeared to be more significant across a group of relatively homogeneous countries, such as the OECD members, and were considerably more important across a broad sample of 98 countries.

Even if $x_{i}^{*}$ and $\hat{y}_{i}^{*}$ are identical across a group of economies, a positive $\beta$ coefficient need not imply that the cross-sectional dispersion of per capita output, $y_{i t}$, diminishes over time. A positive $\beta$ tends to reduce the dispersion in $\log \left(y_{i t}\right)$ from equation 1 , but new shocks, $u_{i t}$, tend to raise it. Equation 1 implies, for a given distribution of $u_{i t}$, that the crosssectional standard deviation of $\log \left(y_{i t}\right)$, denoted $\sigma_{t}$, approaches a constant $\sigma$. The dispersion, $\sigma_{t}$, falls (or rises) over time if it starts above (or below) $\sigma$; hence, $\beta$ convergence (in the sense of $\beta>0$ ) need not imply $\sigma$ convergence (in the sense of a declining $\sigma_{t}$ ). If the steady-state value $\hat{y}_{i}^{*}$ differs across economies, we could also consider a conditional form of $\sigma$ convergence. That is, conditional $\sigma$ convergence applies if the dispersion of the deviations, $\log \left(\hat{y}_{i t}\right)-\log \left(\hat{y}_{i}^{*}\right)$, diminishes over time. Because this concept relies heavily on measures of the $\hat{y}_{i}^{*}$, we have not attempted to implement this idea.

We can bring out the distinction between $\beta$ and $\sigma$ convergence by considering two different kinds of questions. Suppose that we are interested in how fast and to what extent the per capita income of a particular economy is likely to catch up to the average of per capita 
incomes across economies. Then $\beta$ convergence is the concept that matters. Suppose, on the other hand, that we want to know how the distribution of per capita income across economies has behaved in the past or is likely to behave in the future. In this case, $\sigma$ convergence is the relevant concept. ${ }^{11}$

Many disturbances, such as war and shocks to agriculture or oil, affect economies differentially. These disturbances tend to temporarily raise the cross-sectional variance of the error term, $u_{i t}$, and thereby raise $\sigma_{t}$ above $\sigma$. Subsequently, if the long-run distribution of $u_{i t}$ is unchanged, $\sigma_{t}$ tends to fall gradually back to the value $\sigma$. Events related to war, agriculture, or oil can also affect groups of economies in a correlated manner; when such an event occurs, the $u_{i t}$ are not independent draws over the economies, $i$. In our previous work, we used regional dummies and measures of sectoral composition of output to address this problem. That is, we treated the $u_{i t}$ as independent over $i$ once we included these additional variables in the regressions.

The failure to introduce these additional variables can also lead to biased estimates of the coefficient $\beta$, contingent on the realization of a particular shock. Consider, for example, an adverse shock to agricultural output in a setting in which agricultural economies start with below

11. Quah (1990) discusses $\beta$ and $\sigma$ convergence in terms of Galton's fallacy: the observation that heights of persons in a family regress to the mean across generations (a form of $\beta$ convergence) does not imply that the dispersion of heights across the population diminishes over time (an example of $\sigma$ convergence). None of this makes $\beta$ convergence uninteresting, as Quah seems to suggest; it just points out that $\beta$ and $\sigma$ convergence are different concepts. One example of the Quah-Galton effect is the ordinal rankings of teams in a sports league. Although $\sigma_{t}$ is constant by definition (so $\sigma$ convergence cannot apply), we can still think of $\beta$ convergence in terms of how rapidly teams at the bottom of the ranking tend to rebound toward the middle or how quickly champions tend to revert to mediocrity. The sports example also leads naturally to the issue of overshooting: is a currently weak team or country likely to be in a better position than a currently strong team or country at some future date? In the Quah-Galton context, if person 1 is taller than person 2, would we predict that the offspring of person 2 would eventually be taller than those of person 1? This type of overshooting cannot occur in the standard neoclassical growth model, which generates a first-order differential equation that is approximated in the linear log-difference form of equation 1 . Thus, if $x_{i}^{*}$ and $\hat{y}_{i}^{*}$ are the same for all $i$, then if economy 1 starts out ahead of economy 2 we would predict that economy 1 would still be ahead of economy 2 at any date in the future. Our conjecture is that heights also satisfy this property, although we have not examined the data. The possibility of overshooting seems more likely for the rankings of sports teams; in fact, this area may be the best place to apply models of overshooting. For an overview of these models, see Schools Brief (1990). 
Figure 1. Convergence of Personal Income across U.S. States: 1880 Income and Income Growth from 1880 to 1988

Annual growth rate, $1880-1988$ (percent)

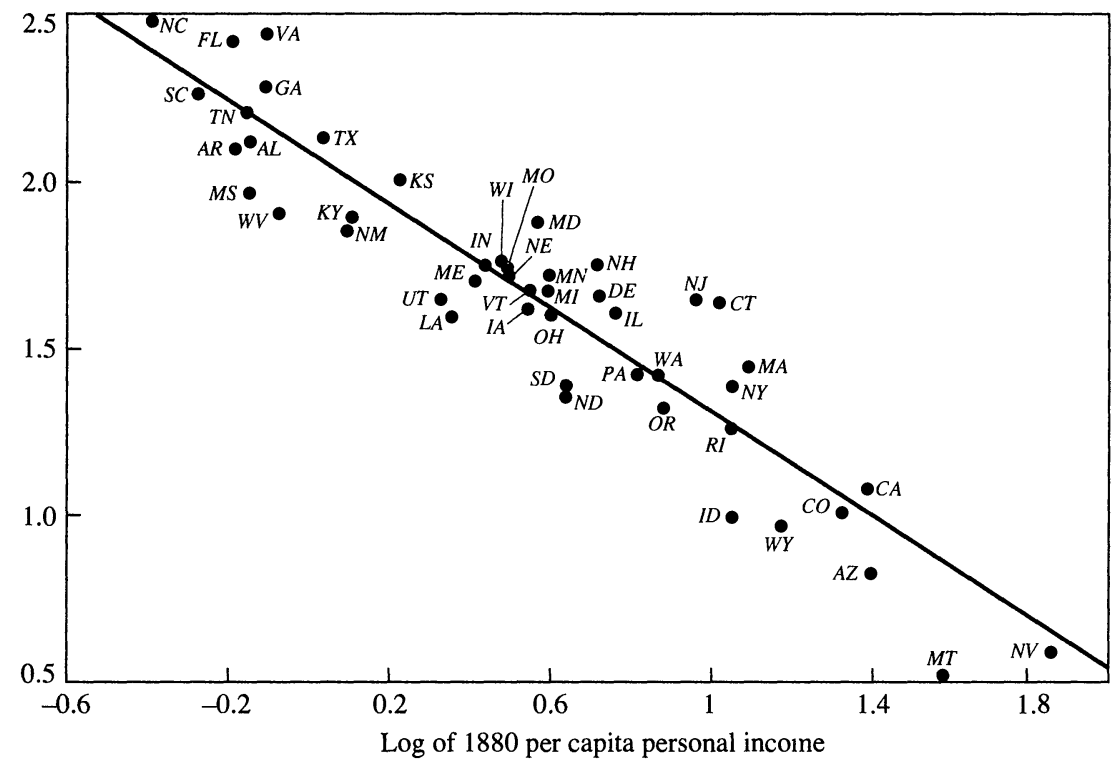

Sources: Bureau of Economic Analysis (1984), Easterlin (1960a, 1960b), and Survey of Current Business, various issues. The postal abbreviation for each state is used to plot the figure. Oklahoma, Alaska, and Hawaii are excluded from the analysis.

average per capita product. Because of the positive correlation of the shock with $y_{i, t-T}$, we would underestimate $\beta$ if we did not hold the shock constant.

\section{Personal Income across U.S. States}

Figure 1 shows the broad pattern of $\beta$ convergence for per capita personal income, exclusive of all transfers, for 47 U.S. states or territories from 1880 to $1988 .{ }^{12}$ The figure shows the strong negative corre-

12. The data on personal income are from Bureau of Economic Analysis (1984), recent issues of Survey of Current Business, and Easterlin (1960a, 1960b). See our 1990 study for a discussion. There are no data for Oklahoma for 1880 (which preceded the Oklahoma land rush) and we exclude Alaska, Hawaii, and the District of Columbia throughout the analysis. We use nominal income figures deflated by the overall consumer price index (CPI). If the price level is the same for all states at each point in time, then we can just as well use 
lation ( -0.93$)$ between the average growth rate from 1880 to 1988 and the log of per capita personal income in 1880 . The means and standard deviations for these and other variables are reported in the appendix tables.

As expected the southern states tended to have low per capita income in 1880 and high average growth rates thereafter. Less well known is that the western states had above-average per capita income in 1880 and below-average growth thereafter.

Although regional catch-up is part of the overall convergence story, figures 2 and 3 show that the pattern between regions (East, South, Midwest, and West) is similar to that within regions. Figure 2 shows the four data points that correspond to the regional means. Figure 3 shows the pattern when the state growth rates and logs of initial income are measured relative to their respective regional means. The relations between growth rates and starting levels from figures 2 and 3 are quantitatively similar.

\section{Basic Regression Results}

Table 1 shows regression estimates of the convergence coefficient, $\beta$, for nine subperiods of the U.S. sample from 1880 to 1988 . The first column is a form of equation 1 that includes only a constant and the log of each state's initial personal income per capita. Although most of the estimated coefficients are significantly positive, the magnitudes vary a great deal and two of the point estimates are negative. (Recall that we define the coefficient $\beta$ in equation 1 so that a positive $\beta$ means that poor economies grow faster than rich ones.) If we constrain the estimate of $\beta$ to be the same for all subperiods, the resulting joint estimate is $\hat{\beta}=$ 0.0175 , or in the neighborhood of 2 percent a year. However, a likelihood-ratio test, shown in the table, strongly rejects the hypothesis that $\beta$ is stable over the subperiods. ${ }^{13}$

nominal income figures in our cross-sectional analysis. If prices differ across states at a point in time - that is, if there are departures from purchasing-power parity-then it would be preferable to use individual-state deflators. We think, however, that the available price indexes across states do not improve on the assumption of a common price level. (The analysis requires only constant relative prices for growth rates, but equal levels of prices for levels of real income.)

13. These results come from an iterative, weighted, nonlinear least squares method, which allows for heteroscedasticity across the subperiods but not for correlation of the error terms over the subperiods. We have also estimated systems that allow for the 
Figure 2. Convergence of Personal Income across U.S. Regions:

1880 Income and Income Growth from 1880 to 1988

Annual growth rate, $1880-1988$ (percent)

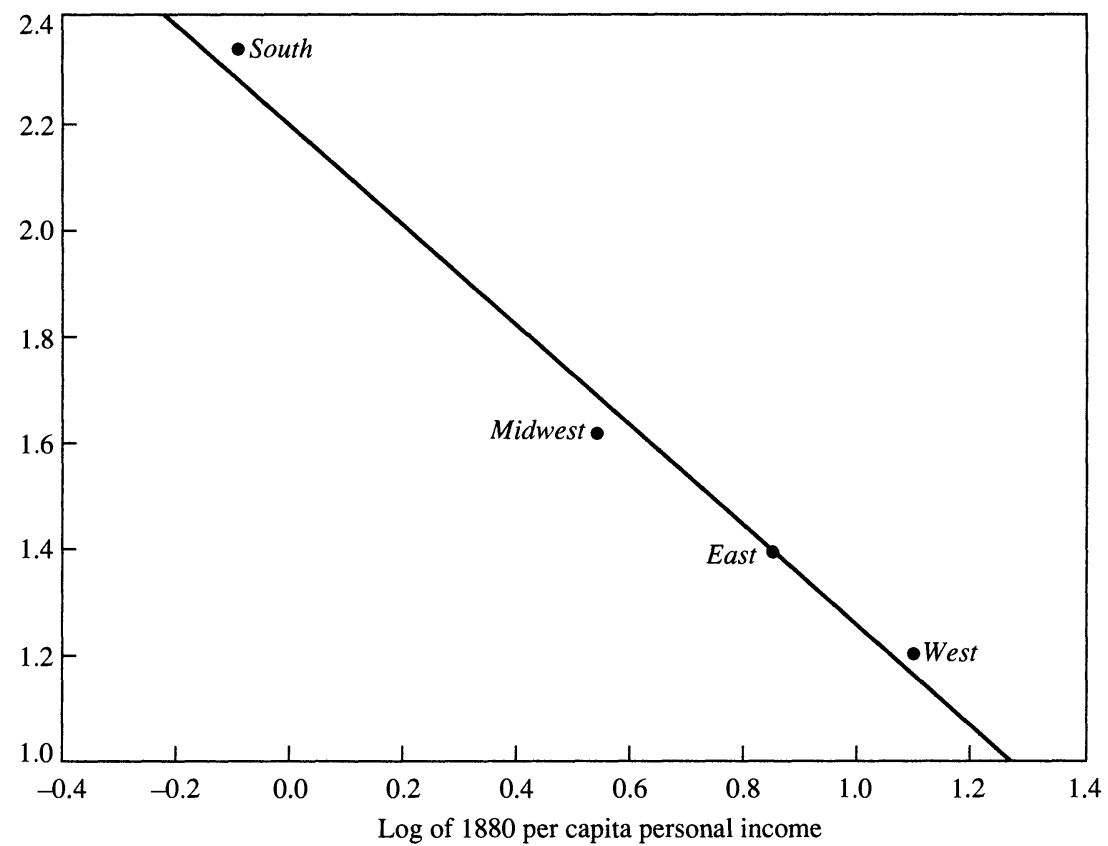

Sources: Bureau of Economic Analysis (1984), Easterlin (1960a, 1960b), and Survey of Current Business, various issues. The four data points correspond to the regional means.

The second equation of table 1 introduces regional dummies for each subperiod. These dummies proxy for differences in the steady-state values, $x_{i}^{*}$ and $\hat{y}_{i}^{*}$, and also absorb fixed regional effects in the error term, $u_{i t}$. Although the fits are improved and the variation in $\hat{\beta}$ over the subperiods is somewhat reduced, the results still reject the hypothesis of $\beta$ stability over the periods. The restricted point estimate, $\hat{\beta}$, for the nine subperiods, 0.0189 , is similar to that reported in the first column. The estimate from the second equation reflects within-region $\beta$ conver-

correlation by using seemingly unrelated regression, or SURE. In most cases, the results of hypothesis tests are similar. In some cases, however, we had difficulty getting the estimates to converge because of the interaction of the nonlinearity in the model with the large number of parameters introduced by the SURE procedure. Probably it would be better to estimate parsimonious representations that allow for a restricted form of serial correlation in the errors, rather than an arbitrary pattern across the subperiods. 
Figure 3. Convergence of Personal Income, U.S. States Relative to Regional Means: 1880 Income and Income Growth from 1880 to 1988

Relative growth rate, $1880-1988$ (percent) $^{\mathrm{a}}$

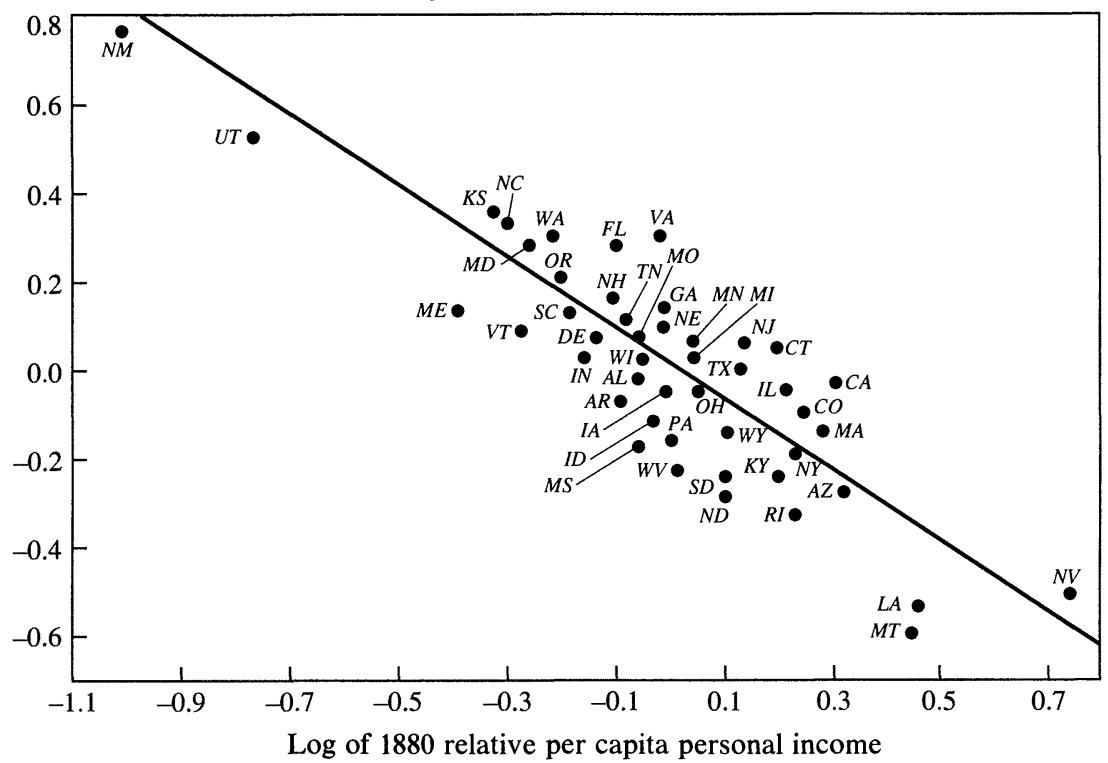

Sources: Bureau of Economic Analysis (1984), Easterlin (1960a, 1960b), and Survey of Current Business, various issues. The postal abbreviation for each state is used to plot the figure. Oklahoma, Alaska, and Hawaii are excluded from the analysis. The figure shows the pattern when the state growth rates and the logs of initial income are measured relative to the respective regional means.

a. Growth is measured by the deviation of the average per capita growth rate of personal income in each state from 1880 to 1988 from the average growth rate for that state's respective region over the same period.

gence, whereas that from the first reflects a combination of within- and between-region convergence. Hence, as also suggested by figures 1-3, the results indicate that the within- and between-region rates of $\beta$ convergence are similar.

\section{Additional Explanatory Variables}

The last equation of table 1 adds two additional variables to the regression. The first, denoted $A_{g r y} y_{i, t-T}$, is the share of personal income originating in agriculture in state $i$ at the start of each subperiod (that is, in year $t-T$ ). This variable is available for all of the subperiods since 1880. As with the regional dummies, the agriculture variable can hold constant the differences in steady-state values, $x_{i}^{*}$ and $\hat{y}_{i}^{*}$, as well as the common effects related to agriculture in the error term.

The second variable, denoted $S_{i t}$ for structure, relates to the break- 
Table 1. Regressions for Personal Income across U.S. States, 1880-1988

\begin{tabular}{|c|c|c|c|c|c|c|}
\hline \multirow[b]{2}{*}{ Period } & \multicolumn{2}{|c|}{ Basic equation } & \multicolumn{2}{|c|}{$\begin{array}{l}\text { Equation with } \\
\text { regional dummies }\end{array}$} & \multicolumn{2}{|c|}{$\begin{array}{l}\text { Equation with } \\
\text { regional dummies } \\
\text { and sectoral } \\
\text { variables }^{\mathrm{a}}\end{array}$} \\
\hline & $\hat{\beta}$ & $R^{2}[\hat{\sigma}]$ & $\hat{\beta}$ & $R^{2}[\hat{\sigma}]$ & $\hat{\beta}$ & $R^{2}[\hat{\boldsymbol{\sigma}}]$ \\
\hline $1880-1900$ & $\begin{array}{c}0.0101 \\
(0.0022)\end{array}$ & $\begin{array}{c}0.36 \\
{[0.0068]}\end{array}$ & $\begin{array}{c}0.0224 \\
(0.0040)\end{array}$ & $\begin{array}{l}0.62 \\
{[0.0054]}\end{array}$ & $\begin{array}{c}0.0268 \\
(0.0048)\end{array}$ & $\begin{array}{c}0.65 \\
{[0.0053]}\end{array}$ \\
\hline $1900-20$ & $\begin{array}{c}0.0218 \\
(0.0032)\end{array}$ & $\begin{array}{c}0.62 \\
{[0.0065]}\end{array}$ & $\begin{array}{c}0.0209 \\
(0.0063)\end{array}$ & $\begin{array}{c}0.67 \\
{[0.0062]}\end{array}$ & $\begin{array}{c}0.0269 \\
(0.0075)\end{array}$ & $\begin{array}{c}0.71 \\
{[0.0060]}\end{array}$ \\
\hline $1920-30$ & $\begin{array}{r}-0.0149 \\
(0.0051)\end{array}$ & $\begin{array}{c}0.14 \\
{[0.0132]}\end{array}$ & $\begin{array}{r}-0.0122 \\
(0.0074)\end{array}$ & $\begin{array}{l}0.43 \\
{[0.0111]}\end{array}$ & $\begin{array}{c}0.0218 \\
(0.0112)\end{array}$ & $\begin{array}{c}0.64 \\
{[0.0089]}\end{array}$ \\
\hline $1930-40$ & $\begin{array}{c}0.0141 \\
(0.0030)\end{array}$ & $\begin{array}{c}0.35 \\
{[0.0073]}\end{array}$ & $\begin{array}{c}0.0127 \\
(0.0051)\end{array}$ & $\begin{array}{c}0.36 \\
{[0.0075]}\end{array}$ & $\begin{array}{c}0.0119 \\
(0.0072)\end{array}$ & $\begin{array}{c}0.46 \\
{[0.0071]}\end{array}$ \\
\hline $1940-50$ & $\begin{array}{c}0.0431 \\
(0.0048)\end{array}$ & $\begin{array}{c}0.72 \\
{[0.0078]}\end{array}$ & $\begin{array}{c}0.0373 \\
(0.0053)\end{array}$ & $\begin{array}{c}0.86 \\
{[0.0057]}\end{array}$ & $\begin{array}{c}0.0236 \\
(0.0060)\end{array}$ & $\begin{array}{c}0.89 \\
{[0.0053]}\end{array}$ \\
\hline $1950-60$ & $\begin{array}{c}0.0190 \\
(0.0035)\end{array}$ & $\begin{array}{l}0.42 \\
{[0.0050]}\end{array}$ & $\begin{array}{c}0.0202 \\
(0.0052)\end{array}$ & $\begin{array}{l}0.49 \\
{[0.0048]}\end{array}$ & $\begin{array}{c}0.0305 \\
(0.0054)\end{array}$ & $\begin{array}{l}0.66 \\
{[0.0041]}\end{array}$ \\
\hline $1960-70$ & $\begin{array}{c}0.0246 \\
(0.0039)\end{array}$ & $\begin{array}{c}0.51 \\
{[0.0045]}\end{array}$ & $\begin{array}{c}0.0135 \\
(0.0043)\end{array}$ & $\begin{array}{c}0.68 \\
{[0.0037]}\end{array}$ & $\begin{array}{c}0.0173 \\
(0.0053)\end{array}$ & $\begin{array}{c}0.72 \\
{[0.0036]}\end{array}$ \\
\hline $1970-80$ & $\begin{array}{c}0.0198 \\
(0.0062)\end{array}$ & $\begin{array}{c}0.21 \\
{[0.0060]}\end{array}$ & $\begin{array}{c}0.0119 \\
(0.0069)\end{array}$ & $\begin{array}{l}0.36 \\
{[0.0056]}\end{array}$ & $\begin{array}{c}0.0042 \\
(0.0070)\end{array}$ & $\begin{array}{c}0.46 \\
{[0.0052]}\end{array}$ \\
\hline $1980-88$ & $\begin{array}{r}-0.0060 \\
(0.0130)\end{array}$ & $\begin{array}{c}0.00 \\
{[0.0142]}\end{array}$ & $\begin{array}{r}-0.0005 \\
(0.0114)\end{array}$ & $\begin{array}{c}0.51 \\
{[0.0103]}\end{array}$ & $\begin{array}{c}0.0146 \\
(0.0099)\end{array}$ & $\begin{array}{c}0.76 \\
{[0.0075]}\end{array}$ \\
\hline \multicolumn{7}{|l|}{ Nine periods combined ${ }^{b}$} \\
\hline$\beta$ restricted & $\begin{array}{c}0.0175 \\
(0.0013)\end{array}$ & $\cdots$ & $\begin{array}{c}0.0189 \\
(0.0019)\end{array}$ & $\cdots$ & $\begin{array}{c}0.0224 \\
(0.0022)\end{array}$ & $\cdots$ \\
\hline $\begin{array}{l}\text { Likelihood-ratio statistic } \\
P \text {-value }\end{array}$ & $\begin{array}{l}65.6 \\
0.000\end{array}$ & $\ldots$ & $\begin{array}{l}32.1 \\
0.000\end{array}$ & $\ldots$ & $\begin{array}{l}12.4 \\
0.134\end{array}$ & $\ldots$ \\
\hline
\end{tabular}

Sources: Authors' own calculations using Bureau of Economic Analysis (1984), Easterlin (1960a, 1960b), and Survey of Current Business, various issues. All regressions are for the continental states, except for the $1880-1900$ period, in which Oklahoma is excluded for all equations and Wyoming is excluded in the last equation. The regressions use nonlinear least squares to estimate equations of the form:

$$
(1 / T) \log \left(y_{i t} / y_{i, t-T}\right)=a-\left[\log \left(y_{i, t-T}\right)\right]\left(1-e^{-\beta T}\right)(1 / T)+\text { other variables, }
$$

where $y_{i, t-T}$ is the per capita personal income in state $i$ at the beginning of the interval, divided by the overall CPI; $y_{i, t}$ is the real per capita personal income in state $i$ at time $t ; T$ is the length of the observation interval; and the other variables are regional dummies and the variables described in note a. Standard errors are in parentheses. The standard errors of the regressions are in brackets.

a. The additional variables in the third column are the share of personal income originating in agriculture at the start of the period, $A g r y_{i, t-T}$, and the structural composition variable, $S_{i t}$, described in the text. Data for $S_{i t}$ are only available since 1929.

b. The combined regression restricts the value of $\beta$ to be the same across all nine subperiods. The restricted $\beta$ are estimated using iterative, weighted, nonlinear least squares.

c. The likelihood ratio test is based on the null hypothesis that the $\beta$ are the same across all nine subperiods. It follows a chi-squared $\left(\chi^{2}\right)$ distribution; the $0.05 \chi^{2}$ value with eight degrees of freedom is 15.5 .

down of state $i$ 's personal income into nine standard sectors: agriculture; mining; construction; manufacturing; transportation; wholesale and retail trade; finance, insurance, real estate; services; and government. We first compute the national growth rates of per capita income originating in each sector for each subperiod. Then we weight the national 
growth rates by the share of each sector in state $i$ 's personal income at the start of the subperiod. Hence, the formula for $S_{i t}$ is

$$
S_{i t}=\sum_{j=1}^{9} w_{i j, t-T} \cdot \log \left(y_{j t} / y_{j, t-T}\right),
$$

where $w_{i j, t-T}$ is the weight of sector $j$ in state $i$ 's personal income at time $t-T$, and $y_{j t}$ is the national average of personal income in sector $j$ at time $t$, expressed as a ratio to national population at time $t$. Aside from the effect of changing sectoral weights within a state, the variable $S_{i t}$ would equal the total growth rate of per capita personal income in state $i$ between years $t-T$ and $t$ if each of the state's sectors grew at the national average rate for that sector. In particular, the variable $S_{i t}$ reflects shocks to agriculture, oil, and so on, in a way that interacts with state $i$ 's concentration in those sectors. We think of $S_{i t}$ as a proxy for common effects related to sectoral composition in the error term, $u_{i t}$. Note that $S_{i t}$ depends on contemporaneous realizations of national variables, but only on lagged values of state variables. Because the impact of an individual state on national aggregates is small, $S_{i t}$ can be nearly exogenous with respect to the individual error term for state $i$.

We have the data to construct $S_{i t}$ only since 1929. For that reason, we also include the variable $\operatorname{Agry}_{i, t-T}$, described above, as a separate influence. We include $A_{g r y} y_{i, t-T}$ for all subperiods, although the results are similar if we omit this variable for the subperiods beginning after 1929.

When the two variables, $A g r y_{i, t-T}$ and $S_{i t}$, are included in the regressions, the principal new finding is that the estimates of $\hat{\beta}$ are much more stable across periods. The greater stability arises because we hold constant the shocks (for some subperiods) that are correlated with initial per capita income as well as hold constant those that affect groups of states in common. For example, agriculture suffered relative to other sectors in the $1920 \mathrm{~s} .{ }^{14}$ Because agricultural states had below-average per capita income in 1920, we estimate negative $\beta$ coefficients for the 1920 30 subperiod in the first two columns. But, once we hold constant the

14. The ratio of the wholesale price index (WPI) for farm products to the CPI for all items fell at an annual rate of 3.5 percent from 1920 to 1930 . Over that period, the average growth rate of real per capita farm income-nominal income divided by the CPI and farm population-was -2.7 percent a year. In contrast, the average growth rate of real per capita nonfarm personal income was 0.8 percent a year. The data are from Bureau of Economic Analysis (1973) and Bureau of the Census (1975). 
differences in agricultural shares, Agry $_{i, t-T}$, we estimate a $\beta$ coefficient for this subperiod that is similar to those found for the other subperiods. The joint estimate for the nine subperiods is now $\hat{\beta}=0.0224$ (s.e. $=$ 0.0022 ) and we accept the hypothesis of coefficient stability at the 5 percent level. Thus, as noted before, the results suggest $\beta$ convergence at a rate somewhat above 2 percent a year. ${ }^{15}$

The estimates of $\beta$ convergence shown in the last columns of the table are net of compositional effects from shifts of persons out of agriculture and toward higher productivity jobs in industry and services. ${ }^{16}$ These effects are held constant by the initial agricultural shares, Agry $_{i, t-T}$, which are included as regressors. In particular, if we add the change in the agricultural share, Agry $_{i t}-$ Agry $_{i, t-T}$, to the regressions, the joint estimate of $\beta$ is virtually unchanged from that shown in the last equation. In general, industry-mix effects matter for the results if shifts in income shares among sectors with different average levels of productivity are correlated with initial levels of per capita income. It is unclear that we would want to filter out this kind of effect in measuring $\beta$ convergence, but, in any event, our examination of productivity data from the postWorld War II period suggests that shifts between agriculture and nonagriculture would be the principal effect of this type.

We have also computed regression estimates that parallel those in the last equation of table 1 but exploit only the between-region variation in

15. It is well known that temporary measurement error in $y_{i t}$ can lead to an overestimate of the convergence coefficient, $\beta$. In previous research we have taken several approaches to assessing the likely magnitude of this effect. See Barro (1991) and Barro and Sala-iMartin (1990). In one approach we related the growth rate of income between $t-T$ and $t$, $(1 / T) \cdot \log \left(y_{i t} / y_{i, t-T}\right)$, to income at a date prior to $t-T$, say to $\log \left(y_{i, t-T-T}\right)$. If measurement error does not persist over an interval greater than $T^{\prime}$ (which we took to be five or ten years), then with a plausible magnitude for $\beta$, the asymptotic bias in this form is in the direction opposite to that in the original form. Because the empirical estimates of $\beta$ from the two forms did not differ greatly, we argued that the effects of measurement error were unlikely to be major.

16. We do not have reliable data on agricultural employment, but the data on farm population suggest that this productivity differential is large, at least in earlier years. We measure farm productivity as farm national income divided by farm population and measure nonfarm productivity as nonfarm national income divided by nonfarm population. Using these concepts of productivity, the ratio of nonfarm to farm productivity was 4.0 in $1889,2.7$ in 1899, 2.3 in 1909, 2.9 in 1920, 3.6 in 1930, 3.7 in 1940, 2.4 in 1960, 1.8 in 1970, 1.6 in 1980, and 1.5 in 1988. The data are from Bureau of Economic Analysis (1973) and Bureau of the Census $(1975,1990)$. One shortcoming of these measures of productivity is that they do not adjust for differences in family size between farm and nonfarm populations. 
growth rates. Because we have four regions and nine subperiods, we now have 36 observations of per capita growth rates. (With a single $\beta$ coefficient, this system has 25 independent variables and therefore 11 degrees of freedom.) The joint estimate of $\beta$ is 0.0187 (s.e. $=0.0069$ ), which does not differ greatly from the joint estimate shown in the last equation of table 1 . Thus, as noted before, the between-region $\beta$ convergence is similar to the within-region convergence. We would not get this similarity if the states in the four regions differed substantially (after holding constant the regional differences in $A g r y_{i, t-T}$ and $S_{i t}$ ) in terms of the steady-state values, $x_{i}^{*}$ and $\hat{y}_{i}^{*}$, in equation 1 . Thus, the findings suggest that the regions are converging toward similar steadystate behavior of per capita income.

\section{Dispersion of Personal Income}

Figure 4 shows the unweighted cross-sectional standard deviation, $\sigma_{t}$, for the log of per capita personal income for 48 U.S. states from 1880 to 1988 . (The observation for 1880 applies to 47 states or territories. The data are plotted for $1880,1900,1920,1929,1930,1940,1950$, and annually since 1955.) We concentrate for now on the data that exclude government transfers, which are the figures that we have used thus far.

Figure 4 shows that the dispersion of personal income declined from 0.54 in 1880 to 0.33 in 1920 , but then rose to 0.40 in 1930 . This rise reflects the adverse shock to agriculture during the 1920s; the effect on $\sigma_{t}$ is pronounced because the agricultural states were already below average in per capita income before the shock. After 1930, $\sigma_{t}$ fell to 0.35 in 1940, 0.24 in 1950, 0.21 in 1960, 0.17 in 1970, and a low point of 0.14 in 1976 . The sharp decline during the 1940s reflects the favorable experience of agriculture. ${ }^{17}$ The pattern of long-term decline in $\sigma_{t}$ reversed after the mid-1970s, and $\sigma_{t}$ rose to 0.15 in 1980 and 0.19 in 1988 . We think that the increase in $\sigma_{t}$ after the mid-1970s relates to oil shocks. A later section discusses these effects in the context of comparing the results for personal income with those based on gross state product.

17. The ratio of the WPI for farm products to the CPI for all items grew at an average annual rate of 9.5 percent from 1940 to 1950 . Over this period, the average growth rate of real per capita farm income (nominal income divided by the CPI and farm population) was 7.8 percent a year, compared to 2.9 percent a year for real per capita nonfarm personal income. The data are from Bureau of the Census (1975). 
Figure 4. Dispersion of Personal Income across U.S. States, 1880-1988

Income dispersion ${ }^{\mathrm{a}}$

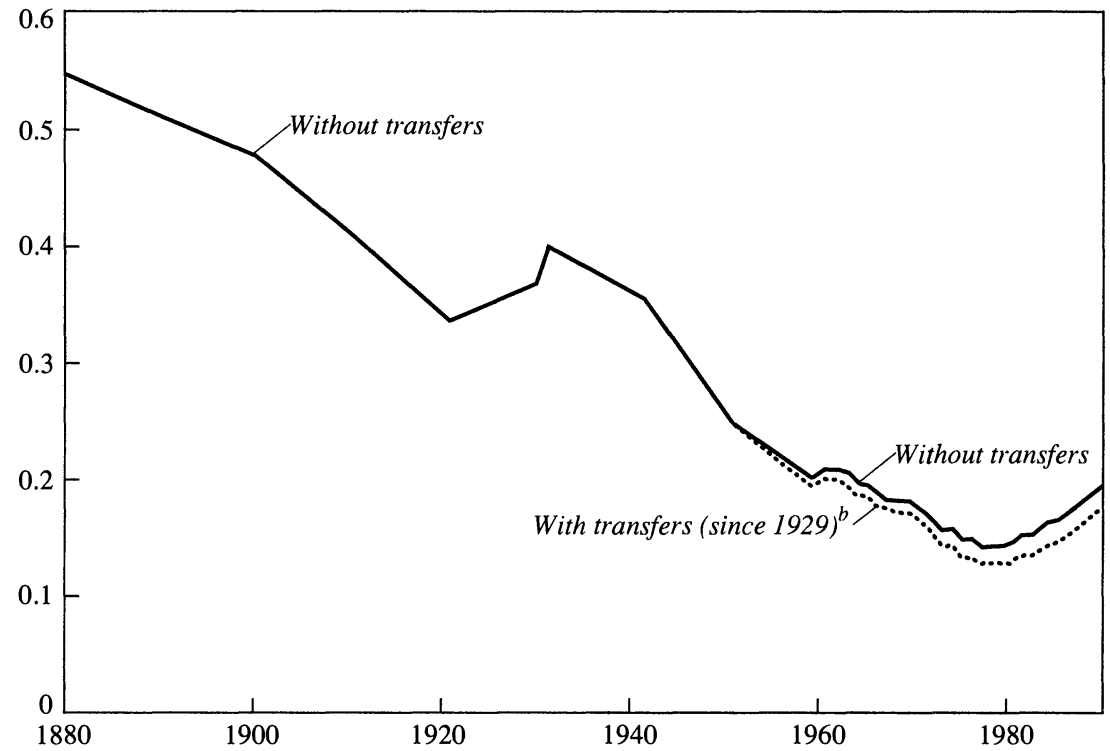

Sources: Authors' own calculations using Bureau of Economic Analysis (1984), Easterlin (1960a, 1960b), and Survey of Current Business, various issues. The data are for the continental U.S. states, except the 1880 figure, which excludes Oklahoma. The data are plotted for $1880,1900,1920,1929,1930,1940,1950$, and annually since 1955.

a. Income dispersion is measured by the unweighted cross-sectional standard deviation of the log of per capita personal income.

b. Data on the dispersion of per capita personal income inclusive of government transfer payments are included since 1929, although the effect of including transfer payments is negligible before 1950 .

The broad observation from figure 4 is a long-term decline in $\sigma_{t}$ from a value above 0.5 to a plateau around $0.15-0.20$. This pattern accords with the $\sigma$ convergence predicted by the neoclassical growth model if the states began, in 1880 , with a dispersion that was well above the steady-state value, $\sigma$. If we use the observed values, $\sigma_{1880}=0.545$ and $\sigma_{1988}=0.194$, and the previous estimate, $\beta=0.02$ a year, then we can estimate the standard deviation, $\sigma_{u}$, of the annual error term as 0.037 . This value implies that the steady-state dispersion is $0.18 .{ }^{18}$

One aspect of the high dispersion in 1880 is the low per capita incomes of southern states relative to nonsouthern states, a pattern that can be

18. To estimate $\sigma_{u}$ we use the first-difference equation for $\sigma_{t}^{2}$, derived in our 1990 study: $\sigma_{t}^{2}=\sigma_{u}^{2} /\left(1-e^{-2 \beta}\right)+\left[\sigma_{0}^{2}-\sigma_{u}^{2} /\left(1-e^{-2 \beta}\right)\right] e^{-2 \beta t}$. The steady-state variance, $\sigma^{2}$, equals the first term in this formula, $\sigma_{u}^{2} /\left(1-e^{-2 \beta}\right)$. 
traced back to the Civil War. As discussed in our 1990 study, in 1840 the average income in the South was not very much below that in the nonSouth, but in 1880 it was about 50 percent of that in the non-South. Another element is that the western states, which resembled new territories in 1880, had relatively high per capita incomes at the start of the sample. Some of this high income represented temporary opportunities in mining.

Figure 4 also shows the values of $\sigma_{t}$ computed from personal income inclusive of government transfer payments. ${ }^{19}$ (Our data on transfers do not separate the amounts received from the federal government from those received from state and local governments.) As might be expected, government transfers reduce the dispersion of personal income, since many of these transfers aim to supplement the income of lower-income individuals. The ratio of transfers to personal income exclusive of transfers is substantially negatively correlated with the log of personal income exclusive of transfers. For example, the correlation between the transfer ratio and the log of personal income exclusive of transfers is -0.76 in 1987. On the other hand, the time pattern for $\sigma_{t}$ is similar with and without transfers. The quantitative effect of the transfer component has been increasing over time. It is negligible in 1950, but by $1987 \sigma_{t}$ exclusive of transfers is 0.187 , whereas $\sigma_{t}$ inclusive of transfers is 0.165 .

When personal income dispersion (excluding transfers) is computed across regions rather than states, the time path is very similar to that in figure 4 . Figure 5 shows the underlying data on average per capita income for the four regions. This figure shows clearly that the average incomes in each region have gotten much closer over time.$^{20}$ The main inference from figure 5 is that a lot of the long-term reduction in $\sigma_{t}$ reflects the typical southern and western state becoming more like the typical eastern and midwestern state.

Figure 6 shows the patterns for $\sigma_{t}$ within each of the four regions. The long-term decline in income dispersion among the western states is apparent, but the other patterns are less straightforward. One clear

19. The data on transfers come from the Commerce Department and only begin in 1929. Since the amounts of transfers for earlier years are small, the behavior of $\sigma$, with and without transfers would be similar before 1929.

20. See Easterlin (1960a) and Borts and Stein (1964, chap. 2) for related analyses of the regional dispersion of per capita personal income. 
Figure 5. Personal Income of U.S. Regions, 1880-1988

Log of real per capita income

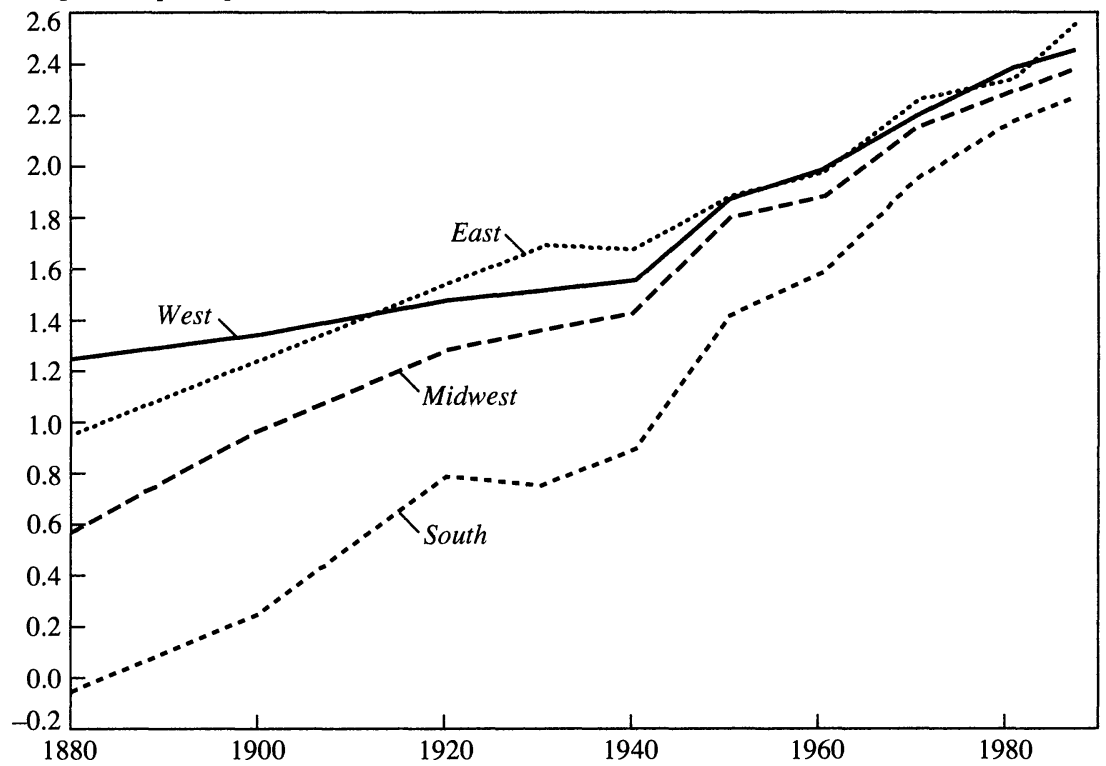

Sources: Authors' own calculations using Bureau of Economic Analysis (1984), Easterlin (1960a, 1960b), and Survey of Current Business, various issues. The data are plotted for 1880, 1900, 1920, every ten-year interval that follows, and 1988.

result, however, is that the values of $\sigma_{t}$ within each of the four regions are essentially the same toward the end of the sample.

The regional patterns highlight the distinction between $\sigma$ and $\beta$ convergence that was discussed earlier. With respect to $\sigma$ convergence, the narrowing of the gap in average incomes across regions is a central element of the story, and the changes within regions are a sideshow. In contrast, the estimated speeds of $\beta$ convergence between and within regions are virtually identical. That is, relatively poor eastern states (such as Maine and Vermont in 1880) tended to catch up to relatively rich eastern states (Massachusetts and Rhode Island in 1880) about as fast as the poor southern state tended to catch up to the better off western or eastern state. These findings are consistent with the underlying model if the initially high values of $\sigma_{t}$ reflected temporary disturbances that affected entire regions (such as the Civil War and the opening of territories in the West). 
Figure 6. Dispersion of Personal Income within U.S. Regions, 1880-1988

Income dispersion $^{\mathrm{a}}$

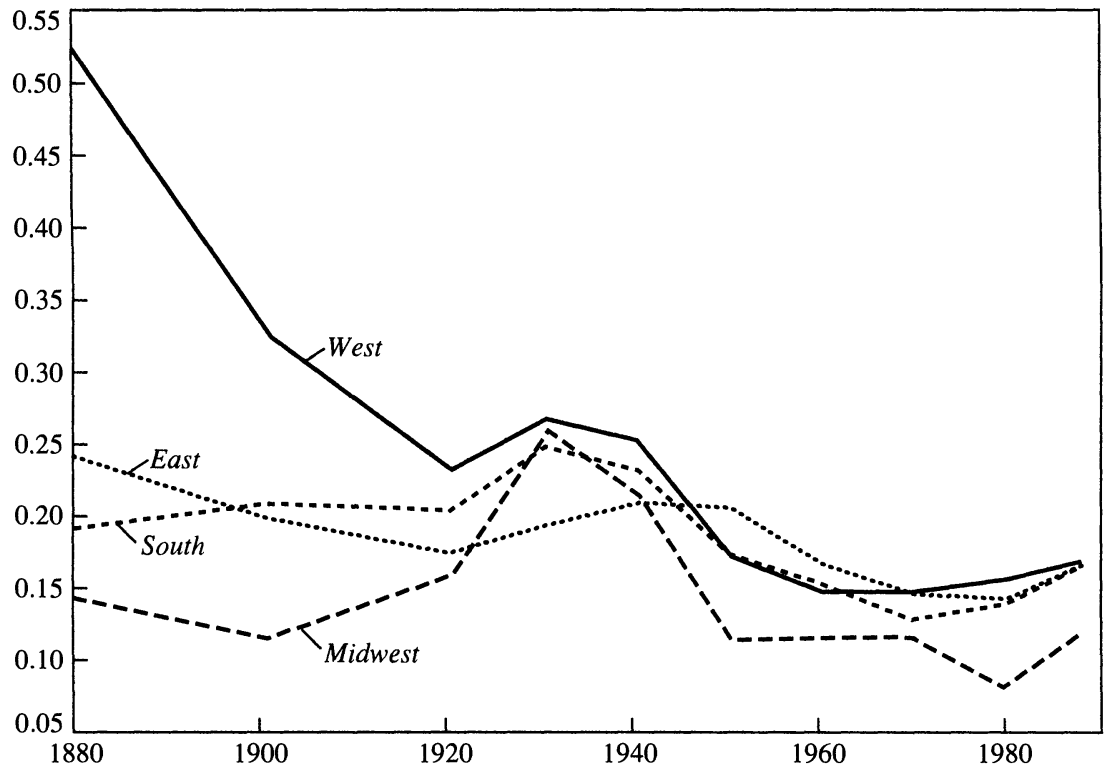

Sources: Authors' own calculations using Bureau of Economic Analysis (1984), Easterlin (1960a, 1960b), and Survey of Current Business, various issues. The data are plotted for 1880, 1900, 1920, every ten-year interval that follows, and 1988 .

a. Income dispersion is measured by the unweighted cross-sectional standard deviation of the log of per capita personal income.

\section{Net Migration across U.S. States}

This section, which extends the work of Sala-i-Martin, examines the migration of persons among the U.S. states in the context of the process of growth and convergence that we have been considering. ${ }^{21}$ As already mentioned, the process of convergence is quickened by movements of people out of areas where ratios of capital to workers are low-and hence wage rates and levels of per capita income are also low-to areas where they are high. We investigate whether the flows of net migration accord with this story and whether these flows are a substantial force in the convergence we have estimated for the U.S. states.

21. Sala-i-Martin (1990, chap. 5). 


\section{Modeling Net Migration}

Suppose that people (and hence workers) are identical and that states offer the same amenities, government policies, and so on. Suppose that places differ by initial ratios of physical capital to labor, and hence by wage rates, and that existing capital cannot move. Then, people are motivated to move from low-wage to high-wage areas.

If moving were costless, the migration of persons would equalize per capita incomes instantaneously according to the model. In truth, however, moving entails costs, which include direct outlays for transportation, costs of familiarizing oneself with new jobs and surroundings, psychic costs of leaving acquaintances, and so on. If we allow for heterogeneity among persons, then the costs of moving differ in accordance with age, family status, occupation, and other characteristics that affect the direct and indirect costs of moving or preferences about moving. Therefore, not all persons in low-wage areas are motivated to leave at a given point in time. This conclusion is reinforced if we allow for heterogeneity of jobs and workers so that wage rates and employment involve features of a matching problem.

Furthermore, the costs of moving into an area may depend on the aggregate flow of persons into that area. This rate of flow could influence job-search costs (which would show up in properly defined wage rates of new entrants) and housing costs. Thus, even if we abstract from matching considerations, these elements imply that not all migrants will go to the same place at a given point in time.

In addition to moving costs, other factors enter into an empirical analysis of net migration. If places differ in the amenities that affect utility or production, such as climate, natural resources, and government policies, then the long-run equilibrium described by Jennifer Roback entails a range of wage rates for identical workers, along with a range of population densities and land prices. ${ }^{22}$ Although wage rates differ across places, these variations perfectly compensate for differences in land prices and amenities; hence people will have no incentive to move. In terms of the reduced form, the equilibrium wage rate and population

22. Roback (1982). 
density for state $i, w_{i}^{*}$ and $\pi_{i}^{*}$ respectively, are determined along with the land prices by the underlying amenities, denoted $\theta_{i}$. We can think, as an approximation, of people having an incentive to move to state $i$ if $\pi_{i}<\pi_{i}^{*}\left(\theta_{i}\right)$, so that $w_{i}>w_{i}^{*}\left(\theta_{i}\right)$. With costs to moving, the rate of migration into state $i$ would be a positive function of the gap $w_{i}-$ $w_{i}^{*}\left(\theta_{i}\right)$. The derivative of this function would be finite.

The analysis is more complicated with variable capital stocks. We are especially interested in analyzing their effects in the context of our data set, which includes information about per capita incomes (which we take as proxies for wage rates) and population densities, but not about capital stocks. If starred variables denote steady-state values, then a place with a temporarily high intensity of physical capital could have $w_{i}>w_{i}^{*}\left(\theta_{i}\right)$ and $\pi_{i}>\pi_{i}^{*}\left(\theta_{i}\right)$. In this case, for a given $w_{i}-w_{i}^{*}\left(\theta_{i}\right)$, a higher $\pi_{i}-$ $\pi_{i}^{*}\left(\theta_{i}\right)$ signals that current capital intensity is higher and hence that capital intensity and wage rates will decline over time. In particular, the greater $\pi_{i}-\pi_{i}^{*}\left(\theta_{i}\right)$ is, the shorter the expected persistence of the gap between $w_{i}$ and $w_{i}^{*}\left(\theta_{i}\right)$ and hence the lower the incentive to migrate into the state.

The above reasoning leads us to write a function for $m_{i t}$, the net rate of migration into state $i$ between years $t-T$ and $t$, as

$$
\begin{gathered}
m_{i t}=f\left(y_{i, t-T}, \theta_{i}, \pi_{i, t-T},\right. \text { and variables that depend on } \\
t \text { but not on } i),
\end{gathered}
$$

where the partial effects of $y_{i, t-T}$ and $\theta_{i}$ are positive (if a higher $\theta_{i}$ means more amenities) and the partial effect of $\pi_{i, t-T}$ is negative. ${ }^{23} \mathrm{We}$ assume that $\theta_{i}$-an exogenous characteristic like climate or geography-does not change over time. (Thus, the analysis would have to be modified for exhaustible resources like silver and oil that are depleted over time and also modified for changing government policies.) The set of variables that depend on $t$ but not $i$ includes any elements that influence the national averages of per capita income and population density; that is, $y_{i, t-T}$ and $\pi_{i, t-T}$ in equation 3 involve comparisons among locations at time $t$. The set also includes effects like technological progress in heating and air conditioning, which affect people's attitudes about climate and other components of the amenities, $\theta_{i}$.

23. See Mueser and Graves (1990) for a related model of migration. 
We have found empirically that a simple functional form of equation 3 does reasonably well in explaining net migration into state $i$ :

$$
m_{i t}=a+b \cdot \log \left(y_{i, t-T}\right)+c_{1} \cdot \theta_{i}+c_{2} \cdot \pi_{i, t-T}+c_{3} \cdot\left(\pi_{i, t-T}\right)^{2}+v_{i t},
$$

where $v_{i t}$ is an error term, $b$ is positive, and the functional form allows for a quadratic in population density, $\pi_{i, t-T} \cdot{ }^{24}$ The marginal effect of $\pi_{i, t-T}$ on $m_{i t}$ is negative if $c_{2}+2 c_{3}$ is negative. Although there is an extensive literature about variables to include in $\theta_{i}{ }^{25}$ the present analysis includes only the log of average heating-degree days, denoted $\log \left(\right.$ Heat $\left._{i}\right)$, which is a disamenity so that $c_{1}$ is negative. The variable $\log \left(\right.$ Heat $\left._{i}\right)$ has a good deal of explanatory power for net migration-we did explore different functional forms as well as the addition of cooling-degree days as an explanatory variable, but the alternative functional forms did not fit as well as the one described in equation 4 and the cooling-degree days variable is insignificant. ${ }^{26}$ Including other variables in $\theta_{i}$ would be important for a fuller study of migration. It would also be useful to introduce migration for retirement, a mechanism that likely explains some outliers like Florida. However, these kinds of modifications probably would not change our basic findings about the relation between net migration and state per capita income and the interaction between migration and the convergence results.

\section{Empirical Results}

Figure 7 shows the simple, long-term relation between in-migration and initial per capita income. The variable on the vertical axis is the average annual in-migration rate for each state from 1900 to $1987 .{ }^{27}$ The horizontal axis plots the log of state per capita personal income in 1900. The figure shows a positive relationship (with a correlation of 0.51 ), but

24. Population density is the ratio of state population to total area (land and water). The data on area are from Bureau of the Census (1990).

25. See, for example, Blomquist, Berger, and Hoehn (1988). Some of the variables that they consider, such as criminal activity, are, however, not exogenous in the same sense as climate or geography.

26. The data on heating- and cooling-degree days refer to average temperatures from 1951 to 1980 and are from Bureau of the Census (1990).

27. The variable is the average of the rates for the subperiods, 1900-20, 1920-30, and so forth through to the final subperiod 1980-87, weighted by the lengths of each interval. The rate for each subperiod is the annual average of net migration divided by state population at the start of the subperiod. 
Figure 7. Migration and Initial State Income, 1900-87

Annual migration rate, $1900-87$ (percent) ${ }^{\mathrm{a}}$

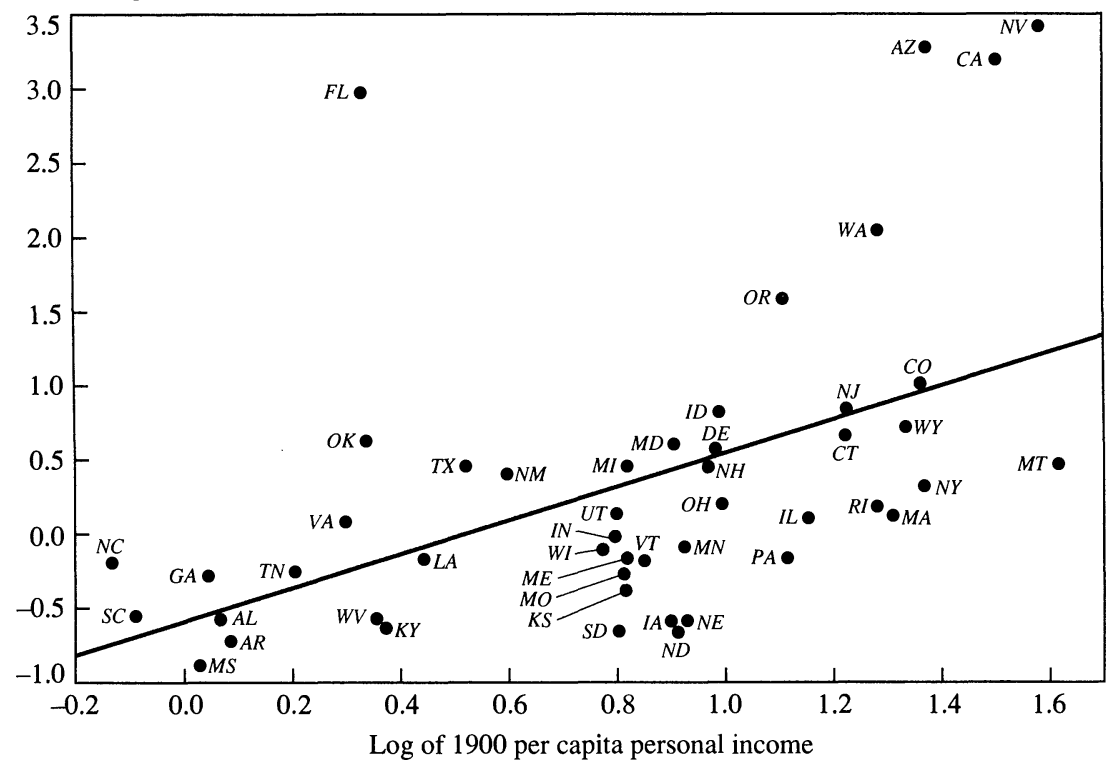

Sources: Bureau of the Census $(1975,1990)$. The postal abbreviation for each state is used to plot the figure. a. The variable is the average of the rates for the subperiods, 1900-20,1920-30, . , 1970-80, and 1980-87, weighted by the length of the subperiod. The rate for each subperiod is the annual average of net migration, divided by state population at the start of the subperiod.

the relation is not nearly as clear-cut as that seen for long-term per capita growth in figure 1. Figure 8 shows the partial relation between the longterm in-migration rate and the log of initial per capita income-after holding constant the values of the right-side variables (at their 1900 levels) contained in equation 4 , the regional dummies, and the agricultural-share variable. The partial correlation is positive and equal to 0.45 .

Table 2 shows regression results, in the form of equation 4 , for net migration into U.S. states. ${ }^{28}$ The results are for eight subperiods beginning with $1900-20 . .^{29}$ The dependent variable, $m_{i t}$, is the ratio of migrants (annual average over each subperiod) to state population at the start of

28. The regressions use an iterative, weighted least squares procedure.

29. The overall results do not change greatly if we add the subperiod 1880-1900. This subperiod includes some enormous rates of in-migration, which correspond to the opening of new territories. Because our simple functional form does not fit well in these years, we decided to exclude this subperiod from the present analysis. 
Figure 8. Partial Relation between Migration and Initial State Income, 1900-87 Annual migration rate, $1900-87$ (percent) $^{\mathrm{a}}$

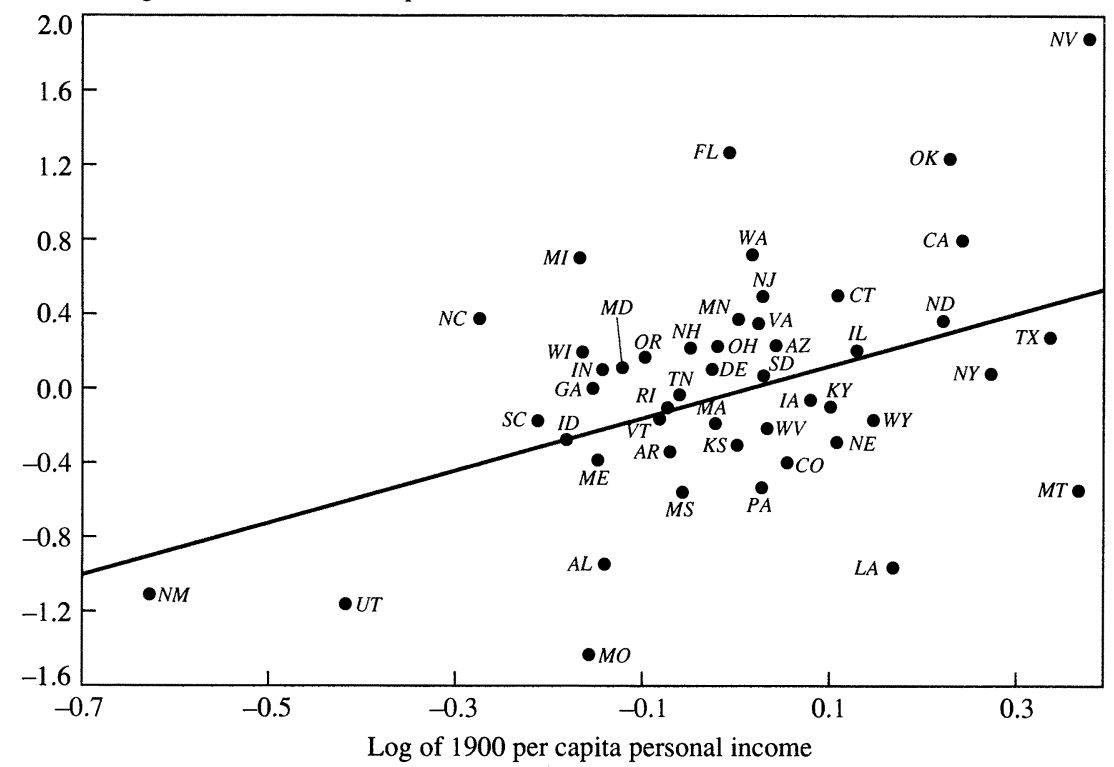

Sources: Bureau of the Census $(1975,1990)$. The figure plots the residuals from an equation explaining the migration rate with the variables in equation 4 against the residuals from an equation explaining the log of 1900 per capita income with the same variables. The postal abbreviation for each state is used to plot the figure.

a. The variable is the average of the rates for the subperiods, $1900-20,1920-30, \ldots, 1970-80$, and 1980-87, weighted by the length of the subperiod. The rate for each subperiod is the annual average of net migration, divided by state population at the start of the subperiod.

the subperiod.$^{30}$ Hence, the dependent variable approximates the contribution of net migration to the state's rate of population growth over the subperiod.

The equations include period-specific coefficients for $\log \left(y_{i, t-T}\right)$ and $\log \left(\right.$ Heat $\left._{i}\right)$, but single coefficients for the two population-density variables, $\pi_{i, t-T}$ (thousands of persons per square mile of total area) and $\left(\pi_{i, t-T}\right)^{2}$. The regressions also include period-specific coefficients for the regional dummies, the agriculture share in personal income, Agry $_{i, t-T}$, and (for subperiods that start in 1930 or later) the structure variable, $S_{i t}$. These variables are the ones used in the last equation of table 1. (The estimated coefficients of these other variables-not shown in table 2are sometimes statistically significant but play a relatively minor role

30. The data on migration are from Bureau of the Census (1975). Recent figures are computed from data on population, births, and deaths from Bureau of the Census (1990). 
Table 2. Regressions for Net Migration into U.S. States, 1900-87

\begin{tabular}{lccccc}
\hline & $\begin{array}{c}\text { Personal } \\
\text { income }^{\mathrm{a}}\end{array}$ & $\begin{array}{c}\text { Heating- } \\
\text { degree } \\
\text { days }^{\mathrm{a}}\end{array}$ & $\begin{array}{c}\text { Population } \\
\text { density }^{\mathrm{b}}\end{array}$ & $\begin{array}{c}\text { Square of } \\
\text { population } \\
\text { density }^{\mathrm{b}}\end{array}$ & $R^{2}[\hat{\boldsymbol{\sigma}}]$ \\
\hline $1900-20$ & 0.0335 & -0.0066 & -0.0452 & 0.0340 & 0.70 \\
& $(0.0075)$ & $(0.0037)$ & $(0.0077)$ & $(0.0092)$ & {$[0.0112]$} \\
$1920-30$ & 0.0363 & -0.0124 & -0.0452 & 0.0340 & 0.61 \\
& $(0.0078)$ & $(0.0027)$ & $(0.0077)$ & $(0.0092)$ & {$[0.0079]$} \\
$1930-40$ & 0.0191 & -0.0048 & -0.0452 & 0.0340 & 0.71 \\
& $(0.0037)$ & $(0.0014)$ & $(0.0077)$ & $(0.0092)$ & {$[0.0042]$} \\
$1940-50$ & 0.0262 & -0.0135 & -0.0452 & 0.0340 & 0.83 \\
& $(0.0056)$ & $(0.0022)$ & $(0.0077)$ & $(0.0092)$ & {$[0.0065]$} \\
$1950-60$ & 0.0439 & -0.0205 & -0.0452 & 0.0340 & 0.76 \\
& $(0.0085)$ & $(0.0031)$ & $(0.0077)$ & $(0.0092)$ & {$[0.0091]$} \\
$1960-70$ & 0.0436 & -0.0056 & -0.0452 & 0.0340 & 0.70 \\
& $(0.0082)$ & $(0.0025)$ & $(0.0077)$ & $(0.0092)$ & {$[0.0069]$} \\
$1970-80$ & 0.0240 & -0.0076 & -0.0452 & 0.0340 & 0.73 \\
& $(0.0091)$ & $(0.0024)$ & $(0.0077)$ & $(0.0092)$ & {$[0.0071]$} \\
$1980-87$ & 0.0177 & -0.0075 & -0.0452 & 0.0340 & 0.73 \\
& $(0.0057)$ & $(0.0018)$ & $(0.0077)$ & $(0.0092)$ & {$[0.0049]$} \\
Eight periods combined & 0.0261 & $\ldots$ & -0.0447 & 0.0329 & $\ldots$ \\
& $(0.0023)$ & & $(0.0078)$ & $(0.0093)$ & \\
\hline
\end{tabular}

Sources: Authors' own calculations using Bureau of Economic Analysis (1984), Easterlin (1960a, 1960b), Bureau of the Census (1990), and Survey of Current Business, various issues. All regressions are for the continental states. The regressions use iterative, weighted least squares to estimate equations of the form:

$$
m_{i t}=a+b \log \left(y_{i, t-T}\right)+c_{1} \log \left(\text { Heat }_{i}\right)+c_{2} \pi_{i, t-T}+c_{3}\left(\pi_{i, t}-T\right)^{2}+\text { other variables, }
$$

where $m_{i t}$ is the average annual net migration into state $i$ between years $t-T$ and $t$, expressed as a ratio to the state's population in year $t-T ; y_{i, t-T}$ is real per capita personal income at the beginning of the subperiod as described in table $1 ;$ Heat $_{i}$ is the average number of heating-degree days for state $i$, formed as an average for available cities in the state; $\pi_{i, t-T}$ is the population density (thousands of people per square mile of area) of state $i$ at the beginning of the subperiod; and the other variables are the regional dummies, the share of agriculture in personal income, and the sectoral composition variable. Standard errors are in parentheses. The standard errors of the regression are in brackets.

a. The logarithms of initial personal income, $y_{i, t-T}$, and the number of heating-degree days, Heat ${ }_{i}$, are used in the regression.

b. The coefficients on the population-density variables, $c_{2}$ and $c_{3}$ in the above equation, are constrained to be the same for all subperiods.

c. The combined regression restricts the value of $b$ to be the same across all eight subperiods. This regression includes separate coefficients for $\log \left(\right.$ Heat $\left._{i}\right)$ for each subperiod. The likelihood ratio statistic for equal $b$ 's is 17.0 and the $p$-value is 0.017 . The $0.05 \chi^{2}$ value with seven degrees of freedom is 14.1 .

overall.) The hypothesis that the coefficient for the population-density variables is stable over time is accepted at the 5 percent level, and the other results change little if period-specific coefficients on these variables are introduced. The hypothesis of stability over the subperiods in the coefficients of $\log \left(\right.$ Heat $\left._{i}\right)$ is rejected at the 5 percent level, although the estimated coefficients, $\hat{b}$, on $\log \left(y_{i, t-T}\right)$ change little if only a single coefficient is estimated for the heat variable. 
The estimated coefficients of $\log \left(\right.$ Heat $\left._{i}\right)$ in table 2 are all negative and most are significantly different from zero. These results indicate that, all else being equal, people prefer warmer states. For population density, $\pi_{i, t-T}$, the jointly estimated linear term is significantly negative, -0.0452 , and the square term is significantly positive, 0.0340 . These point estimates imply that, all else being equal, the marginal effect of population density on in-migration is negative except for a few observations with the highest densities (New Jersey and Rhode Island since 1960 and Massachusetts since 1970). Since the implied marginal effect of population density for these outliers is small and since we are fitting a quadratic approximation, the true effect of population density could be negative throughout.

Although figures 7 and 8 show that the long-term relation between migration rates and initial income is positive but not very strong, the regression results, which are conditioned on the values of $\log \left(y_{i, t-T}\right)$ and $\pi_{i, t-T}$ at the beginning of each subperiod, are considerably clearer. The estimated coefficient, $\hat{b}$, on $\log \left(y_{i, t-T}\right)$ is significantly positive for every subperiod shown in table 2 . The joint estimate, $\hat{b}$, for the eight subperiods is 0.0261 (s.e. $=0.0023$ ), which implies a $t$-value over 11 . Thus, the regressions provide strong statistical evidence that, all else being equal, higher per capita income leads to a greater rate of net in-migration. The estimates in table 2 do, however, reject at the 5 percent level the hypothesis of stability in the $b$ coefficients across the subperiods $(p$-value $=0.02)$.

Recall that we do not use individual state deflators for personal income. We can, however, interpret the population-density variable as a proxy for housing costs; the differences in these costs are a major source of variation in the cost of living across states. Thus, the estimated coefficients of per capita personal income in table 2 likely represent effects for given costs of housing. It turns out, however, that the jointly estimated coefficient of $\log \left(y_{i, t-T}\right)$ is significantly positive (with a $t$-value of 9), even if the only other regressors in the equations are period-specific constant terms. Thus, the results suggest that the measured differences in nominal per capita personal income across states reflect variations in real per capita income.

Although the relation between the rate of in-migration and lagged per capita income is positive and highly significant (holding fixed our measure of amenities, population density, and some other variables), the magni- 
tude of the relation is small. For example, the joint estimate for $b$ implies that, all else being equal, a 10 percent increase in a state's per capita personal income raises net in-migration only by enough to raise the state's rate of population growth by 0.26 percentage points a year. The slow adjustment through net migration means that unless there is a substantial response of a state's fertility or mortality, population densities do not adjust rapidly to differences in per capita income adjusted for amenities. Our previous results suggest that differences in per capita income tend themselves to be eliminated over time, but only at a rate of about 2 percent a year. Thus, disparities in per capita income also persist for a long time. Putting these results together, the implication is that net migration rates are highly persistent over time. The data accord with this conclusion. For example, the correlation of the average net migration rate from 1900 to 1940 with that from 1940 to 1987 is 0.70 . Figure 9 depicts the pattern of persistence.

\section{Migration and Convergence}

As discussed before, the migration of raw labor from poor to rich states speeds up the convergence of per capita income. That is, the estimated coefficients, $\hat{\beta}$, shown in table 1 , include the impact of migration. To quantify the effect of migration on the convergence coefficient, we can relate the estimated response of migration tolog $\left(y_{i, t-T}\right)$ $\hat{b}=0.026$ from table 2 -with the estimate, $\hat{\beta}=0.0210$, which comes from the last equation of table 1 when estimated for the eight subperiods used in table 2 . We have modified the neoclassical growth model to include endogenous migration as a source of linkage between population growth and the log of per capita income. (We neglect here any endogeneity of fertility or mortality.) The effect of migration on the rate of convergence depends in the model on the underlying parameters of preferences and technology and on the quantity of human capital that migrants possess. We use parameter values that are consistent with the estimated values of $\beta$ and $b$ and with information from other studies. ${ }^{31}$ If we assume, unrealistically, that migrants have zero human capital, then-depending on the specification of the underlying parameters-we calculate that $\beta$ without migration would have been between 0.014 and

31. See Barro and Sala-i-Martin (1990). 
Figure 9. Persistence of Migration Rates across U.S. States, 1900-87

Annual migration rate, $1940-87$ (percent)

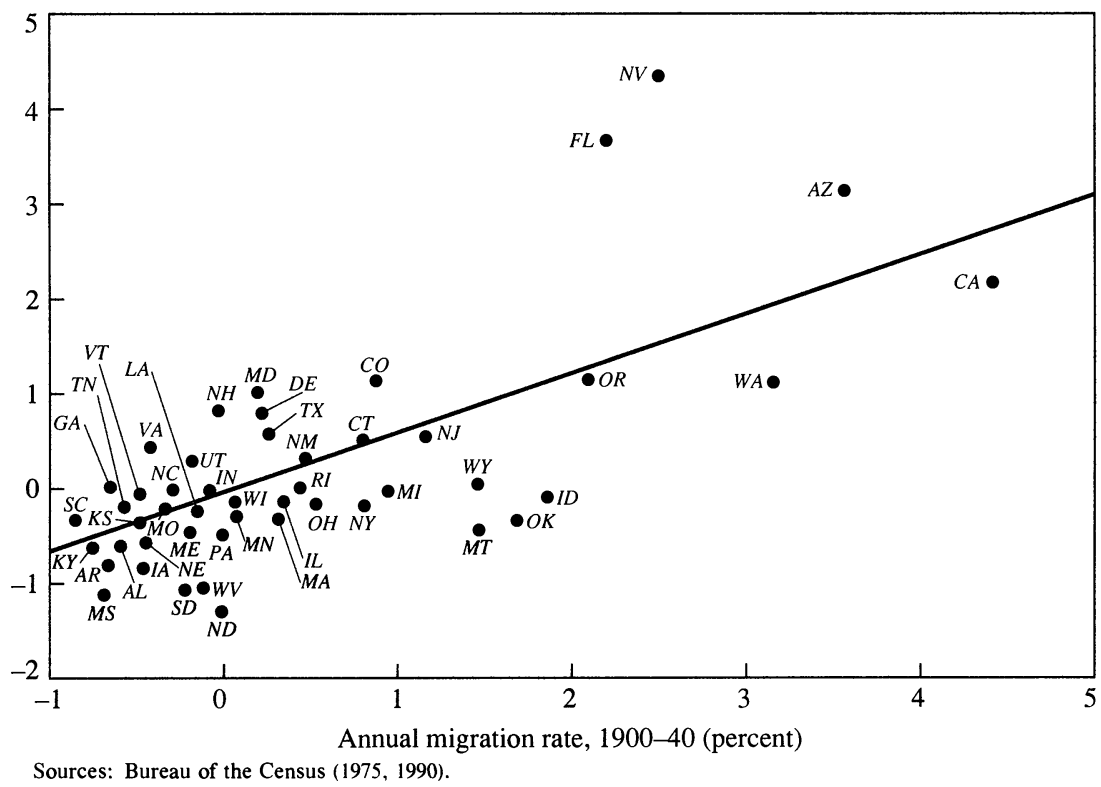

0.016 , instead of the estimated value, 0.0210 . Thus, migration can account for as much as a third of the estimated rate of convergence if we neglect the human capital of migrants. The role of migration is, however, considerably less if we allow for migrants' human capital. For example, if the typical migrant's human capital is half the total capital stock per person in the destination state, then the computed $\beta$ without migration is between 0.018 and 0.019 . Hence, if we allow for a reasonable amount of human capital, migration cannot explain much more than 10 percent of the estimated rate of convergence.

We now attempt to get a direct estimate of the effect of migration on convergence by entering migration rates into the growth-rate regressions. The expectation is that exogenous in-migration will have a negative effect on the per capita growth rate and that the addition of the migration rate as a regressor will lower the estimated $\beta$ coefficient. We first enter the contemporaneous migration rate, $m_{i t}$, into regressions of the type presented in the last equation of table 1 . We drop the first subperiod (1880-1900) and consider only the eight subperiods that begin in 1900. If we restrict the coefficient on $m_{i t}$ to be the same for the eight subperiods, 
the estimated coefficient on $m_{i t}$ is positive and significant: 0.098 (s.e. $=$ 0.029 ). The joint estimate of $\beta, 0.0250$ (s.e. $=0.0027$ ), is actually somewhat higher than the value that arises when the migration rate is excluded from the regression. Thus, contrary to expectations, the estimated $\beta$ convergence does not diminish if we hold net migration rates constant. If we allow for separate coefficients on $m_{i t}$ for each subperiod, all eight point estimates are positive, and the hypothesis of coefficient stability over the subperiods is accepted at the 5 percent level. In any event, the resulting joint estimate of $\beta, 0.0256$ (s.e. $=0.0027$ ), is about the same as that with a single coefficient for $m_{i t}$.

A state's per capita growth rate and net migration rate are simultaneously determined. Suppose, for example, that a state is known to have favorable prospects for growth, but that these prospects are not adequately captured by the explanatory variables that we have included in the regressions for growth and migration. Then the residuals in each equation would tend to be positive; the positive residual in the migration equation reflects the response of migrants to the favorable growth opportunities that are not controlled for by the included regressors. It seems likely that the positive estimated coefficients for $m_{i t}$ in the growthrate regressions reflect this type of interaction.

We have also estimated by an instrumental variables procedure the growth-rate equations that include $m_{i t}$ as an explanatory variable. Aside from the predetermined variables that enter into the growth-rate equations in table 1 , we include as instruments the additional variables that influence the net migration rate in table $2: \log \left(\right.$ Heat $\left._{i}\right), \pi_{i, t-T}$, and $\left(\pi_{i, t-T}\right)^{2} .{ }^{32}$ If the coefficients on $m_{i t}$ in the growth-rate equations are restricted to be the same over the eight subperiods, the estimated coefficient of $m_{i t}$ is 0.010 (s.e. $=0.047$ ), which differs insignificantly from zero. The joint estimate of $\beta, 0.0214$ (s.e. $=0.0030$ ), is close to the value found when the migration rate is omitted from the regression. The findings are basically the same if we allow for separate coefficients on $m_{i t}$ for each subperiod. In particular, the joint estimate of $\beta$ is 0.0209 (s.e. $=0.0032$ ). These results suggest that exogenous shifts in net migration rates do not have a strong contemporaneous interaction with per capita growth: if we hold net migration rates constant, we estimate about the same rate of $\beta$ convergence as we did before.

32. The assumption here is that the instrumental variables, $\log \left(\right.$ Heat $\left._{i}\right)$ and $\pi_{i, t-T}$, do not directly influence per capita growth. 
The empirical conclusion-that migration plays a small part in $\beta$ convergence-should be compared with the values of $\beta$ that we expect to find when we hold migration rates constant. Recall that removing the effects of migration gives an estimate of $\beta$ between 0.014 and 0.016 if migrants have zero human capital and between 0.018 and 0.019 if human capital per migrant is half the total capital stock per person in the destination state. The differences between the estimated coefficient, 0.0209 , and the predicted coefficients are small and statistically insignificant for the values that allow for human capital. Thus, the results are consistent with the modified neoclassical growth model that includes endogenous migration.

To summarize the main points on migration, we find that, all else being equal, per capita income has a highly significant positive effect on net migration rates into a state. Thus, we verify the predicted response of net migration to economic opportunity. We find, however, little contemporaneous interplay between net migration and economic growth. Specifically, we observe little change in the estimated $\beta$ coefficients when we hold net migration rates constant. These results are consistent with a modified neoclassical growth model that allows for endogenous migration; in particular, given the estimated response of migration to per capita income, the modified model predicts that migration would explain only a small part of $\beta$ convergence.

\section{Gross State Product}

Data on gross state product (GSP) for 48 states are available from 1963 to $1986 .{ }^{33} \mathrm{GSP}$, analogous to gross domestic product, refers to the payments to the factors that produce goods within a state, whereas personal income pertains to the returns to the factor owners, who may reside in other states. The main distinction between GSP and personal income arises in the case of income from physical capital.

Table 3 shows regressions for per capita GSP for four subperiods: 1963-69, 1969-75, 1975-81, and 1981-86. Real GSP in this table is the nominal aggregate for the state divided by the national deflator for GSP. ${ }^{34}$

33. The data are from Renshaw, Trott, and Friedenberg (1988). See Barro and Sala-iMartin (1990) for a discussion.

34. Individual-state deflators are unavailable. Since we use a common deflator at each point in time, the particular deflator that we use affects only the constant term in the regressions. 
Table 3. Regressions for Gross State Product across U.S. States, 1963-86

\begin{tabular}{|c|c|c|c|c|c|c|}
\hline \multirow[b]{2}{*}{ Period } & \multicolumn{2}{|c|}{ Basic equation } & \multicolumn{2}{|c|}{$\begin{array}{l}\text { Equation with } \\
\text { regional dummies }\end{array}$} & \multicolumn{2}{|c|}{$\begin{array}{l}\text { Equation with } \\
\text { regional dummies } \\
\text { and sectoral } \\
\text { variables }\end{array}$} \\
\hline & $\hat{\beta}$ & $R^{2}[\hat{\sigma}]$ & $\hat{\beta}$ & $R^{2}[\hat{\boldsymbol{\sigma}}]$ & $\hat{\beta}$ & $R^{2}[\hat{\sigma}]$ \\
\hline $1963-69$ & $\begin{array}{c}0.0317 \\
(0.0067)\end{array}$ & $\begin{array}{l}0.36 \\
{[0.0070]}\end{array}$ & $\begin{array}{c}0.154 \\
(0.0060)\end{array}$ & $\begin{array}{l}0.63 \\
{[0.0056]}\end{array}$ & $\begin{array}{c}0.0157 \\
(0.0060)\end{array}$ & $\begin{array}{l}0.63 \\
{[0.0056]}\end{array}$ \\
\hline $1969-75$ & $\begin{array}{c}0.0438 \\
(0.0166)\end{array}$ & $\begin{array}{l}0.16 \\
{[0.0138]}\end{array}$ & $\begin{array}{c}0.0406 \\
(0.0162)\end{array}$ & $\begin{array}{l}0.41 \\
{[0.0120]}\end{array}$ & $\begin{array}{c}0.0297 \\
(0.0101)\end{array}$ & $\begin{array}{l}0.74 \\
{[0.0081]}\end{array}$ \\
\hline $1975-81$ & $\begin{array}{r}-0.0159 \\
(0.0133)\end{array}$ & $\begin{array}{l}0.03 \\
{[0.0145]}\end{array}$ & $\begin{array}{c}-0.0285 \\
(0.0134)\end{array}$ & $\begin{array}{l}0.17 \\
{[0.0139]}\end{array}$ & $\begin{array}{c}0.0258 \\
(0.0108)\end{array}$ & $\begin{array}{l}0.78 \\
{[0.0072]}\end{array}$ \\
\hline $1981-86$ & $\begin{array}{c}0.1188 \\
(0.0294)\end{array}$ & $\begin{array}{l}0.39 \\
{[0.0205]}\end{array}$ & $\begin{array}{r}0.1130 \\
(0.0251)\end{array}$ & $\begin{array}{l}0.62 \\
{[0.0168]}\end{array}$ & $\begin{array}{c}0.0238 \\
(0.0091)\end{array}$ & $\begin{array}{l}0.92 \\
{[0.0079]}\end{array}$ \\
\hline Four periods combined & & & & & & \\
\hline$\beta$ restricted & $\begin{array}{c}0.0335 \\
(0.0057)\end{array}$ & $\cdots$ & $\begin{array}{c}0.0211 \\
(0.0053)\end{array}$ & $\ldots$ & $\begin{array}{c}0.0216 \\
(0.0042)\end{array}$ & $\cdots$ \\
\hline $\begin{array}{l}\text { Likelihood-ratio statistic }{ }^{b} \\
P \text {-value }\end{array}$ & $\begin{array}{l}75.6 \\
0.000\end{array}$ & $\ldots$ & $\begin{array}{l}31.2 \\
0.000\end{array}$ & $\ldots$ & $\begin{array}{l}1.7 \\
0.637\end{array}$ & $\ldots$ \\
\hline
\end{tabular}

Sources: Authors' own calculations using Renshaw, Trott, and Friedenberg (1988). All regressions are for the continental states. The regressions use nonlinear least squares to estimate equations of the form:

$$
(1 / T) \log \left(y_{i t} / y_{i, t-T}\right)=a-\left[\log \left(y_{i, t-T}\right)\right]\left(1-e^{-\beta T}\right)(1 / T)+\text { other variables, }
$$

where $y_{i, t-T}$ is per capita gross state product (GSP), divided by the national deflator for GSP, in state $i$ at the beginning of the subperiod; $y_{i t}$ is the real GSP at time $t ; T$ is the length of the interval; and the other variables are regional dummies and the structural composition variable described in the text. Standard errors are in parentheses. The standard errors of the regression are in brackets.

a. The combined regression restricts the value of $\beta$ to be the same across all four subperiods. The restricted $\beta$ are estimated using iterative, weighted, nonlinear least squares.

b. The likelihood ratio test is based on the null hypothesis that the $\beta$ are the same across subsamples. It follows a chi-squared $\left(\chi^{2}\right)$ distribution; the $0.05 \chi^{2}$ value with three degrees of freedom is 7.8 .

These figures reflect the current returns to factors of production and are therefore relevant for decisions on investment, migration, and so on. However, the measured growth rates pick up a combination of changes in quantities produced and changes in relative prices across sectors. The effects of the relative-price changes, which interact with the composition of production within a state, can be viewed as part of the error term, $u_{i t}$ in equation 1, that is filtered out by the structural-composition variable, $S_{i t}$. For GSP, the variable $S_{i t}$ is based on a division of production into 54 sectors. Thus, the breakdown is much finer than the nine-sector construct used for personal income in table 1.

Overall, the results on $\beta$ convergence for GSP are similar to those for personal income from table 1 . If we exclude the structure variable and include only lagged GSP (the first equation of table 3 ) or if we add regional dummies (the second equation), then the estimated $\beta$ 's are unstable. The estimates are far more stable when we add the explanatory variable $S_{i t}$ in the last equation. The joint estimate of $\beta$ for the four 
Figure 10. Convergence of Gross State Product across U.S. States: 1963 GSP and GSP Growth from 1963 to 1986

Annual growth rate, $1963-86$ (percent)

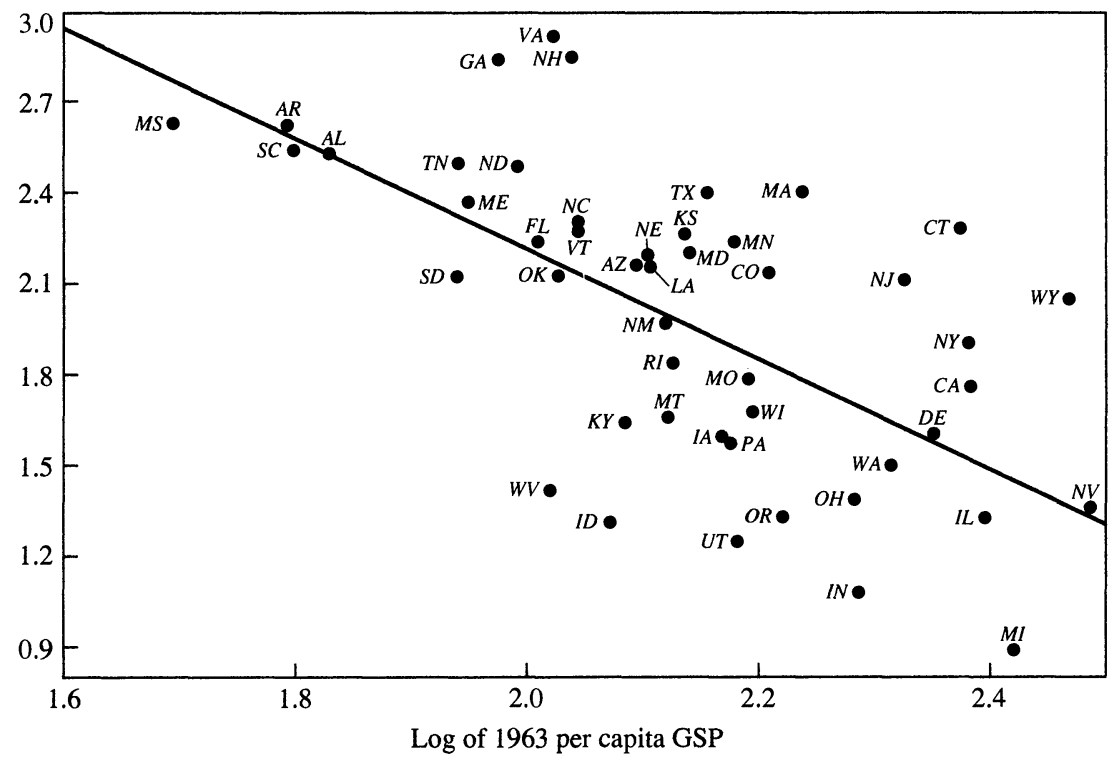

Sources: Renshaw, Trott, and Friedenberg (1988). The postal abbreviation for each state is used to plot the figure. Alaska and Hawaii are excluded from the analysis.

subperiods is 0.0216 , and the hypothesis of stability in the $\beta$ coefficients over the four subperiods is accepted at the 5 percent level.

Figure 10 shows a plot of the average growth rate of per capita GSP from 1963 to 1986 against the log of per capita GSP in 1963. The downward-sloping relation is clear, although the fit is not as good as that for the longer-period relation for personal income shown in figure 1 . The main difference relates to the sample period and not to the distinction between GSP and personal income.

Table 4, which extends an analysis by Sala-i-Martin, breaks down the results by sector for the period $1963-86 .{ }^{35}$ We look at GSP per worker originating in eight standard nonagricultural sectors: mining; construction; manufacturing; transportation; wholesale and retail trade; finance, insurance, real estate (FIRE); services; and government. ${ }^{36}$ We have

35. Sala-i-Martin (1990, chap. 3).

36. The data on employment by sector are from the Bureau of Labor Statistics (various years). 
Table 4. Regressions for Sectors of Gross State Product, 1963-86

\begin{tabular}{|c|c|c|c|c|c|}
\hline \multirow[b]{2}{*}{ Sector } & \multicolumn{2}{|c|}{ Sector share ${ }^{\mathrm{a}}$} & \multirow[b]{2}{*}{$\hat{\beta}$} & \multirow[b]{2}{*}{$R^{2}$} & \multirow{2}{*}{$\begin{array}{l}\text { Standard } \\
\text { error }^{\mathrm{b}}\end{array}$} \\
\hline & 1963 & 1986 & & & \\
\hline Mining & 0.023 & 0.022 & $\begin{array}{c}0.0240 \\
(0.0074)\end{array}$ & 0.49 & 0.0134 \\
\hline Construction & 0.048 & 0.047 & $\begin{array}{c}0.0169 \\
(0.0203)\end{array}$ & 0.20 & 0.0110 \\
\hline Manufacturing & 0.284 & 0.199 & $\begin{array}{c}0.0460 \\
(0.0082)\end{array}$ & 0.73 & 0.0041 \\
\hline Transportation & 0.092 & 0.094 & $\begin{array}{c}0.0257 \\
(0.0176)\end{array}$ & 0.15 & 0.0045 \\
\hline $\begin{array}{l}\text { Wholesale and retail } \\
\text { trade }\end{array}$ & 0.164 & 0.169 & $\begin{array}{c}0.0093 \\
(0.0064)\end{array}$ & 0.24 & 0.0030 \\
\hline $\begin{array}{l}\text { Finance, insurance, } \\
\text { and real estate }\end{array}$ & 0.145 & 0.167 & $\begin{array}{c}0.0150 \\
(0.0062)\end{array}$ & 0.43 & 0.0046 \\
\hline Services & 0.105 & 0.166 & $\begin{array}{c}0.0149 \\
(0.0077)\end{array}$ & 0.27 & 0.0036 \\
\hline Government & 0.102 & 0.115 & $\begin{array}{c}0.0161 \\
(0.0039)\end{array}$ & 0.55 & 0.0032 \\
\hline Eight sectors combined ${ }^{c}$ & 0.963 & 0.978 & $\begin{array}{c}0.0213 \\
(0.0024)\end{array}$ & $\ldots$ & $\ldots$ \\
\hline
\end{tabular}

Sources: Authors' own calculations using Renshaw, Trott, and Friedenberg (1988) and Bureau of Labor Statistics (various years). Each sectoral regression has observations for the continental states, except mining, which only has 42 observations. The regressions use nonlinear least squares to estimate equations of the form:

$$
(1 / T) \log \left(y_{i t} / y_{i, t-T}\right)=a-\left[\log \left(y_{i, t}-T\right)\right]\left(1-e^{-\beta T}\right)(1 / T)+\text { regional dummies, }
$$

where $y_{i t}$ is the ratio of the sector's contribution to state $i$ 's gross state product (GSP) to the employment in the sector for that state at time $t$, with $T$ equal to 23 years. The agricultural sector is omitted because of unreliable data on employment. Standard errors are in parentheses.

a. The share of the sector in aggregate GSP in 1963 and 1986 is shown.

b. The standard error of the regression is shown.

c. Iterative, weighted, nonlinear least squares is used to estimate the eight-sector joint regression with a single value for $\beta$. The likelihood-ratio statistic for equal $\beta$ is 22.4 , and the $p$-value is 0.002 . The $0.05 \chi^{2}$ value with seven degrees of freedom is 14.1

omitted the agricultural sector because data on agricultural employment are not comparable to those for the nonagricultural sectors. The first two columns of the table show the shares of each sector in U.S. aggregate GSP at the beginning and end of the period. The main patterns in the shares, which are well known, are the declines in manufacturing and agriculture (the latter is measured by the increase in the sum of the other eight sectors) and the increases in services and FIRE.

The third column of table 4 shows positive estimates of $\beta$ for each of the eight sectors, although not all of the estimates are statistically 
significant. (Each of these regressions includes a constant, the log of the sector's productivity in 1963, and the regional dummies.) Basically, the $\hat{\beta}$ values for the four service-type sectors-wholesale and retail trade, FIRE, services, and government-are similar and fall in a range from 0.009 to 0.016 . The $\hat{\beta}$ values are higher for the other four sectors, especially for manufacturing, where the estimate is 0.0460 . It is only this high and precisely estimated value for manufacturing that leads to rejection of the hypothesis that the $\beta$ coefficients are the same across the sectors. The joint estimate of $\beta$ for the eight sectors is 0.0213 , but we reject at the 5 percent level the hypothesis that the individual $\beta$ 's are the same. We would accept the hypothesis that the $\beta$ coefficients are the same for the seven sectors other than manufacturing-the estimate is $\hat{\beta}=0.0164$ (s.e. $=0.0024$ ) and the $p$-value for the test of equality for the coefficients is 0.77 .

The main inference that we draw from table 4 is that $\beta$ convergence applies within sectors in a manner that is broadly similar to that found in tables 1 and 3 for state aggregates of personal income and gross state product. Thus, an important part of the overall process of convergence across the states involves adjustments of productivity levels within sectors.

Figure 11 shows the dispersion of GSP across U.S. states, measured by the unweighted cross-sectional standard deviation, $\sigma_{t}$, for the log of per capita GSP from 1963 to 1986 . The decline of $\sigma_{t}$ from 0.18 in 1963 to a low point of 0.13 in 1972 accords with the behavior for personal income shown in figure 4 . We think that the rise in $\sigma_{t}$ to a peak of 0.18 in 1981 reflects the behavior of oil prices. Especially in the 1979-81 period, the oil shocks benefited those states that already had above-average per capita GSP, thereby leading to an increase in $\sigma_{t}$. After 1981, the decline in $\sigma_{t}$ reflects the normal pattern of $\sigma$ convergence, reinforced later by a fall in oil prices.

The different patterns from 1973 to 1986 in $\sigma_{t}$ based on GSP versus $\sigma_{t}$ based on personal income reflect, at least in part, differences in the relation between shares of product or income originating in oil-related industries and the levels of per capita product or income. The correlation of the log of per capita GSP with the share of GSP originating in crude oil and natural gas rises because of the oil shocks from 0.1 in 1973 to 0.4 in 1975 and 0.7 in 1981, and then falls with the decline in oil prices to 0.1 in 1986. In contrast, the correlation of the log of per capita personal income with the share of personal income originating in oil and natural gas is -0.3 in 1970 and 0.0 in 1980 . These divergent patterns reflect the 
Figure 11. Dispersion of Gross State Product across U.S. States, 1963-86

Dispersion $^{\mathrm{a}}$

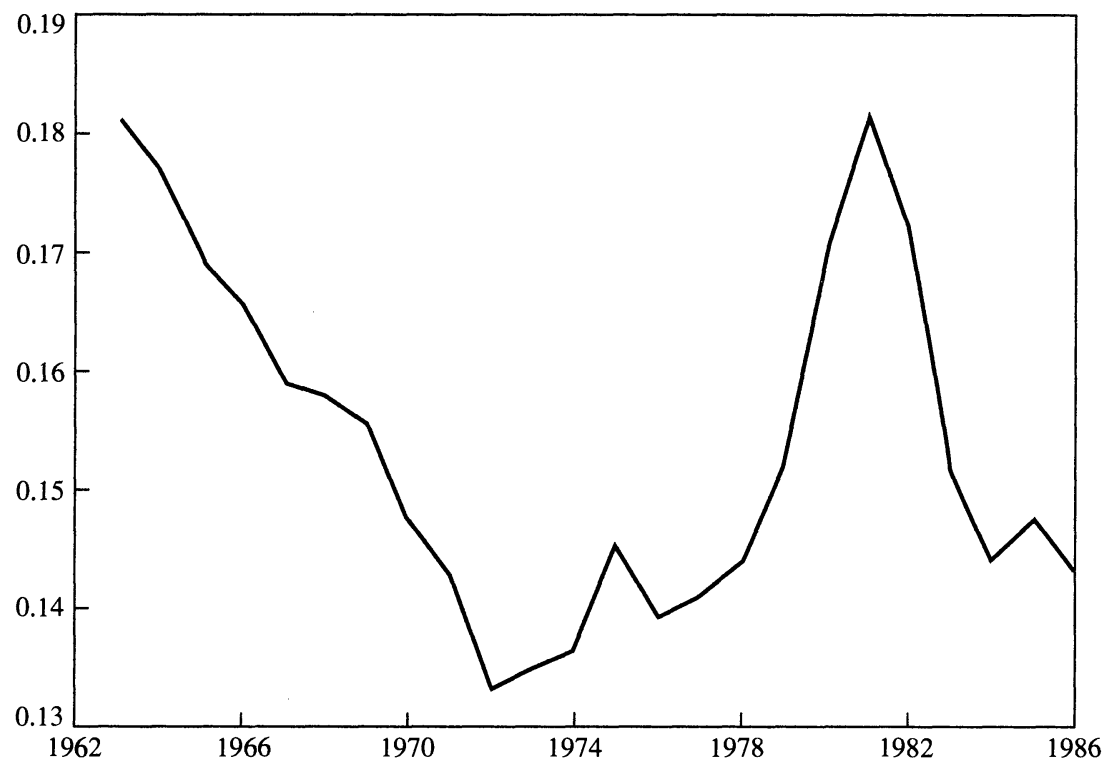

Sources: Authors' own calculations using Renshaw, Trott, and Friedenberg (1988). Alaska and Hawaii are excluded from the analysis.

a. Dispersion of GSP is measured by the unweighted cross-sectional standard deviation of the log of per capita GSP.

distinction between the location of oil and gas facilities and the ownership of these facilities.

From 1973 to 1981 the oil shocks have less of an effect on $\sigma_{t}$ for personal income than for GSP because the increases in oil prices do not particularly harm the states with already low levels of per capita personal income, but they do harm states with lower levels of GSP. Similarly, a possible reason why $\sigma_{t}$ for personal income does not decline later in the 1980 s is that, unlike for GSP, the declines in oil prices do not particularly benefit the states with low per capita incomes.

\section{Convergence across Regions of Europe}

We now apply the analysis to the behavior of gross domestic product (GDP) in the regions of seven European countries. We have data on GDP and a few other variables for 73 regions: 11 in Germany, 11 in the 
United Kingdom, 20 in Italy, 21 in France, 4 in the Netherlands, 3 in Belgium, and 3 in Denmark. ${ }^{37}$ Table 5 lists the regions.

Data for 1950, 1960, and 1970 are from Willem Molle. ${ }^{38}$ Data for 1966 (missing France and Denmark), 1970 (missing Denmark), 1974, 1980, and 1985 are from Eurostat. The nominal figures on GDP are expressed using current exchange rates in terms of a common currency unit. It is unnecessary to deflate the nominal values for the purposes of the crosssection equations that we consider: any common deflation affects only the constant terms in the regressions..$^{39}$ Aside from GDP and population, the data set includes a breakdown of employment into three sectorsagriculture, industry, and services-for 1950, 1960, and 1970, as well as a breakdown of GDP into the same three sectors for 1966 (missing France and Denmark), 1970, 1974, 1980, and 1985. (The sectoral data for Denmark are available only for 1974.)

Figure 12 shows the relation of the growth rate of per capita GDP from 1950 to 1985 to the log of per capita GDP in 1950 for the 73 European regions. (The numbers of the regions correspond to those in table 5. See figure 13 for a map of the regions.) The values are all measured relative to the means of the respective countries. The figure shows the type of negative relation that is familiar from the study of the U.S. states. The correlation between the growth rate and the log of initial per capita GDP in figure 12 is -0.70 .

Because the underlying numbers are expressed relative to owncountry means, the relation in figure 12 pertains to $\beta$ convergence within countries rather than between countries. For the seven countries that we are considering, the estimates of $\beta$ convergence between countries turn out to be similar to those within the countries. Previous research has considered $\beta$ and $\sigma$ convergence among larger groups of countries. ${ }^{40}$ Since the seven-country data set considered here provides much less information about behavior across countries, we shall focus our attention on the within-country results.

37. We lost one region for France because some of the data on Corse are combined with those for Provence-Alpes-Côte d'Azur.

38. Molle (1980). We appreciate Carol Heim's suggestion to look at these data.

39. Departures from purchasing-power parity across countries would not affect our main results, which filter out own-country effects. The growth rates for regions within countries involve the same kind of sensitivity to changes in relative prices that applied to GSP for the U.S. states.

40. See Baumol (1986), De Long (1988), Dowrick and Nguyen (1989), and Barro (1991). 
Table 5. Regions of Europe

\begin{tabular}{|c|c|}
\hline \multirow{2}{*}{\multicolumn{2}{|c|}{ Germany }} \\
\hline & \\
\hline \multicolumn{2}{|l|}{ 1. Schleswig-Holstein } \\
\hline 2. Hamburg & 41. Sicilia \\
\hline 3. Niedersachsen & 42. Sardegna \\
\hline 4. Bremen & France \\
\hline 5. Nordrhein-Westfalen & 43. Region Parisienne \\
\hline 6. Hessen & 44. Champagne-Ardenne \\
\hline 7. Rheinland-Pfalz & 45. Picarde \\
\hline 8. Saarland & 46. Haute Normandie \\
\hline 9. Baden-Württemberg & 47. Centre \\
\hline 10. Bayern & 48. Basse Normandie \\
\hline 11. Berlin (West) & 49. Bourgogne \\
\hline United Kingdom & 50. Nord-Pas-de-Calais \\
\hline 12. North & 51. Lorraine \\
\hline 13. Yorkshire-Humberside & 52. Alsace \\
\hline 14. East Midlands & 53. Franche-Comte \\
\hline 15. East Anglia & 54. Pays de la Loire \\
\hline 16. South-East & 55. Bretagne \\
\hline 17. South-West & 56. Poitou-Charentes \\
\hline 18. North-West & 57. Aquitaine \\
\hline 19. West Midlands & 58. Midi-Pyrénées \\
\hline 20. Wales & 59. Limousin \\
\hline 21. Scotland & 60. Rhône-Alpes \\
\hline 22. Northern Ireland & 61. Auvergne \\
\hline Italy & 62. Languedoc-Roussillon \\
\hline 23. Piemonte & 63. Provence, Alpes, Côte d'Azur, Corse \\
\hline 24. Valle d'Aosta & Netherlands \\
\hline 25. Liguria & 65. Noord \\
\hline 26. Lombardia & 66. Oost \\
\hline 27. Trentino-Alto Adige & 67. West \\
\hline 28. Veneto & 68. Zuid \\
\hline 29. Friuli-Venezia, Giulia & Belgium \\
\hline 30. Emilia-Romagna & 69. Vlaanderen \\
\hline 31. Marche & 70. Wallonie \\
\hline 32. Toscana & 71. Brabant \\
\hline 33. Umbria & Denmark \\
\hline 34. Lazio & \\
\hline 35. Campania & $\begin{array}{l}\text { 73. Fyaelland-Lolland-Falster-Bornnoim } \\
\text { 73. Fyn }\end{array}$ \\
\hline 36. Abruzzi & 74. Jylland \\
\hline 37. Molise & \\
\hline 38. Puglia & \\
\hline 39. Basilicata & \\
\hline
\end{tabular}

Sources: Molle (1980) and Eurostat (various years). Because GDP data from Eurostat for Corse were combined with those for Provence, Alpes, and Côte d'Azur, region 64 has been eliminated leaving a total of 73 regions. 
Figure 12. Convergence of Gross Domestic Product across European Regions: 1950 GDP and GDP Growth from 1950 to 1985

Relative growth rate, $1950-85$ (percent) $^{\mathrm{a}}$

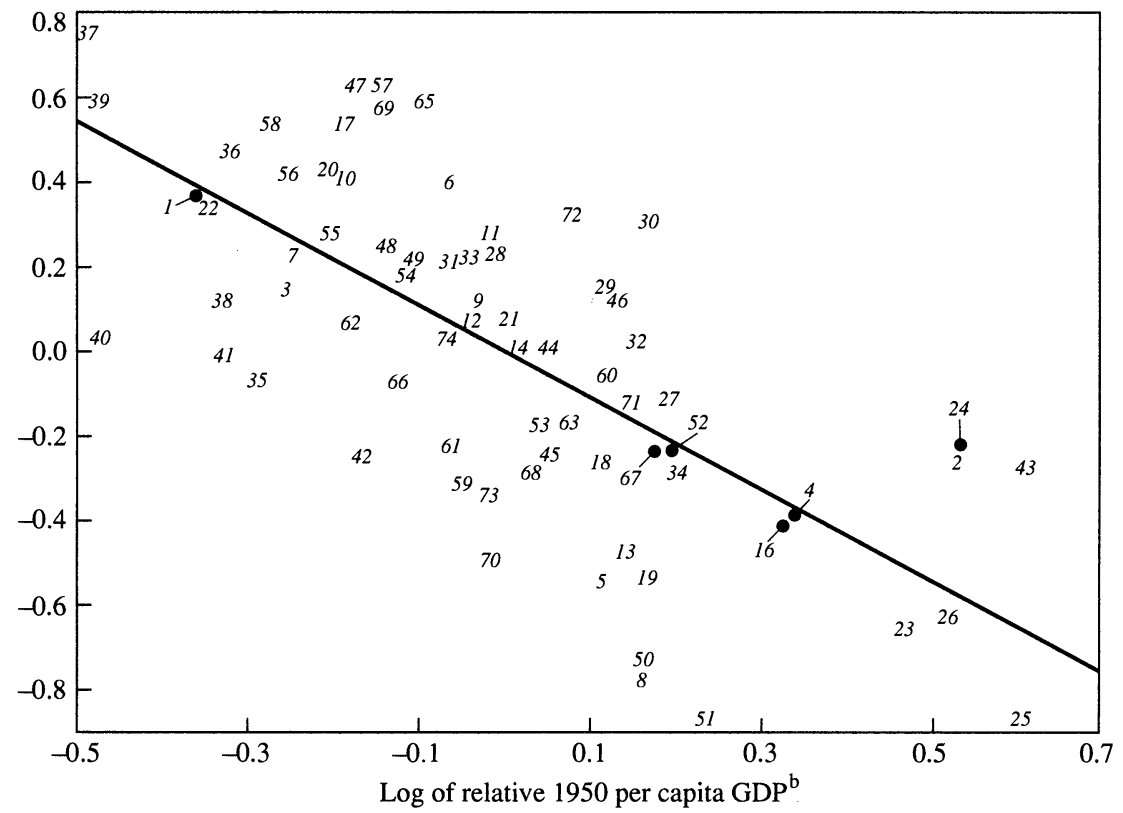

Source: Molle (1980) and Eurostat (various years). Current exchange rates were used to convert nominal GDP figures to a common currency. The numbers in the figure correspond to the regional numbers in table 5 and figure 13.

a. Growth is measured by the deviation of the average per capita growth rate of GDP for each region from 1950 to 1985 from the average growth rate for the country over the same period.

b. The log of initial regional income is measured relative to the respective country mean.

\section{Analysis of $\beta$ Convergence}

Table 6 shows regressions for the European regions over four subperiods: $1950-60,1960-70,1970-80$, and 1980-85. The form of the analysis parallels that for the U.S. states in tables 1 and 3 . The regressions in the first equation of table 6 include only a constant and $\log \left(y_{i, t-T}\right)$ as independent variables. The estimated coefficients, $\hat{\beta}$, are positive but unstable across the periods. The pattern of results over the subperiods is similar to that found for the U.S. states, and the joint estimate is slightly smaller than that found for the United States. The hypothesis of a constant $\beta$ coefficient is again rejected at the 5 percent level.

The second equation of table 6 adds country dummies, which have enormous explanatory power for the growth rates of European regions. We think of the country dummies, which are analogous to the regional 
Figure 13. Regions of Europe

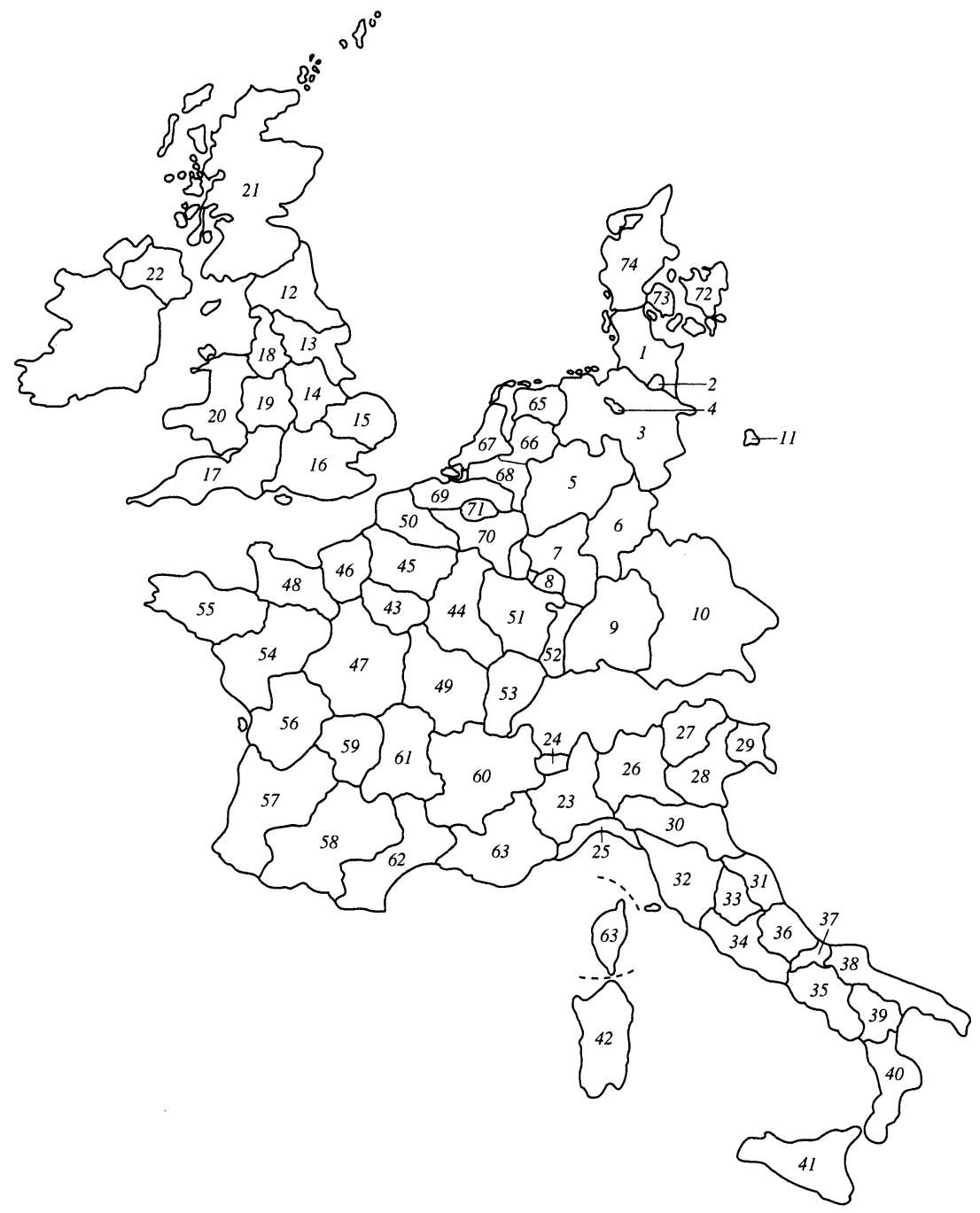

Source: Map is adapted from Molle (1980, p. 20). See table 5 for names of regions.

dummies that we used for the United States, as proxies for the steadystate values, $x_{i}^{*}$ and $\hat{y}_{i}^{*}$, and for countrywide fixed effects in the error term, $u_{i t}$. The addition of the country dummies makes the estimates of $\beta$ in equation 1 markedly more stable across the subperiods, but the joint estimate is very close to that shown in the first column. (This joint 
Table 6. Regressions for Gross Domestic Product across European Regions, 1950-85

\begin{tabular}{|c|c|c|c|c|c|c|}
\hline \multirow[b]{2}{*}{ Period } & \multicolumn{2}{|c|}{ Basic equation } & \multicolumn{2}{|c|}{$\begin{array}{l}\text { Equation with } \\
\text { country dummies }\end{array}$} & \multicolumn{2}{|c|}{$\begin{array}{l}\text { Equation with } \\
\text { country dummies } \\
\text { and structural } \\
\text { variables }^{\mathrm{a}}\end{array}$} \\
\hline & $\hat{\beta}$ & $R^{2}[\hat{\sigma}]$ & $\hat{\beta}$ & $R^{2}[\hat{\sigma}]$ & $\hat{\beta}$ & $R^{2}[\hat{\sigma}]$ \\
\hline $1950-60$ & $\begin{array}{c}0.0106 \\
(0.0051)\end{array}$ & $\begin{array}{l}0.06 \\
{[0.0155]}\end{array}$ & $\begin{array}{c}0.0105 \\
(0.0038)\end{array}$ & $\begin{array}{l}0.78 \\
{[0.0077]}\end{array}$ & $\begin{array}{c}0.0206 \\
(0.0078)\end{array}$ & $\begin{array}{l}0.80 \\
{[0.0076]}\end{array}$ \\
\hline $1960-70^{b}$ & $\begin{array}{c}0.0367 \\
(0.0066)\end{array}$ & $\begin{array}{l}0.39 \\
{[0.0149]}\end{array}$ & $\begin{array}{c}0.0279 \\
(0.0036)\end{array}$ & $\begin{array}{l}0.92 \\
{[0.0057]}\end{array}$ & $\begin{array}{c}0.0241 \\
(0.0062)\end{array}$ & $\begin{array}{l}0.92 \\
{[0.0058]}\end{array}$ \\
\hline $1970-80^{b}$ & $\begin{array}{c}0.0035 \\
(0.0035)\end{array}$ & $\begin{array}{l}0.01 \\
{[0.0098]}\end{array}$ & $\begin{array}{c}0.0184 \\
(0.0049)\end{array}$ & $\begin{array}{l}0.43 \\
{[0.0078]}\end{array}$ & $\begin{array}{c}0.0139 \\
(0.0082)\end{array}$ & $\begin{array}{l}0.44 \\
{[0.0078]}\end{array}$ \\
\hline $1980-85$ & $\begin{array}{c}0.0953 \\
(0.0122)\end{array}$ & $\begin{array}{l}0.60 \\
{[0.0212]}\end{array}$ & $\begin{array}{c}0.0116 \\
(0.0048)\end{array}$ & $\begin{array}{l}0.95 \\
{[0.0077]}\end{array}$ & $\begin{array}{c}0.0111 \\
(0.0060)\end{array}$ & $\begin{array}{l}0.96 \\
{[0.0070]}\end{array}$ \\
\hline $\begin{array}{l}\text { Four periods combined } \\
\quad \beta \text { restricted }\end{array}$ & $\begin{array}{c}0.0183 \\
(0.0029)\end{array}$ & $\cdots$ & $\begin{array}{c}0.0186 \\
(0.0021)\end{array}$ & $\cdots$ & $\begin{array}{c}0.0178 \\
(0.0034)\end{array}$ & $\cdots$ \\
\hline $\begin{array}{l}\text { Likelihood ratio statistic }{ }^{d} \\
P \text {-value }\end{array}$ & $\begin{array}{l}70.9 \\
0.000\end{array}$ & $\ldots$ & $\begin{array}{l}13.3 \\
0.004\end{array}$ & $\ldots$ & $\begin{array}{l}2.6 \\
0.457\end{array}$ & $\ldots$ \\
\hline
\end{tabular}

Sources: Data up through 1970 are from Molle (1980). Data for and after 1970 are from Eurostat (various years). Each regression has observations for the 73 European regions listed in table 5 . The regressions use nonlinear least squares to estimate equations of the form:

$$
(1 / T) \log \left(y_{i t} / y_{i, t-T}\right)=a-\left[\log \left(y_{i, t-T}\right)\right]\left(1-e^{-\beta T}\right)(1 / T)+\text { other variables, }
$$

where $y_{i, t-T}$ is per capita gross domestic product (GDP) in region $i$ at the beginning of the subperiod; $y_{i t}$ is per capita GDP at time $t ; T$ is the length of the interval; and the other variables are country dummies and the shares of agriculture and industry in employment or GDP at the start of the time period (see note a). Standard errors are in parentheses. The standard errors of the regression are in brackets.

a. The additional variables in this column are the shares of agriculture and industry in employment at the start of the subperiod, based on a three-way division of employment into agriculture, industry, and services, for the subperiods $1950-60,1960-70$, and 1970-80. The regression for the subperiod $1980-85$ includes the shares of agriculture and industry in GDP in 1980.

b. We have two alternative sources of GDP for 1970, Molle (1980) and Eurostat (various editions); they do not coincide. We computed the figures for the 1960-70 subperiod from Molle and those for 1970-80 from Eurostat. Since the correlation between the two measures of the levels of per capita GDP in 1970 is 0.988 , this discrepancy should not be important.

c. The combined regression restricts the value of $\beta$ to be the same across all four subperiods. The restricted $\beta$ are estimated using iterative, weighted, nonlinear least squares.

d. The likelihood-ratio test is based on the null hypothesis that the $\beta$ are the same across all subperiods. It follows a chi-squared $\left(\chi^{2}\right)$ distribution. The $0.05 \chi^{2}$ value with three degrees of freedom is 7.8 .

estimation includes period-specific country dummies.) The results in the second equation still reject at the 5 percent level the hypothesis of equal $\beta$ coefficients across the subperiods.

The results with country dummies show within-country $\beta$ convergence and are analogous to that shown in figure 12. In contrast, the results from the first equation show a combination of within- and between-country $\beta$ convergence. The joint estimates of $\beta$ in the two sets of columns are similar because the rates of within- and between-country $\beta$ convergence are nearly the same in this seven-country sample. We 
can also estimate $\beta$ by using only the data on country aggregates (as we did for the U.S. regions). Over the same time period, the jointly estimated $\beta$ coefficient is 0.0183 (s.e. $=0.0029$ ), virtually the same as the value shown in the second equation. Note that the first value, for country aggregates, is an estimate of $\beta$ convergence between countries, whereas the second, with regional dummies, is an estimate within countries.

The last equation of table 6 adds the shares of agriculture and industry in total employment at the start of the subperiod for the 1950-60, 196070 , and 1970-80 subperiods. The regression for the 1980-85 subperiod adds the shares in overall GDP at the start of the period. These share variables are analogous to the agricultural share and structural composition variables that we used for the United States. In effect, the share variables for the European regions are as close as we can come with our present data to the structural variable, $S_{i t}$.

The main new result from adding these variables is the acceptance of the hypothesis of stability in the $\beta$ coefficients at the 5 percent level. (These results allow for period-specific coefficients on the share variables and the country dummies.) The joint estimate, $\hat{\beta}=0.0178$, does not change much from that shown in the second equation. This point estimate-showing $\beta$ convergence at slightly below 2 percent a year-is somewhat less than the corresponding value, 0.0216 , found for the U.S. states in table 3.

We have also estimated the joint system with individual $\beta$ coefficients for the seven countries. This system corresponds to the four-period regression shown in the last equation of table 6 except that the coefficient $\beta$ is allowed to vary over the countries (but not over the subperiods). Thus, the system contains period-specific country dummies and the agricultural and industrial share variables (with coefficients that vary over the subperiods but not across the countries). The resulting estimates for $\beta$ follow.

\begin{tabular}{lc}
\multicolumn{1}{c}{ Country } & $\begin{array}{c}\text { Estimate } \\
\text { (standard error) }\end{array}$ \\
Germany (11 regions) & $0.0230(0.0061)$ \\
United Kingdom (11 regions) & $0.0337(0.0093)$ \\
Italy (20 regions) & $0.0118(0.0036)$ \\
France (21 regions) & $0.0097(0.0059)$ \\
Netherlands (4 regions) & $0.0496(0.0202)$ \\
Belgium (3 regions) & $0.0237(0.0164)$ \\
Denmark (3 regions) & $0.0018(0.0211)$
\end{tabular}


The likelihood-ratio statistic for equality of the $\beta$ coefficients across the seven countries is 12.6 , which coincides with the 5 percent critical value from the chi-squared distribution with six degrees of freedom. We could try to come up with reasons why the regions in the Netherlands and the United Kingdom have higher than average $\beta$ convergence, whereas those in Denmark, France, and Italy have lower than average convergence. But, since the differences are only marginally significant in a statistical sense, the main conclusion is that similar rates of $\beta$ convergence are consistent with the data.

\section{Analysis of $\sigma$ Convergence}

Figure 14 shows the unweighted standard deviation, $\sigma_{t}$, for the log of per capita GDP (expressed relative to the mean for the respective country) for the 73 European regions. (The data point for 1966 is based on partial coverage because figures for France and Denmark are unavailable.) Since the regional data are expressed relative to country means, the values shown in the figure refer to $\sigma$ convergence for regions within countries and not across countries. The principal observation is that $\sigma_{t}$ for the European regions declined from 0.28 in 1950 to 0.18 in 1985 . The value for Europe in 1985 is still somewhat above the 0.14 value for U.S. GSP in 1986 (or the low point of 0.13 in 1972).

Figure 14 shows that the fall in $\sigma_{t}$ for the European regions moderated from 1974 to 1985 . We found somewhat similar behavior for $\sigma_{t}$ based on U.S. GSP in figure 11, although the U.S. results showed a substantial rise in $\sigma_{t}$ from the mid-1970s to the early 1980s. For the United States, we think we can explain part of the pattern in $\sigma_{t}$ after the mid-1970s as an effect of oil shocks; a similar story may account for the behavior of $\sigma_{t}$ for Europe in figure 14. (Although the United Kingdom is the only oil producer among the seven countries, the regions of Europe can still vary substantially in their sensitivity to oil shocks.)

Figure 15 shows the behavior of $\sigma_{t}$ for the regions within the four largest European countries in the sample: Germany, the United Kingdom, Italy, and France. The rank order among these countries does not change over the period: dispersion is highest in Italy, followed by Germany, France, and the United Kingdom. The overall pattern shows declines in $\sigma_{t}$ over time for each country, although little net change occurs since 1970 for Germany and the United Kingdom. In particular, 
Figure 14. Dispersion of Gross Domestic Product across European Regions, 1950-85

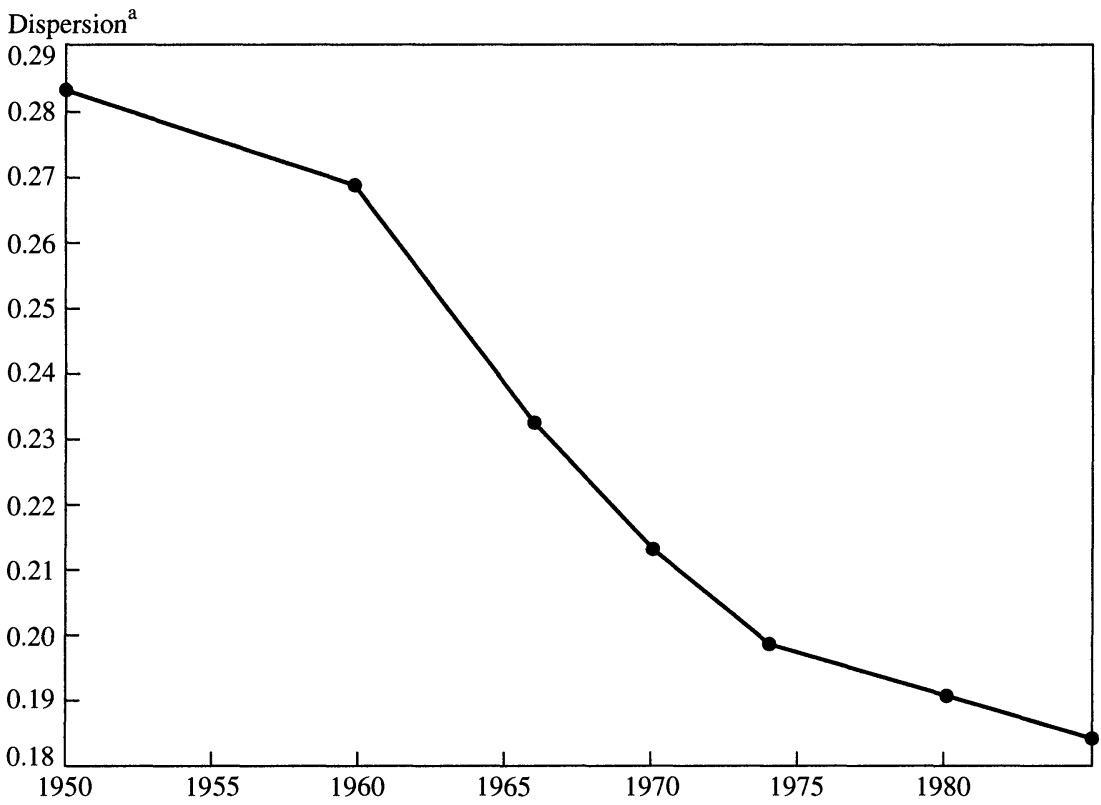

Source: Authors' own calculations using Molle (1980) and Eurostat (various years). The 73 regions listed in table 5 are included in the analysis.

a. Dispersion is measured by the unweighted cross-sectional standard deviation of the log of per capita GDP, relative to the country mean.

the rise in $\sigma_{t}$ from 1974 to 1980 for the United Kingdom—the one oil producer in the European sample-likely reflects the effects of oil shocks. In 1985, the values of $\sigma_{t}$ are 0.26 for Italy, 0.20 for Germany, 0.15 for France, and 0.10 for the United Kingdom, compared with 0.15 for U.S. GSP. Thus, although $\sigma_{t}$ for Italy has fallen from 0.42 in 1950 , Italy still has a way to go to attain the regional dispersion of per capita GDP that is characteristic of the other countries.

The high value of $\sigma_{t}$ for Italy especially reflects the spread between the prosperous north and the poor south. A popular view is that the backward regions of southern Italy will always lag behind the advanced regions of northern Italy (and vice versa for the United Kingdom). Our overall findings do not accord with this type of story since we find substantial evidence of $\beta$ and $\sigma$ convergence across the regions of Europe. For example, with respect to the $\beta$ convergence seen in figure 12 , many of the observations with the highest initial per capita GDP 
Figure 15. Dispersion of Gross Domestic Product within Four European Countries, 1950-85

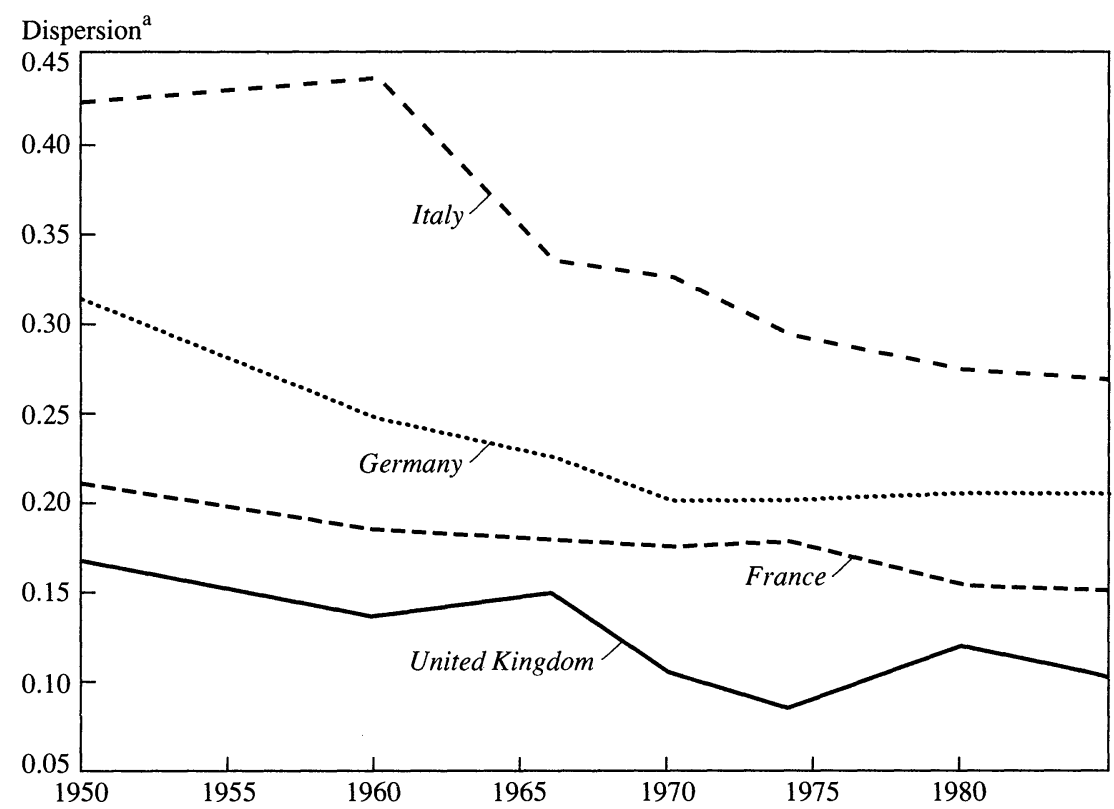

Source: Authors' own calculations using Molle (1980) and Eurostat (various years). See table 5 for a list of regions in each country.

a. Dispersion is measured by the unweighted cross-sectional standard deviation of the log of per capita GDP.

(relative to the own-country mean) are for northern Italy, whereas many with the lowest per capita GDP are for southern Italy (see table 5 and the map in figure 13). These observations scatter reasonably well around the regression line: as predicted, the initially poorer regions in Italy generally grow faster than the initially richer.

Table 7 shows the full array of data for the averages of four prosperous regions in northern Italy and seven poor regions in southern Italy. The northern regions began in 1950 with per capita GDP 70 percent above the mean for Italy, whereas the southern regions began 32 percent below the mean. As predicted, the northern regions grew from 1950 to 1985 at a below-average rate- 0.71 percent a year below the mean-whereas the southern regions grew at an above-average rate- 0.39 percent a year above the mean. Accordingly, in 1985, the northern regions were only 38 percent above the mean, whereas the southern regions were only 25 percent below the mean. The relative growth performances from 1950 
Table 7. Relative Gross Domestic Product and Growth in the North and South of Italy and the United Kingdom, 1950-85

\begin{tabular}{lccccc}
\hline & \multicolumn{2}{c}{ Italy } & & \multicolumn{2}{c}{ United Kingdom } \\
\cline { 2 - 3 } \multicolumn{1}{c}{ Variable } & North & South & & North & South \\
\hline Relative GDP, 1950 & 0.532 & -0.385 & & -0.002 & 0.003 \\
Relative growth, 1950-60 & -0.0014 & 0.0002 & & -0.0002 & 0.0003 \\
Relative GDP, 1960 & 0.518 & -0.383 & & -0.004 & 0.006 \\
Relative growth, 1960-70 & -0.0155 & 0.0080 & & -0.0027 & 0.0041 \\
Relative GDP, 1970 & 0.363 & -0.303 & & -0.031 & 0.047 \\
Relative GDP, 1970 & 0.404 & -0.344 & & -0.044 & 0.066 \\
Relative growth, 1970-80 & -0.0075 & 0.0042 & & 0.0021 & -0.0031 \\
Relative GDP, 1980 & 0.329 & -0.302 & & -0.023 & 0.035 \\
Relative growth, 1980-85 & -0.0011 & 0.0023 & -0.0016 & 0.0024 \\
Relative GDP, 1985 & 0.324 & -0.290 & -0.031 & 0.047 \\
\hline
\end{tabular}

Sources: Data up through 1970 are from Molle (1980). Data after 1970 are from Eurostat (various years). The four northern regions for Italy are Piemonte (number 23 in table 5), Valle d'Aosta (24), Liguria (25), and Lombardia (26). The seven southern regions for Italy are Campania (35), Abruzzi (36), Molise (37), Puglia (38), Basilicata (39), Calabria (40), and Sicilia (41). The six northern regions for the United Kingdom are North (12), Yorkshire-Humberside (13), North-West (18), West Midlands (19), Wales (20), and Scotland (21). Northern Ireland is excluded here. The four southern regions for the United Kingdom are East Midlands (14), East Anglia (15), South-East (16), and SouthWest (17).

a. The variable is regional relative to national per capita GDP, calculated as the ratio of logs. Both regional and national data are unweighted means of the disaggregated data.

b. The variable is regional relative to the national annual growth rate of per capita GDP. Both regional and national data are unweighted means of the disaggregated data.

c. Data are from Molle (1980).

d. Data are from Eurostat (various years).

to 1985 correspond well to the predicted behavior implied by the jointly estimated value from the last equation of table 6 . That value implies that the northern regions should have grown on average at a rate 0.70 percent a year below the mean, whereas the southern regions should have grown on average at a rate 0.51 percent a year above the mean. Thus, there is nothing surprising in the relative performances of the regions of northern and southern Italy. The south of Italy has not yet caught up because it started far behind the north, and the rate of $\beta$ convergence is only about 2 percent a year.

Table 7 also shows comparable statistics for the north and south of the United Kingdom. (The region for Northern Ireland-a substantial outlier for the United Kingdom-is excluded from these calculations.) One immediate observation is that the magnitude of the dispersion between the north and south of the United Kingdom is trivial relative to that between the north and south of Italy. In any event, because the six northern and four southern regions began in 1950 with similar averages 
for per capita GDP, the theory predicts that subsequent growth rates would also be similar. In fact, the northern regions grew by 0.05 percent a year below the mean, whereas the southern ones grew at 0.07 percent a year above the mean. Therefore, in 1985, the average level of per capita GDP in the north was about 3 percent below the mean, whereas that in the south was about 5 percent above the mean. Although the theory does not predict this outcome, these results can likely be explained by sectoral disturbances that affected the regions differentially (and in a way that was uncorrelated with the initial levels of per capita GDP).

\section{The Implications of $\beta$ Convergence}

A striking aspect of our findings is the similarity in the estimated rates of $\beta$ convergence in different contexts. We first summarize the elements of this empirical regularity, then assess the similarity in the estimates from a theoretical perspective, and finally show the significance of the results by applying them to developments in recently unified Germany.

We find ample evidence that poorer regions within a country tend to grow faster than richer regions, a property that we call $\beta$ convergence. For U.S. per capita personal income from 1880 to 1988 , we estimate the speed of convergence, $\beta$, to be around 2 percent a year whether we look within or across the four major geographical regions. We also get similar estimates of $\beta$ when we examine per capita gross state product from 1963 to 1986 . For the output measure, $\beta$ convergence appears within eight standard nonagricultural sectors of production (mining; construction; manufacturing; transportation; wholesale and retail trade; finance, insurance, real estate; services; and government), although the size of $\beta$ for manufacturing is substantially higher than those for the other sectors.

The results for 73 regions of seven European countries (Germany, the United Kingdom, Italy, France, the Netherlands, Belgium, and Denmark) apply to per capita gross domestic product from 1950 to 1985 . The estimated rates of $\beta$ convergence are similar to those found for the United States; in particular, we see no evidence that poor regions, such as those in southern Italy, are being systematically left behind in the growth process. For the seven countries considered in this study, the cross-country estimates of $\beta$ are similar to the within-country estimates.

We have, in other recent work, obtained estimates of $\beta$ for a broader 
cross section of countries in the post-World War II period: one sample contains 20 OECD countries and another comprises a less homogeneous group of 98 countries. ${ }^{41}$ If we examine only the simple relation between the per capita growth rate and initial per capita product, then the estimates of $\beta$ are around 1 percent a year for the OECD sample and near 0 for the larger sample. Recall, however, that the neoclassical growth model summarized by equation 1 predicts a conditional form of convergence in which differences in per capita product enter relative to differences in steady-state positions, $\hat{y}_{i}^{*}$ and $x_{i}^{*}$. If we hold constant additional variables that we interpret as proxies for differences across countries in steadystate positions, then we again obtain estimates of $\beta$ in the neighborhood of 2 percent a year. ${ }^{42}$ These results suggest that the ranking of the divergence in the steady-state values goes from the heterogeneous collection of 98 countries at the top to the relatively homogeneous OECD countries to the still more homogeneous regions within the United States or within the seven European countries. In the regional context, our long-period estimates of $\beta$ depend little on whether we hold constant the proxies for steady-state values, a result that suggests little regional variation of steady-state values within the countries that we have studied.

The neoclassical growth model does not imply that the convergence coefficient, $\beta$, would be the same in all times and places. The coefficient depends, as we discussed before, on the underlying parameters of technology and preferences, but not on differences in technologies or government policies that can be represented as proportional effects on the production function, that is, as variations in the parameter $A$ in the function, $A f(\hat{k})$. These $A$-type effects have important influences on steady-state output per worker, $\hat{y}_{i}^{*}$, but not on the speed with which an economy approaches its steady state. Therefore, economies that differ greatly in some respects may nevertheless exhibit similar rates of $\beta$ convergence.

We noted that a greater degree of labor mobility leads theoretically to a higher convergence coefficient. This effect means that the rates of $\beta$ convergence would be higher for the regions within countries than for across countries. Direct estimates for the effect of net migration across the U.S. states indicate, however, that this effect is small. In particular,

41. Barro and Sala-i-Martin (1991, table 5).

42. See Barro and Sala-i-Martin (1991, table 5). 
the magnitude of the effect is not large enough to generate a statistically detectable gap between the $\beta$ coefficients for regions and countries.

Capital mobility also tends to be greater across regions within a country than across countries. The effects of capital mobility on $\beta$ convergence are, however, difficult to pin down. With identical technologies, capital mobility speeds up convergence for per capita product but slows down convergence for per capita income. Our results for the U.S. states show little distinction in the dynamics of product and income, an observation that leads us to deemphasize capital mobility. Also, if technologies (including government policies) differ across economies, then capital may move from poor to rich economies and thereby lead to divergence of per capita product. Thus, it is not obvious that greater capital mobility across regions than across countries would lead to higher rates of $\beta$ convergence for regions than for countries.

Suppose that, despite the theoretical ambiguities, we take it as an empirical regularity that the rate of $\beta$ convergence is roughly 2 percent a year in a variety of circumstances. We can highlight the potential significance of this finding by showing how it applies to the recent unification of East and West Germany ${ }^{43}$ Suppose that the ratio of the West's per capita income to the East's in 1990 is two, the order of magnitude suggested by George Akerlof and his coauthors. Then a $\beta$ coefficient of 2 percent a year implies that the East's per capita income would grow initially by 1.4 percent a year higher than the West's. ${ }^{44}$ The half-life of this convergence process is 35 years; that is, it would take 35 years for half of the initial East-West gap to be eliminated. Thus, the results extrapolated from our findings for regions of the United States and Europe and for a variety of countries imply that East Germany's achieving "parity" in the short run is unimaginable.

43. A paper, Akerlof and others (1991), in this volume explores the issue of German unification.

44. We can also use the findings for the United States (table 2) to estimate net migration from Germany's East to its West. The resulting estimate (which allows for the differences in per capita income and population density, but not for differences in amenities) is that 1.2 percent, or 203,000 , of the people residing in the East would migrate to the West. Akerlof and others (1991, table 9) show that the net out-migration from the East averaged about 22,800 a month, or 274,000 at an annual rate, over the three months since unification in July 1990. Although this rate exceeds our estimate of 203,000, the extrapolation of the U.S. experience to Germany does provide a reasonable order of magnitude. 


\section{APPENDIX TABLES}

Table A1. Personal Income Data for U.S. States, 1880-1988

\begin{tabular}{|c|c|c|c|}
\hline Variable & $\operatorname{Year}(s)$ & Mean & $\begin{array}{l}\text { Standard } \\
\text { deviation }\end{array}$ \\
\hline Log of income ${ }^{a}$ & $\begin{array}{l}1880^{\mathrm{b}} \\
1900 \\
1920 \\
1930 \\
1940 \\
1950 \\
1960 \\
1970 \\
1980 \\
1988\end{array}$ & $\begin{array}{l}0.478 \\
0.719 \\
0.995 \\
1.026 \\
1.170 \\
1.661 \\
1.805 \\
2.112 \\
2.262 \\
2.425\end{array}$ & $\begin{array}{l}0.545 \\
0.465 \\
0.327 \\
0.401 \\
0.356 \\
0.244 \\
0.208 \\
0.168 \\
0.150 \\
0.194\end{array}$ \\
\hline Growth of income ${ }^{c}$ & $\begin{array}{c}1880-1988^{\mathrm{b}} \\
1880-1900^{\mathrm{b}} \\
1900-20 \\
1920-30 \\
1930-40 \\
1940-50 \\
1950-60 \\
1960-70 \\
1970-80 \\
1980-88\end{array}$ & $\begin{array}{l}0.0181 \\
0.0126 \\
0.0138 \\
0.0030 \\
0.0144 \\
0.0492 \\
0.0143 \\
0.0308 \\
0.0150 \\
0.0204\end{array}$ & $\begin{array}{l}0.0045 \\
0.0083 \\
0.0105 \\
0.0140 \\
0.0090 \\
0.0147 \\
0.0065 \\
0.0063 \\
0.0067 \\
0.0141\end{array}$ \\
\hline Share of agriculture ${ }^{d}$ & $\begin{array}{l}1880^{\mathrm{b}} \\
1900 \\
1920 \\
1930 \\
1940 \\
1950 \\
1960 \\
1970 \\
1980\end{array}$ & $\begin{array}{l}0.307 \\
0.273 \\
0.211 \\
0.134 \\
0.122 \\
0.117 \\
0.058 \\
0.040 \\
0.020\end{array}$ & $\begin{array}{l}0.184 \\
0.150 \\
0.120 \\
0.087 \\
0.084 \\
0.087 \\
0.050 \\
0.040 \\
0.019\end{array}$ \\
\hline Structural composition variable & $\begin{array}{l}1930-40 \\
1940-50 \\
1950-60 \\
1960-70 \\
1970-80 \\
1980-88\end{array}$ & $\begin{array}{l}0.0164 \\
0.0393 \\
0.0103 \\
0.0254 \\
0.0044 \\
0.0464\end{array}$ & $\begin{array}{l}0.0012 \\
0.0020 \\
0.0082 \\
0.0028 \\
0.0026 \\
0.0058\end{array}$ \\
\hline \multicolumn{4}{|l|}{ Regional dummies } \\
\hline $\begin{array}{l}\text { East } \\
\text { South } \\
\text { Midwest } \\
\text { West }\end{array}$ & $\begin{array}{l}\cdots \\
\cdots \\
\cdots\end{array}$ & $\begin{array}{l}0.229 \\
0.292 \\
0.250 \\
0.229\end{array}$ & $\begin{array}{l}\cdots \\
\cdots \\
\cdots\end{array}$ \\
\hline
\end{tabular}

Sources: Bureau of Economic Analysis (1984), Easterlin (1960a, 1960b), and Survey of Current Business, various issues. Except where noted, all figures include observations for the continental states.

a. The log of income is the log of real per capita personal income in state $i$ at time $t$, or $\log \left(y_{i t}\right)$, where $y_{i t}$ is nominal personal income in thousands of nominal dollars per person, divided by the overall CPI (1982 as base year).

b. Oklahoma is excluded from the 1880 data. Wyoming is excluded from the 1880 data on the share of personal income originating in agriculture.

c. The variable is the average annual growth rate of real per capita personal income in state $i$ between years $t-T$ and $t:(1 / T) \log \left(y_{i t} / y_{i, t-T}\right)$.

d. The variable is the share of personal income originating in agriculture in state $i$ at time $t:$ Agry $_{i t}$.

e. The structural composition variable, $S_{i t}$, described in the text is based on the division of production into nine sectors. 
Table A2. Gross State Product Data, 1963-86

\begin{tabular}{|c|c|c|c|}
\hline Variable & Year(s) & Mean & $\begin{array}{l}\text { Standard } \\
\text { deviation }\end{array}$ \\
\hline \multirow[t]{5}{*}{$\log$ of GSPa } & 1963 & 2.138 & 0.181 \\
\hline & 1969 & 2.360 & 0.155 \\
\hline & 1975 & 2.456 & 0.145 \\
\hline & 1981 & 2.580 & 0.181 \\
\hline & 1986 & 2.659 & 0.142 \\
\hline \multirow[t]{5}{*}{ Growth of GSPb } & $1963-86$ & 0.0227 & 0.0050 \\
\hline & $1963-69$ & 0.0370 & 0.0087 \\
\hline & $1969-75$ & 0.0159 & 0.0149 \\
\hline & $1975-81$ & 0.0207 & 0.0146 \\
\hline & $1981-86$ & 0.0159 & 0.0260 \\
\hline \multirow[t]{4}{*}{ Structural composition variable ${ }^{c}$} & $1963-69$ & 0.0282 & 0.0037 \\
\hline & $1969-75$ & 0.0053 & 0.0060 \\
\hline & $1975-81$ & 0.0156 & 0.0080 \\
\hline & $1981-86$ & 0.0158 & 0.0112 \\
\hline \multicolumn{4}{|l|}{ Growth of sectoral productivityd } \\
\hline Construction & $1963-86$ & -0.0223 & 0.0117 \\
\hline Mininge & $1963-86$ & -0.0082 & 0.0178 \\
\hline Manufacturing & $1963-86$ & 0.0282 & 0.0076 \\
\hline Transportation & $1963-86$ & 0.0230 & 0.0047 \\
\hline Trade & $1963-86$ & 0.0105 & 0.0033 \\
\hline FIRE & $1963-86$ & 0.0006 & 0.0058 \\
\hline Services & $1963-86$ & -0.0053 & 0.0041 \\
\hline Government & $1963-86$ & -0.0062 & 0.0045 \\
\hline \multicolumn{4}{|l|}{ Log of sectoral productivity ${ }^{d}$} \\
\hline Construction & 1963 & 2.233 & 0.172 \\
\hline Mininge & 1963 & 2.727 & 0.505 \\
\hline Manufacturing & 1963 & 2.213 & 0.224 \\
\hline Transportation & 1963 & 2.631 & 0.076 \\
\hline Trade & 1963 & 2.065 & 0.087 \\
\hline FIRE & 1963 & 3.494 & 0.190 \\
\hline Services & 1963 & 1.996 & 0.118 \\
\hline Government & 1963 & 1.840 & 0.216 \\
\hline \multicolumn{4}{|l|}{ Log of sectoral productivityd } \\
\hline Construction & 1986 & 3.697 & 0.282 \\
\hline Mininge & 1986 & 4.353 & 0.456 \\
\hline Manufacturing & 1986 & 3.737 & 0.119 \\
\hline Transportation & 1986 & 4.300 & 0.109 \\
\hline Trade & 1986 & 3.318 & 0.096 \\
\hline FIRE & 1986 & 4.750 & 0.153 \\
\hline Services & 1986 & 3.325 & 0.114 \\
\hline Government & 1986 & 3.285 & 0.161 \\
\hline
\end{tabular}

Source: Renshaw, Trott, and Friedenberg (1988). Except where noted, all figures include observations for the continental states.

a. The log of GSP is the log of real per capita GSP in state $i$ at time $t$, or $\log \left(y_{i t}\right)$, where $y_{i t}$ is nominal GSP in thousands of nominal dollars per person, divided by the national deflator for GSP (1982 as base year).

b. The variable is the average annual growth rate of real per capita GSP between years $t-T$ and $t:(1 / T) \log \left(y_{i t} /\right.$ $y_{i, t-T)}$.

c. The structural composition variable for GSP is based on a division of production into 54 sectors.

d. Sectoral productivity is defined as the contribution of the sector to real GSP per worker.

e. Connecticut. Delaware, Maine, Massachusetts, New Hampshire, and Rhode Island, which have negligible mining, are excluded from the analysis. 
Table A3. Data for European Regions, 1950-85

\begin{tabular}{|c|c|c|c|}
\hline Variable & $\operatorname{Year}(s)$ & Mean & $\begin{array}{l}\text { Standard } \\
\text { deviation }\end{array}$ \\
\hline \multirow[t]{6}{*}{$\log$ of GDPa } & 1950 & $\ldots$ & 0.395 \\
\hline & 1960 & $\ldots$ & 0.387 \\
\hline & $1970^{\mathrm{b}}$ & $\ldots$ & 0.306 \\
\hline & $1970^{\mathrm{c}}$ & $\ldots$ & 0.334 \\
\hline & 1980 & $\ldots$ & 0.337 \\
\hline & 1985 & $\ldots$ & 0.234 \\
\hline \multirow[t]{5}{*}{ Growth of GDPa } & $1950-85$ & $\ldots$ & 0.0088 \\
\hline & $1950-60$ & $\ldots$ & 0.0159 \\
\hline & $1960-70$ & $\ldots$ & 0.0190 \\
\hline & $1970-80$ & $\ldots$ & 0.0098 \\
\hline & $1980-85$ & $\ldots$ & 0.0331 \\
\hline \multicolumn{4}{|c|}{ Sectoral shares in employment } \\
\hline \multirow[t]{3}{*}{ Agriculture } & 1950 & 0.319 & 0.199 \\
\hline & 1960 & 0.231 & 0.165 \\
\hline & 1970 & 0.142 & 0.110 \\
\hline \multirow[t]{3}{*}{ Industry } & 1950 & 0.373 & 0.125 \\
\hline & 1960 & 0.412 & 0.106 \\
\hline & 1970 & 0.430 & 0.080 \\
\hline \multicolumn{4}{|c|}{ Sectoral shares in GDPd } \\
\hline \multirow[t]{3}{*}{ Agriculture } & 1970 & 0.076 & 0.051 \\
\hline & 1980 & 0.050 & 0.035 \\
\hline & 1985 & 0.045 & 0.030 \\
\hline \multirow[t]{3}{*}{ Industry } & 1970 & 0.430 & 0.079 \\
\hline & 1980 & 0.403 & 0.066 \\
\hline & 1985 & 0.362 & 0.065 \\
\hline \multicolumn{4}{|l|}{ Country dummies } \\
\hline Germany & $\ldots$ & 0.151 & $\ldots$ \\
\hline Italy & $\ldots$ & 0.274 & $\ldots$ \\
\hline United Kingdom & $\ldots$ & 0.151 & $\ldots$ \\
\hline France & $\ldots$ & 0.288 & $\ldots$ \\
\hline Netherlands & $\ldots$ & 0.055 & $\ldots$ \\
\hline Belgium & $\ldots$ & 0.041 & $\ldots$ \\
\hline Denmark & $\ldots$ & 0.041 & $\ldots$ \\
\hline
\end{tabular}

Sources: Data up through 1970 are from Molle (1980). Data after 1970 are from Eurostat (various years)

a. The levels of per capita GDP for different years are based on noncomparable indexes.

b. Data are from Molle (1980).

c. Data are from Eurostat (various years).

d. Three regions of Denmark are excluded from the sectoral share in GDP data. For the regressions, the 1980 values for Denmark were approximated from the available data for 1974. 
Table A4. Migration Data for the U.S. States, 1880-1987

\begin{tabular}{cccc}
\hline Variable & Year $(s)$ & Mean & $\begin{array}{c}\text { Standard } \\
\text { deviation }\end{array}$ \\
\hline Net migration rate $^{\mathrm{a}}$ & $1900-87$ & 0.0034 & 0.0107 \\
& $1900-40$ & 0.0051 & 0.0119 \\
& $1940-87$ & 0.0019 & 0.0113 \\
& $1900-20$ & 0.0107 & 0.0187 \\
& $1920-30$ & -0.0002 & 0.0115 \\
& $1930-40$ & -0.0086 & 0.0069 \\
& $1940-50$ & 0.0004 & 0.0140 \\
& $1950-60$ & 0.0009 & 0.0167 \\
& $1960-70$ & 0.0009 & 0.0112 \\
& $1970-80$ & 0.0055 & 0.0123 \\
& $1980-87$ & 0.0020 & 0.0086 \\
& $1880^{c}$ & 0.0388 & 0.0521 \\
& 1900 & 0.0559 & 0.0797 \\
& 1920 & 0.0771 & 0.1145 \\
& 1930 & 0.0906 & 0.1342 \\
& 1940 & 0.0935 & 0.1379 \\
& 1950 & 0.1062 & 0.1553 \\
& 1960 & 0.1247 & 0.1817 \\
Heat $_{i}$ & 1970 & 0.1416 & 0.2081 \\
& 1980 & 0.1504 & 0.2099 \\
& $\ldots$ & 5,033 & 2,116 \\
& $\ldots$ & 8.407 & 0.539
\end{tabular}

Source: Bureau of the Census $(1975,1990)$. Except where noted, the figures include observations for the continental states.
a. The variable is the average annual rate of net in-migration, $m_{i}$
b. Population density, $\pi_{i t}$, is thousands of people per square mile of total area.
c. Oklahoma is excluded from the 1880 data. 


\section{Comments and Discussion}

Olivier Jean Blanchard: Macroeconomists have rediscovered regional economics. The reasons are simple. Regions offer them a new, larger data set; there are many more regions (cities and states) than countries, and econometric exploration of the Summers and Heston country data set is suffering from strongly decreasing returns. ${ }^{1}$ Comparisons of regions offer much better controlled experiments than comparisons of countries. And, in many cases, what we hope to uncover, from the roles of increasing returns and externalities in growth to the workings of labor markets, may be easier to pick up at a higher level of disaggregation.

Two papers by Robert Barro and Xavier Sala-i-Martin, this one and a predecessor, present the basic facts of regional growth. ${ }^{2}$ Both establish what has long been known as a stylized fact: the convergence of income across regions in the United States is a robust fact. Their contribution is both in the simple conceptual framework they use to set up the appropriate regressions and in the clarity of the results they obtain. I have no doubt that these two papers will trigger substantial further research.

With this in mind, I shall organize my comments in two parts. In the first I shall propose an alternative but, I think, more appropriate framework for interpreting the results of regional convergence. In the second, empirical, part I shall use the time dimension of the data more systematically to strengthen and extend the authors' results.

\section{U.S. States as Small Open Economies}

In their initial model the authors characterize the U.S. states as $\mathbf{5 0}$ small closed "Solow economies" producing identical goods. Labor and

1. See Summers and Heston (1991) for the most recent version of the data.

2. Barro and Sala-i-Martin (1990). 
capital mobility, as well as random shocks, are later introduced, but largely as add-ons. This may be the right first-pass model when comparing countries; it surely is not when comparing U.S. states-it may actually give the wrong message. In light of that model, the reader may conclude that the main fact about regional growth in the United States has been the convergence of personal income per capita, presumably caused by the adjustment of capital-labor ratios. This conclusion would be wrong. Surely, an equally important fact is the amazing range of employment growth rates across states; as is shown in my figure 1, over the last 40 years average annual employment growth rates have ranged from close to 0 percent for West Virginia to above 5 percent for Nevada, Arizona, and Florida. The challenge is to reconcile this range of growth rates with the authors' fact of convergence in incomes per capita.

To do this, a better starting point is to think of the 50 states as 50 small open economies, each producing different goods, under conditions of high factor mobility. ${ }^{3}$ This has a number of implications for convergence. To draw them out, I sketch a simplistic model and use it to study convergence under alternative assumptions about shocks, technology, and factor mobility.

PRODUCTION, DEMAND, AND FACTOR MOBILITY. Assume that there are $n$ states, denoted by $i$, with $i=1, \ldots, n$, each producing a different good. Then assume that the production and demand functions for the good $i$ are given by:

$$
\begin{aligned}
& \left(q_{i t}-q_{t}\right)=a\left(l_{i t}-l_{t}\right)+(1-a)\left(k_{i t}-k_{t}\right)+\theta_{i t}, \\
& \left(p_{i t}-p_{t}\right)=-d\left(q_{i t}-q_{t}\right)+\epsilon_{i t} .
\end{aligned}
$$

All variables are in logs. The variables $q_{i t}, l_{i t}, k_{i t}$, and $p_{i t}$ stand for state output, employment, capital, and output price respectively. The same variables without an $i$ subscript refer to national averages. ${ }^{4}$ Equation 1 is obtained by subtraction of the aggregate production function from the state production function: states are assumed to have the same production function but different technological shocks; $\theta_{i t}$ stands for the statespecific technological shock. The relative demand for the state output is

3. This alternative approach is obviously not original; indeed it underlies most previous studies of regional growth. See for example the remarkable 1951 Department of Commerce study of regional trends; Wardwell (1951).

4. This formalization makes the standard fudge of implicitly defining averages as geometric rather than arithmetic means. 
Figure 1. Growth in Employment and Per Capita Income across U.S. States, 1950-88

Per capita income growth (percent)

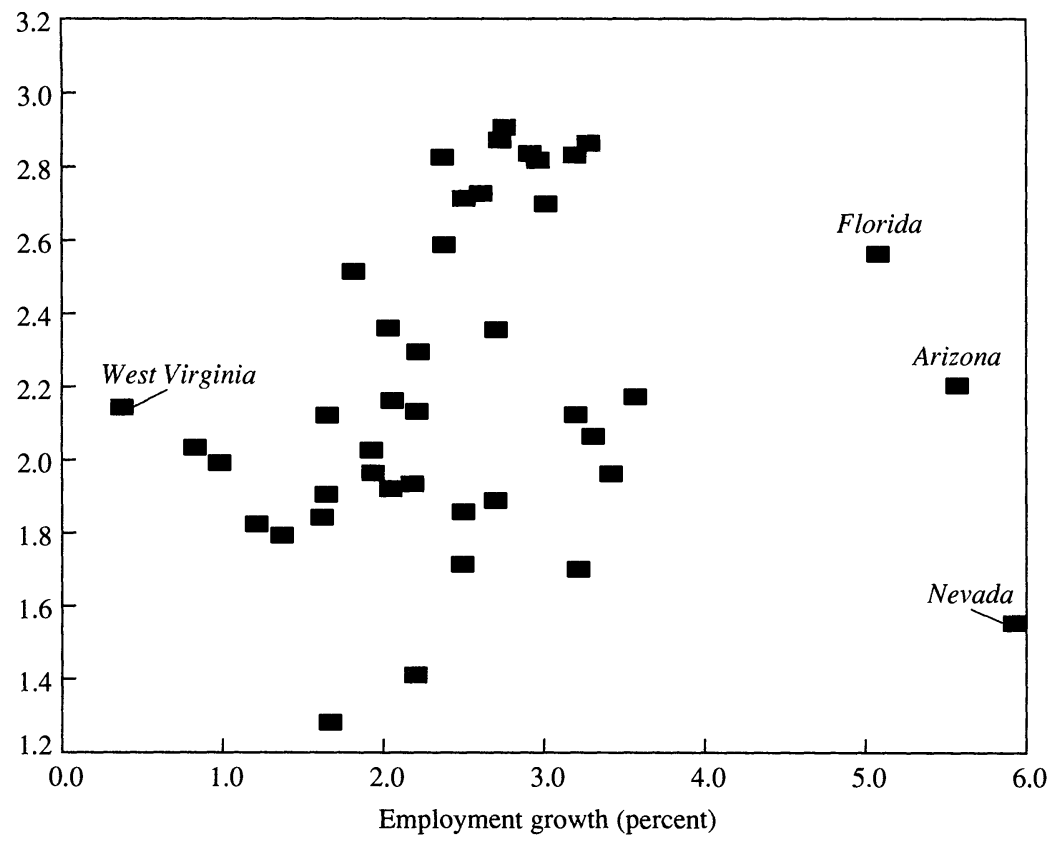

Source: Barro and Sala-i-Martin and DRI data base. The average annual growth in employment and real per capita income in each state over the period is shown. Connecticut, Maine, Rhode Island, Delaware, Maryland, Michigan, and Hawaii are excluded.

a decreasing function of its relative price; $\epsilon_{i t}$ stands for the shock to relative demand. To the extent that states produce different goods, shifts in relative productivity or in relative demand are likely to contain a permanent component. Thus, in what follows, I shall assume both $\theta_{i t}$ and $\epsilon_{i t}$ to be nonstationary.

Clearly, the assumption that states produce a given good, or even a given basket of goods, is too strong. That, at any point in time, there is substantial specialization across states in the production of goods is not at issue; behind the scene, increasing returns must play an important role. This theme has been most recently explored, both analytically and empirically, by Paul Krugman. ${ }^{5}$ His Gini coefficients of sectoral dispersion by state show the degree to which U.S. states indeed differ in their com-

5. Krugman (1991). 
position of production. But, it is also true that as goods experience their life cycles, states move from the production of old goods to that of new goods. The question is whether this complex process is better approximated by the assumptions above or, by, say, the assumption that $\theta_{i t}$ and $\epsilon_{i t}$ are stationary, that by changing the basket of goods they produce states can avoid permanent effects of changes in relative demand and relative technological progress. One fact suggests that nations are good at changing their basket of goods over time: nations that grow fast do not experience steady decreases in their terms of trade, as would likely be the case if they sold an unchanging production basket. ${ }^{6}$ But as anybody who has seen the movie Roger and Me and the desperate attempts of Flint, Michigan, to replace the employment lost in the automobile industry knows, cities often have a hard time replacing dying industries. Having flagged the issue, I shall leave it at that in these comments.

Mobility of factors across states is crucial to understanding the dynamics of regional growth in the United States, but because of data limitations direct evidence on capital mobility is sketchy. To the best of my knowledge the most recent study of capital flows across U.S. states is a 1965 study by J. Thomas Romans, using data up to $1957 . .^{7}$ Figure 2 plots his findings for gross saving and investment rates in 1957 for the eight U.S. regions. There is roughly zero correlation between investment and saving: saving rates are rather similar across regions, while investment rates vary from around 11 percent for New England to over 20 percent in the Southwest. The Feldstein-Horioka puzzle clearly does not apply across U.S. regions, and capital mobility was already very high in $1957 .{ }^{8}$ With respect to the mobility of labor, Barro and Sala-iMartin document the scope of migration. Another revealing statistic relating to migration is the range of annual employment growth rates across states that I mentioned earlier, a range much larger than the range across European countries, for example.

I assume labor and capital mobility are given by:

$$
\begin{aligned}
\left(l_{i t+1}-l_{t+1}\right) & =\left(l_{i t}-l_{t}\right)+b\left(w_{i t}-w_{t}\right), \\
\left(k_{i t+1}-k_{t+1}\right) & =\left(k_{i t}-k_{t}\right)+c\left(r_{i t}-r_{t}\right),
\end{aligned}
$$

6. See for example Krugman (1989).

7. Romans (1965).

8. Feldstein and Horioka (1980). 
Figure 2. Saving and Investment Rates across U.S. Regions, 1957

Gross investment rate (percent)

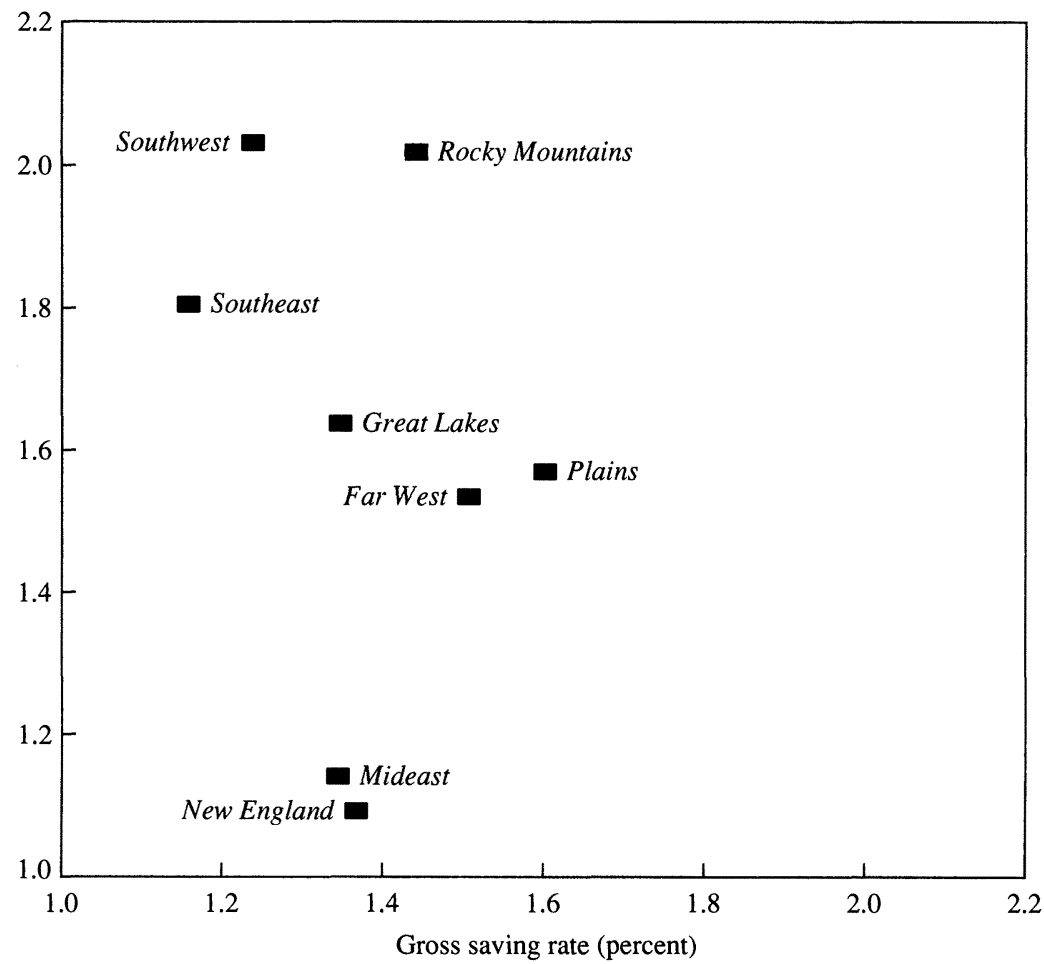

Source: Romans (1965).

where $w$ and $r$ stand for logarithms of wages and of rates of return on capital; they are assumed to equal the value marginal products of labor and capital respectively. Under this specification, factors are fixed within the period. Short-run (one-period) elasticities to wage and interest rate differentials are given by $b$ and $c$ respectively. And, unless $b$ or $c$ equals zero, the long-run elasticities are infinite. An implicit assumption is that people have the same consumption across states. Relaxing this assumption or allowing for state-specific amenities to enter the labor mobility equation is straightforward but unimportant in what follows.

It is easy under these assumptions to derive the joint behavior of capital, employment and output in each region. But in the general case the equation characterizing output is of higher order than that derived 
by the authors under their set of assumptions. I shall thus consider two special cases: zero labor mobility $(b=0, c>0)$ and zero capital mobility $(c=0, b>0)$, for which the reduced form for regional per capita output is the same as the authors'. Those special cases are enough for my purposes.

CONVERGENCE UNDER CAPITAL Mobility. Assume that labor is immobile, so that $b=0$, and is identically distributed across states, so that $l_{i t}-l_{t}=0$. Let $y_{i t} \equiv q_{i t}+p_{i t}-l_{i t}$ be the nominal value of state output per capita and $y_{t} \equiv q_{t}+p_{t}-l_{t}$ be the corresponding national average. Like the authors, I am interested in the behavior of $y_{i t}-y_{t}$, relative real state output per capita, both across time and across states.

Using the equations and assumptions above and solving for the wage and the return to capital, it is easy to derive the time-series behavior of $y_{i t}-y_{t}$, or "relative output" in what follows:

$$
\left(y_{i t}-y_{t}\right)=(1-\beta)\left(y_{i t-1}-y_{t-1}\right)+z_{i t},
$$

where $\beta \equiv c[1-(1-a)(1-d)]$, and

$$
z_{i t} \equiv\left[(1-d) \theta_{i t}+\epsilon_{i t}\right]-(1-c)\left[(1-d) \theta_{i t-1}+\epsilon_{i t-1}\right] .
$$

Thus, relative output follows a first-order process with forcing term $z_{i t}$. Equation 5 can be rearranged to give the growth rate in state $i$ for a given $t$,

$$
\left(y_{i t}-y_{i t-1}\right)=\left(y_{t}-y_{t-1}\right)-\beta\left(y_{i t-1}-y_{t-1}\right)+z_{i t} .
$$

The growth rate in state $i$ depends on the U.S. growth rate, on the difference between the initial state and U.S. levels, and on the disturbance term. Finally, rearranging and solving recursively from time 0 to time $t$ gives an equation similar to that derived by the authors:

$$
\begin{aligned}
(1 / T)\left(y_{i T}-y_{i 0}\right)= & (1 / T)\left(y_{T}-y_{0}\right) \\
& -(1 / T)\left[1-(1-\beta)^{T}\right]\left(y_{i 0}-y_{0}\right)+u_{i T}, \\
\text { where } u_{i T} \equiv(1 / T)\left[z_{i T}+\right. & \left.(1-\beta) z_{i T-1}+\ldots+(1-\beta)^{T-1} z_{i 1}\right]
\end{aligned}
$$

The average rate of growth in state $i$ over $T$ periods depends on the national growth rate, the difference at time 0 between the state and national levels, and a disturbance term, which in turn depends on the value of the shocks between time 1 and $T$. Two conclusions follow from equations 5,6 , and 7 .

First (assuming that $\beta$ can be estimated consistently in a cross-section 
regression of equation 7, an issue to which I shall return below), the economy will exhibit a positive $\beta$ and will show, using the authors' terminology, " $\beta$ convergence" as long as either $a$ or $d$ is positive. Thus, even if states exhibit constant returns to capital, so that $a=0$, $\beta$ convergence will hold as long as they do not face a perfectly elastic demand for their product. In this sense, $\beta$ convergence for U.S. regions does not by itself tell us much about the crucial technological parameter in endogenous growth models, the returns to scale to adjustable factors.

Second, even when $\beta$ is positive, if the state-specific shocks to technology and relative demand are nonstationary, state outputs per capita will eventually diverge arbitrarily far from each other. ${ }^{9}$ Technically, this comes from the fact that in equation 5 the disturbance term is the sum of nonstationary processes and is itself nonstationary; this in turn implies that relative state output per capita is also nonstationary. ${ }^{10}$ The intuition behind the result is straightforward. In a world of statespecific shocks and no labor mobility, the movement of capital will amplify the effects of the shocks on output per capita, by moving to the states that are experiencing positive shocks. This amplification effect can be seen further by assuming, for example, that both the $\epsilon$ and $\theta$ shocks follow random walks and by computing the elasticity of relative output with respect to an innovation in either of the two shocks. It is easy to see that in this case the ratio of the long-run to the short-run elasticity of per capita relative output is equal to $1 /[1-(1-a)(1-d)]$, which, if $\beta$ is positive, exceeds unity.

To summarize, given an arbitrary distribution of capital and an absence of shocks, an economy with capital mobility and no labor mobility will converge to equal per capita state output; this is what is captured by $\beta$ convergence. But capital movements will reinforce the effects of shocks and, if the shocks include a permanent component, will eventually lead to divergence in per capita state outputs. Let me now contrast these results with the opposite case of labor mobility and no capital mobility.

CONVERGENCE UNDER LABOR MOBILITY. Assume now that capital is immobile, so that $c=0$, and identically distributed across states, so

9. Again using the terminology developed by Barro in earlier papers and briefly referred to in this paper, this economy will not exhibit $\sigma$ convergence.

10. If $c$ is equal to zero, that is if there is no capital mobility, the disturbance term is stationary but $\beta$ is equal to zero, so that relative state outputs per capita are still nonstationary. 
that $k_{i t}-k_{t}=0$. Then following the same steps as before, the behavior of relative state output per capita is given by:

$$
\left(y_{i t}-y_{t}\right)=(1-\beta)\left(y_{i t-1}-y_{t-1}\right)+z_{i t},
$$

where now $\beta \equiv b[1-a(1-d)]$, and

$$
z_{i t} \equiv\left[(1-d) \theta_{i t}+\epsilon_{i t}\right]-\left[(1-d) \theta_{i t-1}+\epsilon_{i t-1}\right] .
$$

As before, we can reorganize and solve recursively to obtain an equation for the state rate of growth over $T$ periods. The equation is the same as equation 7, though $\beta$ and $z_{i t}$ are defined as above.

What can we say about convergence in this economy? This economy will exhibit $\beta$ convergence as long as either $a$ is less than unity or $d$ is positive (and as long as $\beta$ can be estimated consistently). Thus, again $\beta$ convergence may hold even if the technology exhibits constant returns to the adjustable factor, in this case labor.

But, and this is now different from the case of capital mobility, this economy also exhibits convergence, even when the shocks to technology and demand have a permanent component. Because of the stochastic nature of the shocks, the states do not converge to the same value, but eventually the economy settles in a stochastic steady state with a stable distribution of output per capita across states. Technically, this is because in equation 8 the shocks $\theta$ and $\epsilon$ enter as first differences, so that even when they are not stationary, the disturbance term $z_{i t}$ in equation 8 , and by implication the relative state output per capita, is stationary. In other words, just like the movement of capital earlier the movement of labor amplifies the effects of the shocks on total output by moving to the states that are experiencing positive shocks; but, because of decreasing returns to labor, the movement of labor into those states decreases the effects of the shocks on output per capita. In response to a shock, labor moves until wages are again equalized. At that point, outputs per capita are also equalized.

In the general case of capital and labor mobility, the behavior of state output follows a slightly more complex process than that in equation 8 , and I shall not characterize it here. ${ }^{11}$ But the results are easy to state. Such an economy is likely to exhibit $\beta$ convergence, so that $\beta$ convergence does not tell us much about the underlying technology. The

11. A case that is simple to solve is $b=c=1$. In that case, the equation of motion for output is again the same form as equation 9 . 
dynamic effects of shocks on state output per capita are amplified by capital mobility, dampened by labor mobility. Yet the presence of labor mobility leads eventually to convergence and a stable distribution of state outputs per capita.

\section{Are U.S. States Converging?}

In the first part of my comments I have argued that $\beta$ convergence does not imply convergence. In the second part, I want to do two things. First, I want to show how one can use the same data as Barro and Salai-Martin to test (informally, at this point) for convergence. To do this, however, one must exploit the time dimension of the data more systematically than the authors have done. I shall follow two different approaches; both strongly suggest convergence. Second, I want to glance at the relation between employment and per capita income growth and see how it conforms to the model sketched above.

DISPERSION OVER TIME. The first approach is based on a simple idea. If there really is convergence, then, controlling for initial levels, average rates of growth of states should become more similar as they are computed over longer periods of time.

To implement the idea, consider the cross-section regression version of equation 7 , the regression of the $T$-period state growth rates on their initial level and a constant:

(9) $(1 / T)\left(y_{i T}-y_{i 0}\right)=A_{T}-(1 / T)\left[1-(1-\beta)^{T}\right] y_{i 0}+u_{i T}$, for $i=1$ to $n$;

where $A_{T} \equiv(1 / T)\left(y_{T}-y_{0}\right)+(1 / T)\left[1-(1-\beta)^{T}\right] y_{0}$, and

$$
u_{i T} \equiv(1 / T)\left[z_{i T}+(1-\beta) z_{i T-1}+\ldots+(1-\beta)^{T-1} z_{i 1}\right] .
$$

In that regression, note that the disturbance term, $u_{i t}$, is a weighted sum, with decreasing weights of current and past $z_{i t}$ 's, which are themselves linear combinations of the underlying demand and production shocks. For the economy to exhibit convergence, the $z_{i t}$ 's must be stationary; this was the case in the previous section under the assumption of labor mobility.

This suggests a simple test, based on looking at what happens to the estimated standard error of the regression, $\sigma(T)$, as we increase $T$. If the underlying $z_{i t}$ 's are indeed stationary, then the estimated $\sigma(T)$ should go to zero. In other words, controlling for initial conditions, the average 
annual state rates of growth of output over $T$ periods should converge to the same value. But, if the $z_{i t}$ 's are nonstationary-as was the case with capital but no labor mobility- $\sigma(T)$ should instead converge to a strictly positive value.

The values of $\sigma(T)$ obtained from estimation of equation 9 over $T=$ 1 to 38 , using data from 1950 to 1988 on personal income per capita, are shown in figure 3. In all regressions, the initial level is the 1950 level. Thus, for example, the "actual value" of $\sigma(5)$, which is near 0.01 percent, is the standard error of the regression of state growth rates from 1950 to 1955 on a constant and their initial level in 1950. As a reference, the

Figure 3. Actual and Predicted Dispersion of Per Capita Income

Dispersion $^{\mathrm{a}}$

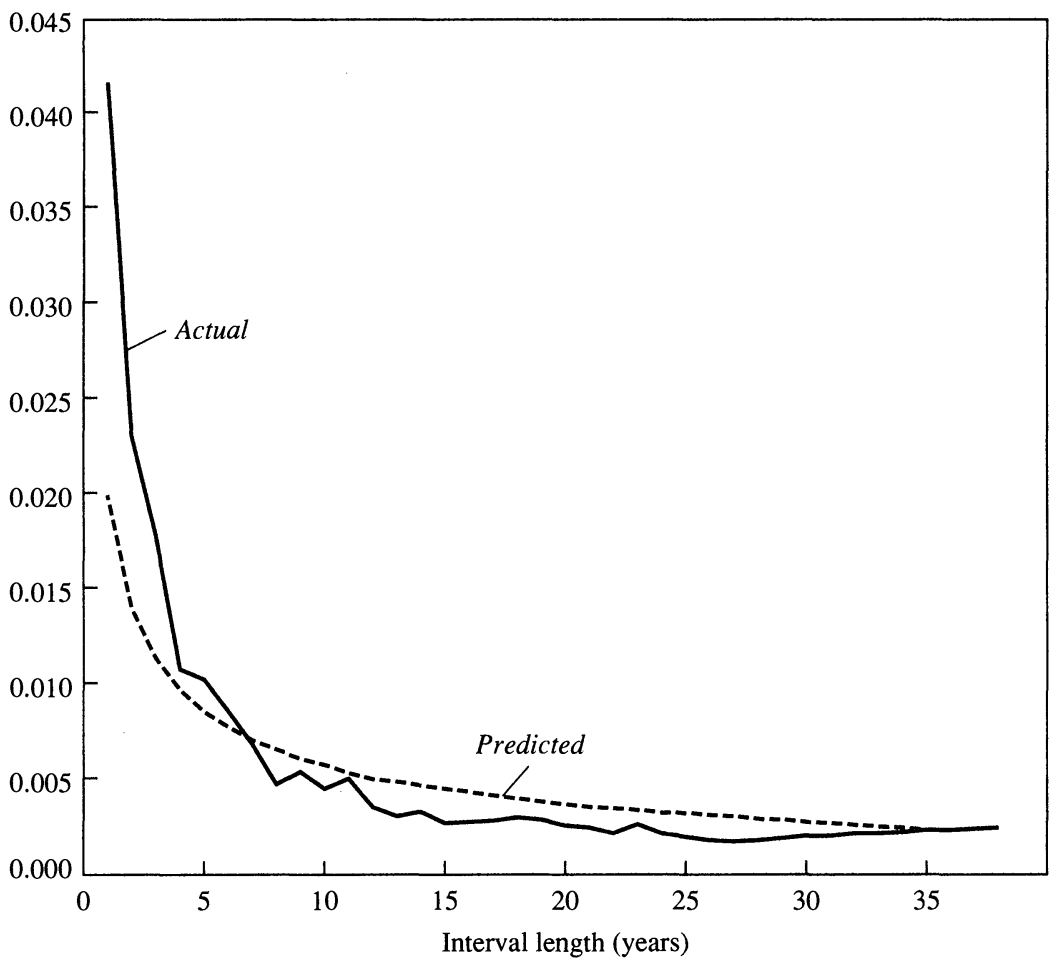

Source: Author's own calculations using annual data from DRI data base.

a. Dispersion is measured by the standard error of the regression of equation 9 in the text over $T=1$ to 38 , using annual data from 1950 to 1988 . The predicted value of the standard error of the regressions for an economy that exhibits convergence (see the assumptions listed in the text) is also shown. 
figure also gives the predicted behavior of $\sigma(T)$ for an economy that exhibits convergence. More specifically, it gives the predicted value of the standard error of the regression under the following assumptions: the two underlying shocks, $\epsilon_{i t}$ and $\theta_{i t}$, follow random walks; $\beta$ is equal to 2 percent a year; $z_{i t}$ is equal to the sum of the first differences of $\epsilon_{i t}$ and $\theta_{i t}$ (as in the case of labor mobility treated in the previous section); and innovations in $z_{i t}$ have a standard error of 2 percent a year.

The figure speaks fairly clearly. The estimated standard error decreases strongly with $T$, the horizon over which average growth rates are computed. It actually declines faster at the beginning than would be predicted in an economy that exhibited convergence and in which statespecific shocks followed random walks. This suggests the presence of a substantial transitory component in state-specific shocks. At long horizons, however, the predicted and actual values are roughly indistinguishable and appear to converge to zero at the same slow rate. The evidence in this figure supports convergence.

CONVERGENCE COEFFICIENT OVER TIME. The second approach is also based on a simple idea. Suppose that shocks to relative demand and production had permanent effects on state output per capita, so that the economy did not exhibit convergence. Suppose that, to a first approximation, at the beginning of the authors' sample in 1880 , the distribution of capital and income across states was mostly the result of historical accidents such as the Civil War: that is, historical events with no or few steady-state implications. Then, we would expect to observe strong convergence at the beginning of the sample. But, were we to estimate, for example, the authors' regression over successive ten-year intervals, we would expect the initial level of income for each of these ten-year intervals to be more and more correlated with the permanent effects of shocks along the way, and thus convergence to be weaker and weaker.

It is easy to make the argument more formal. Consider running for a given $t$ a cross-section regression of yearly growth rates on initial levels along the lines of equation 6 , which I repeat for convenience:

$$
\left(y_{i t}-y_{i t-1}\right)=\left(y_{t}-y_{t-1}\right)-\beta\left(y_{i t-1}-y_{t-1}\right)+z_{i t} .
$$

Suppose that the economy does not exhibit convergence, so that the $z_{i t}$ 's are nonstationary. Suppose that for $t=1$, the correlation between the $z_{i 1}$ and the initial level of $y_{i 0}$ is indeed zero. Then ordinary least squares estimation of $\beta$ will lead to a consistent estimate. But, as we redo the 
same regression for higher values of $t$, that is, using later parts of the sample, both $z_{i t}$ and $y_{i t-1}$ are likely to depend more on past $z_{i t}$ 's, and thus to be more correlated. This leads to a larger downward bias in $\beta$. If the economy instead exhibits convergence, the $z_{i t}$ 's are stationary, and there is no reason to expect an increasing bias as we move to later samples.

The same arguments apply if instead of estimating one-year growth rates one looked at successive ten-year samples, using ten-year average growth rates. This line of reasoning suggests a simple test, and one which is performed in tables 1 and 3 by the authors, that of estimating $\beta$ over successive intervals. While the estimated $\beta$ is not stable through time and is lower in the 1970s and 1980s, there is no strong evidence of a steady decrease. Thus, this also supports the hypothesis of convergence.

EMPLOYMENT AND OUTPUT PER CAPITA. Ultimately, we want to identify the sources and mechanisms of convergence and the respective roles of capital and labor mobility. The authors make progress in studying the response of migration. I want to go a bit further. To the extent that states differ in their rates of natural population growth-as indeed they do-and as part of migration may not be related to employment (Florida, for example), I think it is better to focus directly on employment rather than on migration.

Suppose that, as the previous evidence suggests, the U.S. economy exhibits both $\beta$ as well as true convergence. What would we expect the correlation between state employment growth and state output per capita growth to be? Again, the earlier model with labor mobility can be used to derive the correlation between the growth rates over different horizons. I shall, however, keep the argument informal. In thinking about correlation between the two growth rates, there are two effects to keep in mind.

First, to the extent that relative differences in growth rates during the sample at hand are due to capital and labor being reallocated to undo initial conditions, the model predicts a negative correlation. States that are behind at the beginning of the period should experience capital inflows and labor outflows. Growth in output per capita should be higher and employment growth should be lower. Other things equal, this should generate a negative correlation.

But, to the extent that growth during the sample is due to the reaction of capital and labor to state-specific shocks, the correlation should be positive instead. Favorable shocks should lead to an increase in relative 
Figure 4. The Effect of an Innovation in Personal Income Per Capita on Itself

Deviation from equilibrium

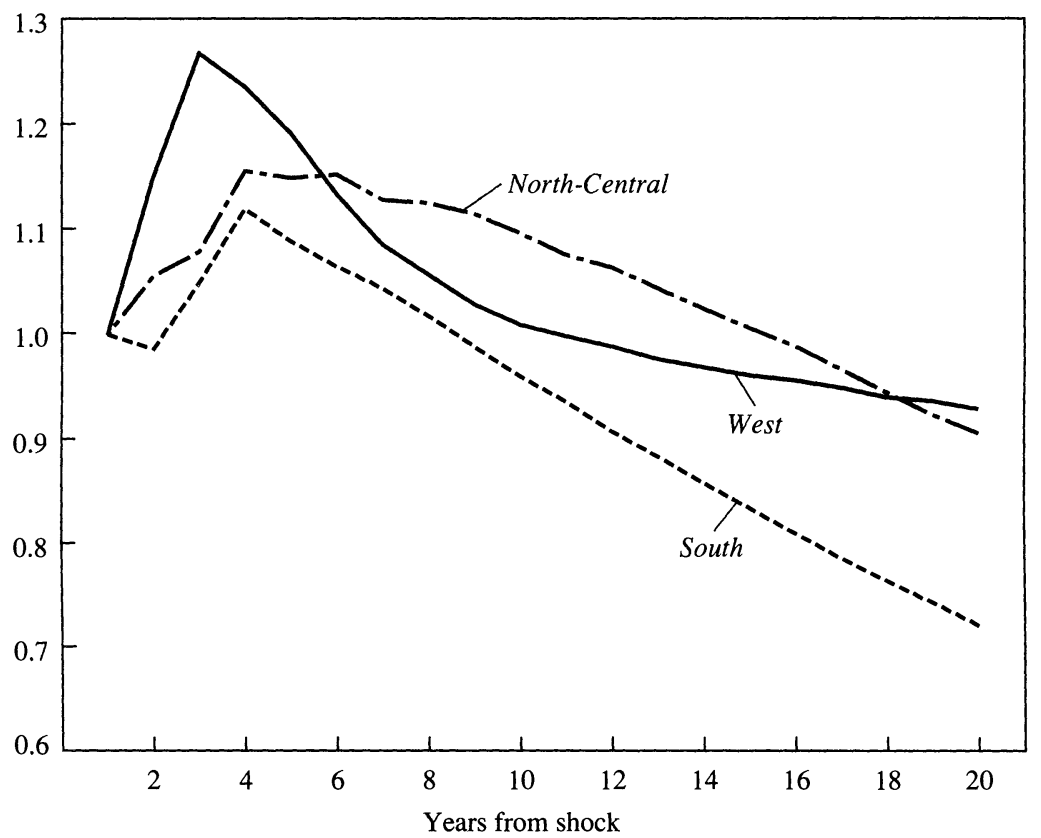

Source: Author's own calculations using annual data from DRI data base for the period 1950-88. The figure shows the estimated dynamic response of the logarithm of relative per capita personal income to an innovation in per capita personal income, which enters as a shock of 1 to $\epsilon_{y i t}$ in equation 11 .

output per capita and trigger higher employment growth. Over time, full labor mobility implies that employment growth should take place until relative output per capita is back to its previous level. Thus, the correlation between employment growth and relative output should be positive but go to zero when computed over long intervals.

Figures 4 and 5 (as well as figure 1) give some evidence about the relation between employment growth and relative output per capita growth. Figure 1 gives the rates of employment and personal income per capita across states for the period 1950-88. A regression of one on the other does not show much significance. If, however, Nevada is left out (but why should it be?), the relation becomes positive and significantthe effect of relative output per capita growth on employment growth is 0.79 , with a $t$-statistic of 2.4. An extra point of growth in per capita 
Figure 5. The Effect of an Innovation in Personal Income Per Capita on Employment

Deviation from equilibrium

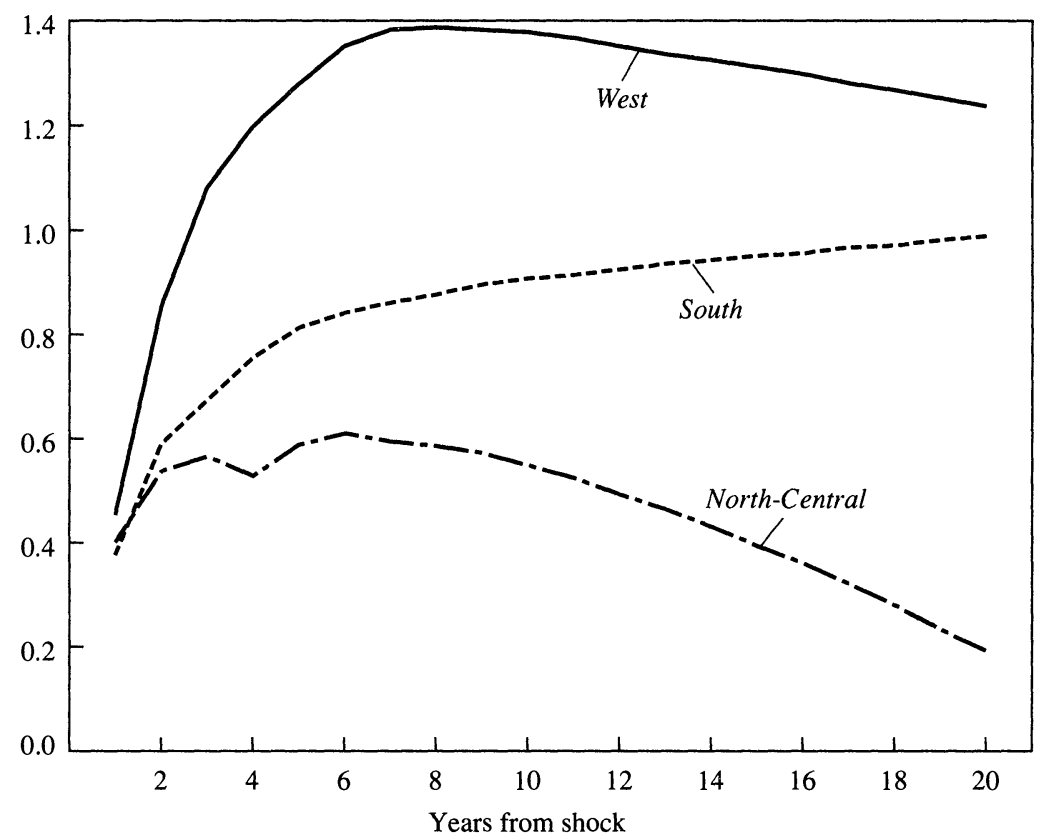

Source: Author's own calculations using annual data from DRI data base for the period 1950-88. The figure shows the estimated dynamic response of the logarithm of relative employment to an innovation in per capita personal income, which enters as a shock of 1 to $\epsilon_{y i t}$ in equation 11 .

income is associated with an increase of 0.79 in employment growth. Results are similar when four regional dummies are used as the authors do. ${ }^{12}$ Thus, both the figure and the simple regressions suggest that the relative shocks triggering employment increases are important to explaining regional growth rates.

One can clearly go further. In the model I sketched earlier, shocks first show up in personal income per capita, triggering a response of both labor and capital. As employment adjusts, personal income eventually returns to normal. This suggests a simple bivariate exercise, one that traces the dynamic effects of an innovation in personal income on both

12. Because of data limitations, the figure and the regressions, as well as the regressions reported below, are based on only 43 states. The excluded states are Connecticut, Maine, Rhode Island, Delaware, Maryland, Michigan, and Hawaii. 
employment and personal income. I have taken a rough first pass at it. I have estimated the following bivariate process for employment and personal income per capita:

$$
\begin{aligned}
& \Delta\left(l_{i t}-l_{t}\right)=a_{11}(L)\left(y_{i t}-y_{t}\right)+a_{12}(L) \Delta\left(l_{i t-1}-l_{t-1}\right)+\epsilon_{n i t}, \\
& \left(y_{i t}-y_{t}\right)=a_{21}(L) \Delta\left(l_{i t-1}-l_{t-1}\right)+a_{22}(L)\left(y_{i t-1}-y_{t-1}\right)+\epsilon_{y i t} .
\end{aligned}
$$

The indexes $i$ and $t$ denote state and time. The variable $l$ stands for the $\log$ of nonagricultural employment, and $y$ stands for the logarithm of personal income per capita. (As in the authors' paper, gross state output would be better but is not available for a long enough period of time.) The $a_{k j}(L)$ are lag polynomials, and the presence of the current value of relative income in the employment equation implies that the two $\epsilon$ 's are uncorrelated. The sign $\Delta$ stands for first differences. The specification in terms of the level of $y_{i t}-y_{t}$ and the first difference in $l_{i t}-l_{t}$ is consistent with the theory that implies stationarity of relative personal income per capita and nonstationarity of employment and also with the characteristics of the data.

While this bivariate process can in principle be estimated for each state separately, I found that the dynamics were not precisely estimated when coefficients were allowed to be state specific. I thus estimated the bivariate process by grouping states into three groups, North-Central, West, and South, and forcing the coefficients to be equal with each group. ${ }^{13}$ I used annual data for the period 1950-88. Figures 4 and 5 give the implied estimated dynamic responses of the levels of the logarithms of relative personal income and employment to an innovation in personal income, a shock of 1 to $\epsilon_{y i t}$.

The model sketched earlier implied that an innovation in personal income should lead to a permanent increase in relative employment, as labor is attracted by the higher marginal product, and to an eventual return of relative personal income to normal, as labor mobility runs its course. Figures 4 and 5 are nearly but not fully consistent with the model. In figure 4, personal income initially increases, but then returns to normal, confirming the findings of the authors. And in figure 5, employment increases for all three regions. In both the South and the West, it

13. The groupings do not seem to do too much violence to the facts. I have left out the states in the "West-North-Central" region, Iowa, Kansas, Missouri, Minnesota, Nebraska, North Dakota, and South Dakota, which depend more heavily on agriculture and appear to be different from other states. 
remains at a higher level, and the effects of an innovation in personal income appear to be permanent. The long-run elasticity of employment to the initial innovation is a bit above unity. In the case of the NorthCentral regions, however, the dynamic response suggests no long-run effect of the innovation in personal income on employment, something that only happens in the formal model if the underlying relative technology and demand shocks have no permanent component.

What conclusions do I draw from the set of results in this section? There appears to be not only $\beta$ convergence but also convergence of output per capita across U.S. states. The distribution of relative outputs per capita seems to be converging toward a stable stochastic steadystate distribution. And a crucial element appears to be labor mobility in response to state-specific production and demand shocks. What remains on the agenda is a better identification of the adjustment process, of the change in the basket of goods being produced, and of the role of returns to scale and of capital and labor mobility. This will require the use of both the time-series and cross-section aspects of the regional data set.

Robert E. Hall: Robert Barro and Xavier Sala-i-Martin have marshaled impressive and persuasive evidence that convergence of real incomes is the rule. From a given starting point, areas with lower output per worker grow faster than those with higher output.

From the start, proponents of convergence have had to deal with the obvious econometric point that errors in measuring output could explain the relation between levels and subsequent growth, but a glance at figure 1 in this paper persuades me that the finding is no artifact of errors in the data.

What I get out of figure 1 is the following. In 1880 , some states had high levels of income, either because of advanced overall development (the Northeast and California) or the high rate of exploitation of minerals (other western states). Other states had low levels-mainly the states of the Confederacy, which in $\mathbf{1 8 8 0}$ were still much affected by the Civil War. In the ensuing 108 years, other states reached advanced development, the exploitation of minerals abated in the West, and the South recovered, in part. All of this evidence is reasonably summarized by the statement that states tend to converge toward a common level of income.

The paper presents strong evidence that historically special factors were at work in 1880 . The dispersion of income per capita across states 
fell dramatically after 1880 , as shown in figure 4 . The authors comment on the Civil War and the West's mining boom as factors making 1880 unusual. They also mention that the cross-sectional dispersion was apparently lower in the earlier part of the nineteenth century.

Our ability to identify the special factors creating cross-sectional dispersion in one particular year does not weaken the point of the paper that convergence is a general phenomenon. Each idiosyncratic eventwars, opening up of minerals, and the like-pushes an area away from its long-run growth path, but the process of convergence turns it back toward that path.

Convergence is not unique to the states of the United States. Further careful work in this paper shows that the same 2 percent annual rate of convergence applies for European regions. Additional empirical work reported in the paper shows that there is much more to the convergence process than migration from low-income to high-income regions.

What are the lessons for growth theory in this careful and persuasive empirical paper? Surprisingly to me, the authors seem to be reluctant to draw conclusions with respect to the controversies in the blossoming field of new growth theory. In equation 1 of this paper, the crucial variable, $\hat{y}_{i}^{*}$, which is the steady-state level of per capita income for state $i$, has significance for growth theory. I therefore discuss several important features of this variable.

First, if states are geographically and mineralogically featureless, there is an argument that $\hat{y}_{i}^{*}$ has the same value for all states. Consider two snapshots like figure 1, taken far enough apart in time to eliminate the influence of the idiosyncratic events creating the dispersion in the first snapshot. The ordering of the states in the second snapshot should be independent of the ordering in the first one. Refutation of this hypothesis of strong convergence would presumably occur if this idea were pursued in a formal statistical test. States are not homogeneous in this sense.

Second, the authors extend the model to make $\hat{y}_{i}^{*}$ depend on observed variables-table 1 presents the results. The authors could construct a new version of figure 1 in terms of deviations from the estimated $\hat{y}_{i}^{*}$ for each state, instead of raw income levels. Then the same test mentioned above could see if there were important unobserved differences among steady-state income levels across states.

Third, a further extension of the model would consider permanent 
unobserved differences in the $\hat{y}_{i}^{*}$. Estimates of these parameters could be fished out of the panel data by standard methods. Then the interesting hypothesis to test would be the stability over time of the relative values of $\hat{y}_{i}^{*}$ across states.

Fourth, a final extension would let the unobserved differences across states evolve over time. I would expect the time series process to be highly persistent-for example, it may be that the difference between Massachusetts and Connecticut's steady-state real income levels evolves as a random walk. In this model, it remains true that convergence occurs and the estimated beta is positive. On the other hand, the random-walk difference in steady-states is the type of behavior predicted by new growth theory models that do not imply convergence. Convergence to random-walk steady-state real income levels would be predicted by a hybrid of old and new growth models.

I believe that the data support the last version. The main reason is work done by Andrew Bernard and Steven Durlauf in an econometric framework that asks a different question-is convergence complete (in the sense of a constant $\hat{y}_{i}^{*}$ over time) or is it partial (toward a drifting $\left.\hat{y}_{i}^{*}\right) .{ }^{1}$ Bernard and Durlauf find it to be partial. The basic evidence is a unit root in the difference between the log incomes of pairs of states. However, as Bernard and Durlauf are aware, there are problems in interpreting the evidence in the presence of low but positive rates of convergence from widely varying starting points.

The last word is not in on the question of drift of the target of convergence. I suspect that ultimately we will need to consider drift.

Convergence occurs because of reasons identified in neoclassical growth theory - the diminishing marginal product of labor, in particular. Drift in steady-state income occurs because of reasons identified in nonconvex new growth models. If the evidence supports both types of behavior, then we need to adopt hybrid models, with both neoclassical and nonconvex elements.

The new growth models probably cannot explain the convergence found in this paper. But the developers of those models, when confronted with the problems of predicting the effects of the Civil War or the opening up of western mining, would probably augment their models to consider the convergence toward normal that would follow special events like

1. Bernard and Durlauf (1991). 
these. In this respect, the evidence favoring convergence is not unfavorable to modern endogenous growth theory.

Thus, it is reasonable, but not terribly surprising, to conclude that a full growth model must contain convergence features. On the other hand, drift in steady-state incomes calls for something more than the neoclassical model. The data support new ideas as well. The careful documentation of convergence in this paper should not limit our interest in new growth models.

\section{General Discussion}

William Nordhaus and Martin Baily wished the authors had made a greater effort to distinguish among different kinds of shocks and their impacts. They proposed alternatives to capital deepening as the cause of convergence. Nordhaus suggested, for example, that the rapid growth of the United States during World War II was driven largely by demand. $\mathrm{He}$ also found it difficult to regard the slow recovery of the South following the Civil War and the rapid recovery of Western Europe after World War II as examples of the same growth process. Both Nordhaus and Baily believed the decline in the importance of agriculture since the end of the nineteenth century was significant for convergence and noted that the authors' device of simply including the agricultural share obscured its potential importance. Baily reasoned that since income from agriculture is largely dependent upon the productivity of the land, differences in agricultural income would not converge. However, the increased importance of manufacturing over the sample period tended to equilibrate income levels. Baily and Nordhaus also noted that since transportation costs were high at the beginning of the sample, economic activity tended to be concentrated in small geographical regions. Regions where activity was high had high levels of income. As transportation costs fell, activity became more dispersed, leading to convergence.

Both panelists found it premature to draw conclusions about production parameters based on the speed of convergence. In particular, in their view the finding of a beta of 2 percent a year was more likely due to the presence of persistent shocks to income than a capital coefficient of 0.8 . Nordhaus pointed out that if the high coefficient on capital is to be explained by the presence of human capital, then the convergence 
should have been much greater in the early periods when human capital was not as important. Christopher Sims noted that controlling for characteristics that might explain permanent differences in income increased the apparent rate of convergence. Hence focusing on similar regions and conditioning on an increasing number of potential sources of differences in income are likely to increase the estimates of beta. He noted, however, that such conditioning changes the meaning of beta. Since the conditioning variables themselves are unexplained, a larger fraction of the variance in income is unexplained. In effect, the betas give estimates of the speed of convergence of the residual, not the economic variable of interest. On the other hand, Sims found the evidence of sigma convergence persuasive. He was struck by the pervasiveness of this phenomenon, showing up for different countries and time periods. Sims thought this was strong evidence against models that imply nonstationary differences in the levels of income across countries.

Several panelists suggested reasons the authors' estimates may understate the response of migration to differences in income. Olivier Blanchard proposed three possible explanations. First, the long-run elasticity may be high even if the short-run elasticity is low, and these long-run effects may be hard to capture econometrically. Second, much of migration is not employment related and should not be expected to respond to wage and income differentials. Retirees' migration to Florida is an example. He would have preferred the authors' focusing on employment migration. Lastly, together with Robert Gordon, he noted that the authors were unable to control for differences in the regional cost of living. Since demand shocks are likely to move the cost of living and nominal wages in the same direction, this omission is likely to bias downward the authors' estimates of the effect of income differences on migration. Sala-i-Martin responded that evidence from metropolitan CPI data suggests the differences in costs of living are not great enough to have a significant effect on their results.

In a related point, Barry Bosworth was surprised that the inclusion of country dummies did not have a significant effect upon the estimates of the rates of convergence across regions in Europe. He had expected that the difficulty of migrating between countries as opposed to between regions would lead to quite different estimates. Barro suggested that the 
effect would have been more pronounced on a different data set, as the countries included were all part of the European Community.

Edmund Phelps and Nordhaus both observed that the authors' sample choice may have biased the results toward convergence. Phelps noticed that the definition of the south of Italy used in table 7 was unweighted by population and included some small middle states whose income rose more than average over the sample. The four large states that extend farthest south, Calabria, Poulia, Sicily, and Sardinia, did not catch up with the rest of Italy over the sample period. Nordhaus observed that Alaska and Hawaii were not included while New Mexico was included even though New Mexico was not a state at the beginning of the sample period. He also suggested that since Puerto Rico and Mexico are within the economic sphere of the United States, they should also be included. Incomes in Alaska and Mexico have diverged from U.S. incomes.

Gordon and Lawrence Katz both asked about the implication of these results for convergence across countries. Gordon wondered, in light of the fact that this last decade has been one of backsliding for Africa and Latin America, how important it was that South Carolina was catching up to Connecticut. Katz noted that the regions studied by the authors have similar institutions, laws, and customs. He wondered whether that is why regions in the United States and Europe converge and African nations, for example, do not. Whether the impediments to growth in LDCs are shortages of capital and other resources or institutional factors is a crucial policy issue, which unfortunately cannot be addressed with the authors' data. 


\section{References}

Akerlof, George A., and others. 1991. "East Germany in from the Cold: The Economic Aftermath of Currency Union." BPEA, 1:1991, 1-87.

Barro, Robert J. 1991. "Economic Growth in a Cross Section of Countries." Quarterly Journal of Economics 106: 407-43.

Barro, Robert J., and Xavier Sala-i-Martin. 1990. "Economic Growth and Convergence across the United States." Working Paper 3419. Cambridge, Mass.: National Bureau of Economic Research (August).

. 1991. Economic Growth. Unpublished manuscript, Harvard University.

Baumol, William J. 1986. "Productivity Growth, Convergence, and Welfare: What the Long-Run Data Show." American Economic Review 76: 1072-85.

Bernard, Andrew, and Steven Durlauf. 1991 (forthcoming). "Convergence of International Output Movements." Working paper, National Bureau of Economic Research.

Blanchard, Olivier J. 1985. "Debt, Deficits, and Finite Horizons." Journal of Political Economy 93: 223-47.

Blomquist, Glenn C., Mark C. Berger, and John P. Hoehn. 1988. "New Estimates of Quality of Life in Urban Areas." American Economic Review 78: 89-107.

Borts, George H., and Jerome L. Stein. 1964. Economic Growth in a Free Market. New York: Columbia University Press.

Borjas, George J. 1990. Friends or Strangers: The Impact of Immigrants on the U.S. Economy. New York: Basic Books.

Bureau of the Census. 1975. Historical Statistics of the United States, Colonial Times to 1970, Bicentennial Edition, Parts 1 and 2. Washington: U.S. Department of Commerce.

- 1990. Statistical Abstract of the United States: 1990. Washington: U.S. Department of Commerce.

Bureau of Economic Analysis. 1973. Long Term Economic Growth, 18601970. Washington: Government Printing Office.

- 1984. State Personal Income by State: Estimates for 1929-1982, and a Statement of Sources and Methods. Washington: U.S. Department of Commerce.

Bureau of Labor Statistics. Various years. Employment and Earnings, States and Areas. Washington: U.S. Department of Labor.

Cass, David. 1965. "Optimum Growth in an Aggregative Model of Capital Accumulation." Review of Economic Studies 32: 233-40.

Cohen, Daniel, and Jeffrey Sachs. 1986. "Growth and External Debt under Risk of Debt Repudiation.' European Economic Review 30: 526-60.

De Long, J. Bradford. 1988. "Productivity Growth, Convergence, and Welfare: Comment." American Economic Review 78: 1138-54. 
Dowrick, Steve, and Duc-Tho Nguyen. 1989. “'OECD Comparative Economic Growth 1950-85: Catch-Up and Convergence." American Economic Review 79: $1010-30$.

Easterlin, Richard A. 1960a. "Regional Growth of Income: Long Run Tendencies." In Population Redistribution and Economic Growth, United States, 1870-1950. II: Analyses of Economic Change, edited by Simon Kuznets, Ann Ratner Miller, and Richard A. Easterlin. Philadelphia: The American Philosophical Society.

- 1960b. "Interregional Differences in Per Capita Income, Population, and Total Income, 1840-1950." In Trends in the American Economy in the Nineteenth Century. A Report of the National Bureau of Economic Research, New York. Princeton: Princeton University Press.

Eurostat. Various years. Basic Statistics of the Community: A Comparison with Some European Countries, Canada, the USA, Japan, and the USSR. Luxembourg: Statistical Office of the European Communities.

Feldstein, Martin S., and Charles Horioka. 1980. "Domestic Saving and International Capital Flows." Economic Journal 90: 314-29.

Koopmans, Tjalling C. 1965. "On the Concept of Optimal Economic Growth." In Study Week on the Econometric Approach to Development Planning. Pontificiae Academiae Scientiarum Scripta Varia, no. 28. Chicago: Rand McNally.

Krugman, Paul R. 1989. "Differences in Income Elasticities and Trends in Real Exchange Rates." European Economic Review 33: 1031-54.

—. 1991 (forthcoming). Geography and Trade. Cambridge, Mass.: MIT Press.

Molle, Willem. 1980. Regional Disparity and Economic Development in the European Community. Farnborough, England: Saxon House.

Mueser, Peter R., and Philip E. Graves. 1990. "Examining the Role of Economic Opportunity and Amenities in Explaining Population Redistribution.' Working Paper 90-4. University of Missouri-Columbia (October).

$\rightarrow$ Nelson, Richard R., and Edmund S. Phelps. 1966. "Investment in Humans, Technological Diffusion, and Economic Growth." American Economic Review, Papers and Proceedings 56: 69-75.

Quah, Danny. 1990. "Galton's Fallacy and Tests of the Convergence Hypothesis." Unpublished paper, Massachusetts Institute of Technology (May).

Rebelo, Sergio T. 1990. "Long Run Policy Analysis and Long Run Growth." Working Paper 3325. Cambridge, Mass.: National Bureau of Economic Research (April).

Renshaw, Vernon, Edward A. Trott, Jr., and Howard L. Friedenberg. 1988. "Gross State Product by Industry, 1963-1986." Survey of Current Business 68 (May): 30-46.

Roback, Jennifer. 1982. "Wages, Rents, and the Quality of Life." Journal of Political Economy 90: 1257-78. 
Romans, J. Thomas. 1965. Capital Exports and Growth among U.S. Regions. Middletown, Conn.: Wesleyan University Press.

Sala-i-Martin, Xavier. 1990. "On Growth and States." Ph.D. diss., Harvard University.

Schools Brief. 1990. "Why Currencies Overshoot." In The Economist, December 1, pp. 89-90. Brief on "Expectations and Exchange Rate Dynamics," by Rudiger Dornbusch, in Journal of Political Economy 84: 1161-76.

Solow, Robert M. 1956. "A Contribution to the Theory of Economic Growth." Quarterly Journal of Economics 70: 65-94.

Summers, Robert, and Alan Heston. 1991. "The Penn World Table (Mark 5): An Expanded Set of International Comparisons, 1950-1988." Quarterly Journal of Economics 106: 327-68.

Uzawa, Hirofumi. 1968. "Time Preference, the Consumption Function, and Optimum Asset Holdings." In Value, Capital, and Growth: Papers in Honour of Sir John Hicks, edited by J. N. Wolfe. Chicago: Aldine Publishing Company.

Wardwell, Charles A. R. 1951. Regional Trends in the United States Economy. Washington: Government Printing Office. 